$Q L$
503.46 $F_{63}$

$\frac{1}{10}$

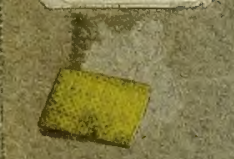




\section{QL 503.A6F63 \\ Cornell University Library}

The hog louse, Haematopinus suis Linne:

|||||||||||||||||||||||||||||||||||||||||||||||||||||||||||||||||

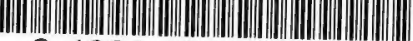

31924001027899

CORNELL UNIVERSITY

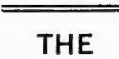

Tflomer Heterinary Tithrary

FOUNDED BY

ROSWELL P. FLOWER

for the use of the

N. Y. State Veterinary College 1897 


\title{
CORNELL UNIVERSITY
}

\author{
AGRICULTURAL EXPERIMENT STATION
}

HE HOG LOUSE, HAEMATOPINUS SUIS LINNÉ: ITS BIOLOGY, ANATOMY, AND HISTOLOGY

\section{LAURA FLORENCE}

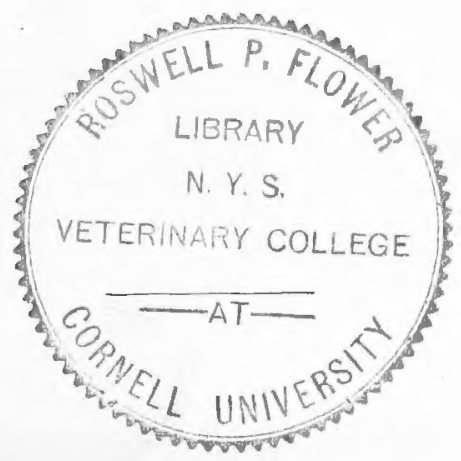

ITHACA, NEW YORK

PUBLISHED BY THE UNIVERSITY 


\section{Cornell University Library}

The original of this book is in the Cornell University Library.

There are no known copyright restrictions in the United States on the use of the text. 


\section{CONTENTS}

PAGE

Historical review. . . . . . . . . . . . . . . . . . . . . . . . . . . 642

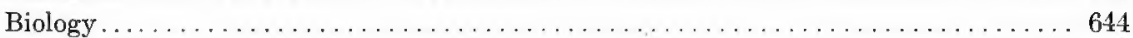

The early stages. . . . . . . . . . . . . . . . . . . . . . . . . . . . . 651

The adult lice . . . . . . . . . . . . . . . . . . . . . . . . . . . . . . 653

The male . . . . . . . . . . . . . . . . . . . . . . . . . . . . . . . 653

The female. . . . . . . . . . . . . . . . . . . . . . . . . . 654

The integument and body wall . . . . . . . . . . . . . . . . . . . . 654

The respiratory system . . . . . . . . . . . . . . . . . . . . . . . 656

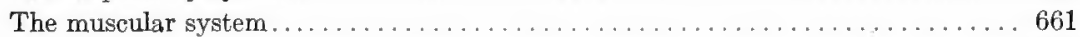

The vaseular system . . . . . . . . . . . . . . . . . . . . . . . . 666

The nervous system . . . . . . . . . . . . . . . . . . . . . . 668

The stomodaeum, mouth parts, and salivary glands................ 671

The haustellum . . . . . . . . . . . . . . . . . . . . . . . . . . . 675

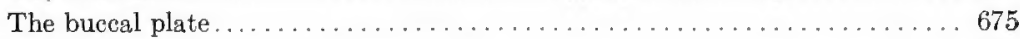

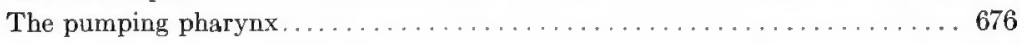

The pumping pharyngeal tube ........................ 676

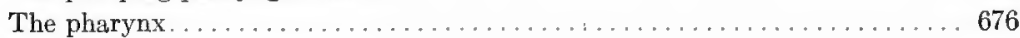

The esophagus. . . . . . . . . . . . . . . . . . . . . . . . 677

The "mandibles" of Enderlein ........................... 677

Musculature of the stomodaeum .......................678

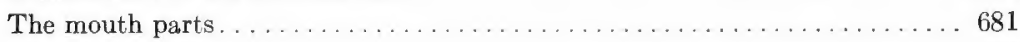

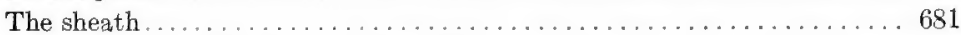

The piercers and the salivary duct. . . . . . . . . . . . . . . . 682

Musculature of the mouth parts. . . . . . . . . . . . . . . . . 683

The salivary glands. . . . . . . . . . . . . . . . . . . . . 687

The aiimentary canal and its appendages...................... 690

Feeding and digestion $\ldots \ldots \ldots \ldots \ldots \ldots \ldots \ldots \ldots \ldots \ldots \ldots \ldots \ldots \ldots \ldots \ldots \ldots$

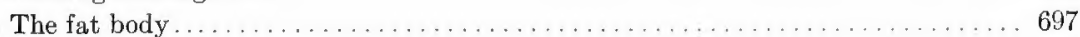

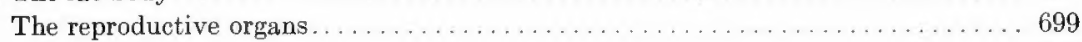

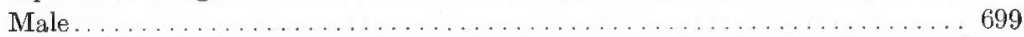

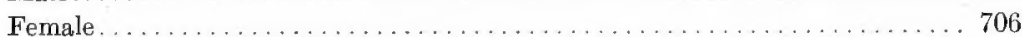

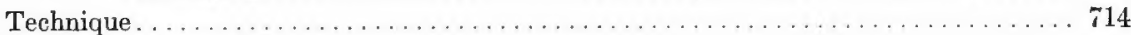

Summary . . . . . . . . . . . . . . . . . . . . . . . . . . . . . . 716

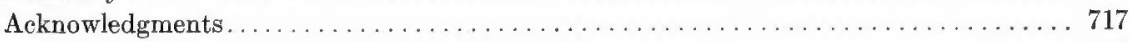

Bibliography . . . . . . . . . . . . . . . . . . . . . . . . . 719 

THE HOG LOUSE, HAEMATOPINUS SUIS LINNE: ITS BIOLOGY, ANATOMY, AND HISTOLOGY 


\section{THE HOG LOUSE, HAEMATOPINUS SUIS LINNE: ITS BIOLOGY, ANATOMY, AND HISTOLOGY ${ }^{1}$}

\section{Laura Florence}

Because of their habitat on man and beast, lice have been known from the earliest times. Their systematic position has been a subject of controversy for more than a century, and the hog louse, on account of its large size and wide distribution, has frequently been used for the study of the morphology of the order. About the middle of the nineteenth century there was a controversy among physicians and entomologists as to the nature of the mouth parts of the pediculi infesting man, and the mouth parts of the hog louse were brought into the discussion by Burmeister. A detailed account of this discussion is given in a paper by Schjödte (1864, English trans. 1866:213). Since the pediculi infesting man have been shown to be an etiological factor in the transmission of certain diseases, much accurate work has been done on their life history and morphology, and the many points of interest raised through such detailed study suggested that a parallel study of an animal parasite might be equally profitable. The aim of the present work has been to give an accurate account of the general internal anatomy of the hog louse, with a detailed description of the histology of certain parts. The relation between the parasite and its host has not been considered, and references to veterinary literature do not appear in the bibliography.

The study was begun in 1917 in the Entomological Laboratory of Cornell University under Dr. William A. Riley, now of the University of Minnesota, and was continued under Dr. O. A. Johannsen, to both of whom thanks are due for helpful eriticism. Since June, 1918, by the courtesy of the Scientific Directors of the Rockefeller Institute, and, in particular, of Dr. Theobald Smith, Director of the Department of Animal Pathology, it has been made possible for the writer to complete the investigation.

\footnotetext{
1 From the Department of Entomology of the New York State College of Agriculture at Cornell University, and the Department of Animal Pathology of the Rockefeller Institute for Medical Research. Also presented to the Faculty of the Graduate School of Cornell University, June, 1920, as a thesis in partial fulfillment of the requirements for the degree of doctor of philosophy.
} 


\section{HISTORICAL REVIEW}

According to Moufetti (1634, English trans. 1658), the earliest reference to the hog louse is to be found in the works of Albertus, a writer of the twelfth century, who named the insect Pediculus urius. Moufetti retained this name and described the louse as somewhat larger than that infesting oxen and calves, and so hard that it could not be crushed between the fingers. Linnaeus (1758:2915) described the louse under the name Pediculus suis. Panzer (quoted by Stevenson, 1905), in 1798, followed the nomenclature of Linnaeus and stated that in the classification of Fabricius this parasite was placed "with Pediculus asini of Redi (1671)." Leach (1817:65) broke up the 'genus Pediculus into four genera, Phthirus, Haematopinus, Pediculus, and Nirmus, making the hog louse the type of the new genus Haematopinus. This classification was not immediately accepted, and Nitzsch (1818:305) revived the old name of Albertus. He was followed in this by Burmeister (1839:58), who gave the synonymy and a brief description of the louse, and later (1847:569) gave a detailed description of the structure of the mouth parts.

Systematic descriptions and figures of the species are to be found in the monographs of Denny (1842:34), Giebel (1874:45), and Piaget (1880: 654 ), of which the last is the most detailed. More recent and popular descriptions are given in three bulletins of the United States Department of Agriculture. Two of these are the work of Osborn (1891 and 1896), and in them the sections on the hog louse are identical. He calls attention to " a curious provision in the feet for strengthening the hold upon the hair, which does not seem to have been hitherto described." The third bulletin, written by Stevenson (1905), is valuable on account of the complete synonymy and the extent of the bibliography.

Between 1903 and 1906 a number of papers relating to the systematic position of the Pediculidae appeared in Europe. Most authors confined their investigations to the mouth parts, and for a time a bitter controversy was waged between Cholodkovsky of St. Petersburg and Enderlein of Berlin. Cholodkovsky (1903:120.and 1904:368) studied numerous sections of the head of the embryo of Pediculus capitis, while Enderlein (1904 and 1905), using cleared preparations and gross dissections, studied the hog louse in greatest detail of all the species used. Cholodkovsky's findings in regard to adult lice were confirmed by his pupil, Pawlowsky (1906:156), whose paper contains a discussion and criticism of the literature to date. 
In the same year Gross (1903:347) published the results of his investigation of the ovaries of the Mallophaga and the Pediculidac. In his introduction he sums up an earlier investigation as follows:

Handlirsch (1903) places them [the Pediculidae] in a special order Siphunculata, Meinert next the Mallophaga in his subclass Blattaeformia. Börner (1904) gives them the same name, but raises the family to the rank of a suborder which, together with the Corrodentia, the Thysanoptera, and the Rhynchota, forms his order of Acercaria. Cholodkovsky (1904) joins the Pediculidxe and the Mallophaga in one order, related with the Orthoptera rather than with the Hemiptera, for which he proposes the name Pseudorhynchota. Finally, Enderlein (1904) interprets the Pediculidae as one with the Anoplura - a name originating with Leach an order lying near to the Rhynchota. None of the four opinions mentioned is to be considered as entirely new. They are all found in similar form in the old entomologies of the preceding century. ${ }^{2}$

Gross next emphasizes the importance of using other less delicate organs than the mouth parts as a basis for comparison.

A historical review of lice from the time of Aristotle, together with an account of the general characteristics of the order and descriptions of species, was prepared by Von Dalla Torre (1908) for the Genera Insectorum. For this Enderlein's work served as a basis, as it did also later for the section on lice in the textbook of Patton and Cragg (1913:525). Neumann (1909:530) criticized Enderlein's splitting-up of the old genus Haematopinus of Leach as being for the presant unnecessary, and retained the original classification in his descriptions of species (1911). Mjöberg (1910) published comparative studies of Anoplura and Mallophaga dealing with both the morphclogical and the systematic aspects of the question. Previous to this time only the dissertation of Ströbelt (1882, English trans. 1883:73) had dealt with the anatomy of a species of Hacmatopinus $H$. tenuirostris, now Linognathus vituli. The observations of the earliest workers - Hooke (1665), Swammerdam (1682), and Lecuwenhoek (1695) and the investigations of the scientists of the latter half of the nineteenth century, dealt exclusively with the species infesting man. The presence of great armies in the field during the five years from 1914 to 1918, inclusive, compelled intensive studies of these species from medical and sanitary standpoints, with the subsequent publication of many valuable papers, of which a liberal use has been made in interpreting the anatomy of the species under investigation.

The classification followed throughout this paper is that suggested by Nuttall (1919:329) in a recent review of the systematic literature of the

2 Translated from the original German. 
Pediculidae. He points out that the order Anoplura Leach 1817 contains two suborders - Siphunculata Meinert 1891 and Mallophaga Nitzsch 1818 - and says (page 332 of reference cited): "Since, however, the name Anoplura Leach (1817) was applied to both Siphunculata and Mallophaga, and in this sense agrees with modern views, it should henceforth be used in its original sense only, there being no justification for continuing to apply it to Siphunculata alone."

\section{BIOLOGY}

The hog louse is the largest louse affecting domestic animals and is of common occurrence wherever the hog is found. The hog is its only host, and when not molested the parasite is likely to increase in large numbers and cause an unthrifty condition in a herd. The lice frequent the folds of the skin on the neck and the jowl, the inside and the base of the ears, the inside of the legs, the flanks, and, in smaller numbers, the back, where they crawl under the scalcs to get in contact with the new skin. They are well adapted for experimental work, because they are easy of access and feed readily on man, while their size and their habit of taking hold of any object placed in front of them lessen the difficulty of keeping them in confinement.

From the time of hatching, hog lice feed readily on man if they have not become weakened through too long fasting. During the course of this investigation hundreds of lice have been fed on the forearm without any resulting reaction, except, in a few cases, a slight redness which disappeared within half an hour, and, in cases in which the mouth parts were inserted but no blood was drawn, a slight swelling which disappeared within an hour. This is contrary to the finding of Sikora (1915:536), who saw no reaction on the first or the second day of the feeding but states that thereafter the skin turned red in an area from 1 to 5 millimeters around the point of puncture and swelled slightly, remaining thus for more than twenty-four hours. Recently Moore and Hirschfelder (1919:8) have published a detailed account of serious pathological effects of the bite of the clothes louse and clinical observations of the resulting illness. According to Stevenson (1905:12),

Stockmen handling hogs often become temporary hosts of the louse, but it has never been known to remain for any length of time on the human body and is not known to exist on any animal other than the hog. Attempts made at this Iaboratory [United States Bureau of Animal Industry] to propagate Haematopinus suis on dogs have met with repeated failure. 
Several attempts have been made to feed the lice on guinea pigs, but without success. The dense hair of the pigs hampers the movements of the lice, and, if shaving be resorted to, the lice are left without a foothold. If the finger be pricked and lice brought in contact with the freshly escaped blood, the lice immediately move away. Widmann (1915 b: 1337) described a similar reaction in man-infesting lice, which refused to feed on various organs just removed from freshly killed mice.

When placed on the arm, hog lice may feed at once or may move about more or less rapidly. When walking they appear to move sicleways as often as straight forward with the head in front. The peculiar structure of the feet, first described by Osborn (1891:20 and 1901:107), enables the lice to grasp the hairs on the arm. The tibia (Plate LVIII, 1) increases at the distal end to twice the width of the proximal end, and the dorsal half only articulates with the tarsus. The remaining part is concave and its ventral border is drawn out to a spur, bearing a stout spine at the apex. In the concavity rests a stalked, protrusible, subcircular pad bearing two spines and two hairs. On the inner edge of the tarsus, in line with the surface of the extended pad, is a blunt process bearing a spine. Tho inner surface of the claw is slightly serrated. In holding a bristle or a hair, the claw is bent over to rest on the tibial spur and the pad is pushed against the opposite side of the bristle, thus preventing the insect from slipping. Enderlein (1904:141), to whom Osborn's earlier description was evidently unknown, describes the pad as a strongly chitinized skcletal piece of triangular shape. In specimens cleared in potash and mounted under a cover glass it frequently has this shape, while in living and in uncleared specimens it always appears subeircular. Enderlein names this pad the pretarsal sclerite, which name is retained by Neumann (1911: 407 ) in his description of the insect.

The earliest description of a louse fecding is that of Hooke (1665:211213). He described the passage of blood from his arm into a louse which he had placed there after it had fasted for several days, and the working of a pumplike apparatus in the head. Swammerdam (1682, English trans. 1758:33-35) gave a more detailed description, but he disagreed with Hooke's description of the mouth parts, saying: "The louse has neither beak, teeth, nor any kind of mouth, as Dr. Hooke described it, for the entrance into the gullet is absolutely closed; in the place of all these, it has a proboscis or trunk, or, as it may be otherwise called, a pointed and 
hollow aculeus or sucker, with which it pierces the skin, and sucks the human blood." He also described the pumplike structure in the head, the peristalsis of the alimentary tract, and the ejection of feces during feeding. Leeuwenhoek (1695) described the hook-bearing part of the proboscis and its eversion during feeding, in addition to other characteristic actions associated with the process.

When fed in captivity, the louse moves its head back and forth close to the surface of the arm and rapidly jerks the antennae up and down. Then, with the head held at right angles to the body, it seems to anchor itself to the skin, probably by the everted teeth of the haustellum. While the stylets are being inserted, the thorax and the abdomen are raised and gently rocked from side to side, and the claws make irregular scratching motions. After the insertion the insect is holding itself in a more or less straight line and at an angle of from $40^{\circ}$ to $45^{\circ}$ with the arm. As the feeding progresses the body is gradually lowered, until it rests on the arm and with its head forms an oblique angle The act of sucking blood can best be watched in freshly molted specimens. The blood is first seen anterior to the eyes in the pumping pharynx, which dilates and contracts with great rapidity, driving its contents into the true pharynx (larynx of Enderlein), whence they disappear under the brain to reappear as a thin red line in the slender esophagus before this passes under the fat cells and muscle of the thorax. Throughout the process a continuous peristalsis passes.along the whole alimentary tract, but this has manifestly no connection with the drawing of the blood, as suggested by Widmann (1915 a: 290). It seems rather to be a means of removing from the posterior region of the stomach and from the intestine the debris of the preceding meal, since it is the habit of the hog louse - at any rate when kept and reared in captivity - to continue feeding until not only all the feces, but also a drop of blood, have been ejected. The latter may be pushed out by the interlocking of the six longitudinal folds of the epithelial lining of the intestine immediately behind the stomach, in order to prevent the escape of the blood from the mesenteron during digestion. At the first feeding after hatching, no blood has been seen to be ejected, and in some cases after the second feeding feces but no blood have been ejected. The average length of a meal is from eight to twelve minutes, but sometimes it lasts from twenty to thirty minutes, and at the close the mouth parts are apparently withdrawn by a short jerk of the head. Occasionally lice 
have gorged themselves and have been seen to turn pink within a few minutes, owing to the rupture of the stomach and the spread of blood through the colon. This phenomenon, which has been invariably followed by death, has been seen also by Nuttall (1917 d:173) in the pediculi infesting man. The unfed louse is of a grayish color and much wrinkled, while the fed louse has a highly refractive, smooth tegument showing very clearly the areas of stronger chitinization. During keeping and rearing, immature lice have been given four, and adult lice three, opportunities for feeding in twenty-four hours, and these were not always taken advantage of. Temperature influences the rate of digestion, and the higher the temperature in which lice are kept, the more frequent must be the opportunities given them for feeding.

Sexual maturity is attained on the third day after the final molt, when, with or without fecundation, egg-laying begins. The position for copulation has been observed a number of times. While a female was feeding and still had the abdomen somewhat elevated, the male crawled underneath and interlocked his first and second pairs of legs with the second and third pairs of the female. She at once raised her abdomen, resting only on the head and the first pair of legs and bearing the whole weight of the male. The abdomens of both were curved dorsad and the male was seen to insert the parameres (dilator of Nuttall) into the sexual orifice of the female. Gradually the bodies were lowered until the third pair of legs of the male rested on the arm, and the head was under that of the female. They remained in this position for almost ten minutes, during which time the male constantly stroked the head of the female with his antennae. In its main features this resembles copulation in the pediculi infesting man as described by several workers, the most detailed account being that of Nuttall (1917 a:316). Hog lice in captivity have not been seen to remain in copulation longer than from ten to fifteen minutes, while the species infesting man crawl into hiding and remain so for several hours.

The eggs (Plate LVIII, 2) are laid, one at a time, on the bristles of the hog and are attached to them by a clcar cement. They are most abundant on the lower parts of the body. The egg-laying process has becn watched on the human arm during feeding. After drawing blood for almost ten minutes, the female withdrew the mouth parts but remained stationary, holding the end of the abdomen bent downward in an unusual manner. 
Neither feces nor blood was ejected from the anus, but a drop of hyaline fluid escaped from the sexual orifice almost simultaneously with the pointed. end of an egg. After a few seconds the louse moved away, leaving the egg attached to a hair on the arm. The position of the gonopods could not be seen, but the posterior lobes of, the ninth abdominal segment surrounded the hair on which the egg was laid. According to Sikora (1915:536), who has described the act of egg-laying on a bristle by a hog louse in captivity in a vial, the insect remained motionless for almost ten minutes after the first appearance of the egg, and then noved off leaving the egg attached to the bristle. Watts (1918:9) says, "The entire operation requires but a few seconds, so that one seldom sees a female lay an egg unless watching closely for some time." In the ovaries the eggs are oriented according to Hallez' law, and, when laid, the ventral surface is attached to the bristle. The cement surrounds the bristle but does not appear to surround the egg, which is attached to the bristle between its transverse median line and its posterior end. One or more eggs may be laid on the same bristle, not always pointing in the same direction. After attachment we have always found them immorable, but Watts (1918:9) states that he has found they can be slipped along the hairs and are often pulled away from the body by the rubbing of the animal. This, however, does not agree with his earlier statement on the same page, that "each egg is glued to the base of a hair and is laid so that the smaller end practically touches the skin of the host, which keeps the egg warm until it hatches, several days later"; and, since the diameter of the bristle diminishes toward the tip, the cement ring large enough to surround the base of the bristle would tend to slip off, carrying the egg with it, thus causing an excessive mortality not provided for by overproduction.

In captivity the eggs are laid on bristles or threads of gauze, and the number laid daily appears to depend on the opportunity to feed, as the following table shows:

Opportunities of feeding in 24 hours

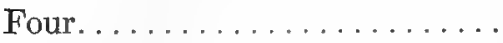

Continuous.

Continuous for 7 days......... Two
Number of eggs
laid in 24 hours

$2 \ldots \ldots \ldots$

$4 \ldots \ldots \ldots$

$3 \ldots \ldots \ldots$

1-2
Authority

Sikora

Sikora

Claassen $^{3}$

Florence

"Unpublished data kindly communicated to the writer by Professor P. W. Claassen, of the Department of Entomology, Cornell University. 
The last data relate to a female reared in captivity. Three days after the last molt, when put on the arm to feed, she moved rapidly about for thirty minutes, repeatedly elevating the posterior end of the abdomen, and made no attempt to draw blood. She was returned to the vial and two hours later was given another opportunity to feed, when an egg was found attached to a bristle in the vial. Twice a male was placed in the vial for some hours, but in neither case was copulation seen to occur. During a period of sixteen days eighteen eggs were laid, none of which hatched. The female died six days after laying the eighteenth egg, and gross dissection showed the ovaries very much shrunken. That oviposition continues without fecundation has been observed by various workers, and the unfertilized eggs are easily recognizable because they quickly change color and shrivel up.

When laid, the egg is an iridescent pearly white. As development progresses it becomes more opaque, and toward the end of the incubation period it appears light amber in color. Its average length is 1.5 to 1.75 millimeters, and its average breadth at the widest part is 0.5 to 0.75 millimeter. It is symmetrical, tapers posteriorly, and is bluntly rounded at the anterior end, where the operculum is situated. The widest part is just behind the operculum (Plate LVIII, 2). The surface is covered with small punctations, which are somewhat larger on the operculum than on the main part of the egg. The junction of the egg with the operculum is indicated by a small ridge bearing striations parallel to the longitudinal axis of the egg.

Hatching has not been observed, but eggs have been seen shortly after being hatched. The operculum opened away from the bristle and remained attached to the egg by a small hinge; protruding from the egg was a small fragment of the vitelline membrane (Plate LVIII, 2). A number of authors have mentioned points in connection with the hatching of pediculi infesting man, and Sikora (1915:530) was the first to give a short description of the process, which has since been confirmed and extended by Nuttall (1917 d:148). Probably in the hog louse the process is essentially the same. The following data show that the period of incubation is influenced by temperature, and suggest a reason for the seasonal variation in the development of the eggs on the hog:

Conditions

On hog
Eggs hatched after

About 5 days
Authority

Coburn $^{4}$

\footnotetext{
1 Data from Coburn (1888).
} 


\section{Conditions}

On hog

Room of ordinary humidity, at temperature of $85^{\circ} \mathrm{F}$., in September

Same conditions, but eggs kept in a closed dish containing a receptacle filled with water

Temperature by day of $26^{\circ} \mathrm{C}$. and by night of $35^{\circ} \mathrm{C}$.

Incubator at constant temperature of $37^{\circ} \mathrm{C}$., dry heat

In vials, worn constantly next the body

Conditions as in last preceding
Eggs hatched after

Authority

From 13th to 20th day, maximum about 16 th day.

Watts
12 days . . . . . . . . Stevenson

17 days. . . . . . . . . Sikora

11 to 12 days (5 eggs

hatched, out of 24).. Florence

14 days (9 eggs hatched, out of 19$) \ldots . . . \ldots$ Florence

13 days (4 eggs hatched, out of 5$) \ldots \ldots$. Florence

The period of incubation evidently lies between twelve and twenty days, with a minimum period of about thirteen to fourteen days when the eggs are kept constantly at body temperature. It is interesting to compare this with the recent work of Bacot and Linzell (1919:388), who found the incubation period of the eggs of the horse louse, Haematopinus asini, to be apparently from sixteen to twenty days, and the minimum period under natural conditions about fifteen to sixteen days.

In the course of their development hog lice undergo three molts, and rearing in captivity has proved the cycle from egg to egg to occupy from twenty-nine to thirty-three days. The life history, as we have observed it, is summarized in the following table:

Time from laying to hatching of eggs......... 13 to 15 days First molt occurred after.............. 5 to 6 days Second molt occurred after................ 4 days Third molt occurred after............... 4 to 5 days Sexual maturity occurred after............. 3 days 
Time of development from first-stage larva to mature adult.

Temperature and other conditions.

16 to 18 days

$35^{\circ} \mathrm{C}$., continually next to body, in vials

1 to 4

29 to 33 days

Number of feedings in 24 hours

Duration of cycle from egg to egg.

\section{THE EARLY STAGES}

The newly hatched louse has 5-segmented antennae and a 9-segmented abdomen, as are found in the adult. The claws and the pad, already described, are present as in the adult, but no joint between the tibia and the tarsus appears until after the final molt (Plate LVIII, 1 and 5). Attention was drawn to this point by Gillette in his brief description of the species written for Coburn (1912:497). The head is large in proportion to the almost colorless body. Only the claws, and the sides of the head in the region of the clypeus, show marked chitinization. During the first instar (Plate LVIII, 3) the dark color gradually extends along the lateral and posterior dorsal regions of the head and the thorax, the legs become more strongly chitinized, and there is some indication of the transverse abdominal plates. The chitinous plates of the pleurites are represented by small, light brown spots close to the spiracles. In the second instar (Plate LVIII, 4) the chitinization is generally more marked, but the buccal tube can still be clearly seen through the integument. The transverse abdominal plates are more developed, the plates of the pleurites are approximately four times as large as in the first instar, and between these two are small circular chitinous areas. In the third instar (Plate LVIII, 5) the head is more strongly chitinized and the buccal tube can no longer be seen throughout its length. The plates of the pleurites resemble those of the adult but are somewhat lighter in colour. The ninth abdominal segment shows no chitinization but is turned slightly dorsad, and the first antennal segment, which in the previous stages was almost of the same diameter as the four other segments, is now considerably larger than these. At the third molt the chitinous plates, which are the external indications of sex, appear at the posterior end of the body. In both male and female, maturity is indicated by a sternal chitinous plate which appears on the thorax about the third day after the final molt (Plate LVIII, 6). The 
mature female averages about 4.6 millimeters long by 2.19 millimeters at the broadest part of the abdomen, and the male averages about 3.9 millimeters long by 2.1 millimeters broad. The following table gives the average measurements throughout the life history:

\begin{tabular}{|c|c|c|c|c|}
\hline Age & Instar & $\begin{array}{l}\text { Number } \\
\text { of feedings } \\
\text { since } \\
\text { preceding } \\
\text { molt }\end{array}$ & $\begin{array}{c}\text { Length } \\
\text { (millimeters) }\end{array}$ & $\begin{array}{c}\text { Breadth } \\
\text { (millimeters) }\end{array}$ \\
\hline 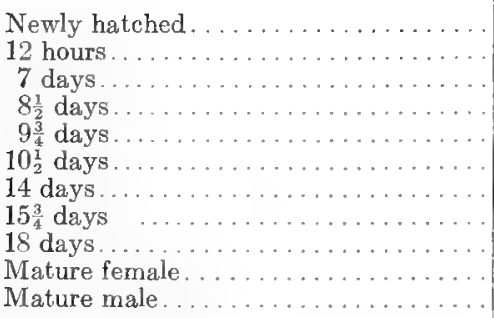 & \begin{tabular}{|r}
1 \\
1 \\
1 \\
2 \\
2 \\
3 \\
3 \\
4 \\
4 \\
4 \\
$4 \ldots$
\end{tabular} & $\begin{array}{r}0 \\
3 \\
(?) \\
8 \\
1 \\
3 \\
1 \\
1 \\
4 \\
2 \\
\ldots \ldots \ldots\end{array}$ & $\begin{array}{l}1.00 \\
\mathbf{1} .25 \\
\mathbf{1} .75 \\
2.25 \\
2.50 \\
2.75 \\
3.00 \\
3.25 \\
4.00 \\
4.60 \\
3.90\end{array}$ & $\begin{array}{l}0.50 \\
0.50 \\
0.75 \\
1.00 \\
1.00 \\
1.25 \\
1.25 \\
1.50 \\
2.00 \\
2.19 \\
2.10\end{array}$ \\
\hline
\end{tabular}

In immature lice the lines along which the tegument ruptures at molting are very distinct. When about to molt the insect raises itself until only the postcrior end of the abdomen, and the claws of the second pair of legs, are touching the surface on which it rests, the back has a humped appearance, and the head is bent downward at right angles to the body. The first rupture is along the dorsal median line of the thorax and gradually extends caudad to the fifth or sixth abdominal segment and cephalad to the frons, where it divides, passing to the base of each eye. Air is sucked up into the pharynx and passes through the alimentary canal to escape at the anus. The body is inflated, pushed through the dorsal ruptures, and so drawn away from the old skin. The body is lowered until it touches the hair or bristle on which the louse is resting, when the legs are folded laterally across it and the ventral surface of the thorax and the abdomen (Plate LVIII, 7). The head and the thorax are gradually drawr upward until the eyes and the proximal segments of the antennae are seen, disclosing at the same time on the old slin a ventral T-shaped rupture, the stem of the $T$ lying along the median line from a point midway between the bases of the antennae to the prosternum, where there is a 
transverse split; the chitin on each side of the median rupture is stretched back so that the opening resembles a triangle. The first pair of legs is next withdrawn, and these, pushing down the skin, help in the final freeing of the head and the mouth parts. These now occupy their normal position, and the second and then the third pair of legs are withdrawn, pushing the insect forward and freeing it from the old skin, which remains anchored to the surface upon which the insect has emerged. The process took place when a louse had been put on the arm to feed and was watched through a binocular. From the first rupture of the old skin until the complete emergence of the insect, thirty minutes elapsed; Sikora (1915: 525-526) describes the process in Pediculus vestimenti as lasting but five minutes. No deseription of the act has been found in the literature of the hog louse, and the slowness in the case observed may have been due to the unnatural environment of the insect; moreover, death followed within an hour of molting.

\section{THE ADULT LICE}

The male and the female are recognized by their difference in size, the shape of the abdomen, and the structure of the two posterior abdominal segments. Both are without pigmented eyes, but the projections on the sides of the head have a lateral, slightly convex, refractive surface suggestive of a lens. While the thorax of the female is somewhat shorter and broader than that of the male, the legs of the sexes are identical, showing no modifications for clasping in relation to copulation. No constant variations in pigmentation have been observed.

\section{THE MALE}

The abdomen of the male is considerably shorter than that of the female, so that, although it measures the same or even slightly less in its widest region, it appears considerably broader. The tergites of segments 1 and 2 are small, but clearly defined. Hairs are present in each abdominal segment in a transverse row. Posteriorly the abdomen is rounded; the terminal segment curves dorsad and anterior, bringing the rectal and sexual orifices into a dorsal position (Plate LVIII, 8). On the ventral surface there is a strongly chitinized plate of characteristic shape extending from the transverse median line of segment 7 through segment 8 to segment 9 , its posterior edge being visible from the dorsal aspect of the 
abdomen. Anterior to this plate, in segments 7 and 6 , the anterior end of the basal plate can be seen shining through the integument (Plate LVIII, 9).

\section{THE FEMALE}

In the female, as already said, the abdomen is longer than in the male, and in consequence it appears more slender. The tergites of segments 1 and 2 are similar to those of the male. Hairs are fewer in number and arranged with much less regularity. The ninth segment has a deep indentation on the posterior median line, and the lateral regions are modified into rather blunt, strongly chitinized processes pointing inward and slightly ventrad, apparently a modification for clasping the bristle during egg-laying, and, according to Mjöberg (1910:216), not unusual in Siphunculata (Anoplura). On the dorsal surface of the segment there is a strongly chitinized plate extending onto each projection, and between it and the edges of the indentation is a row of stout hairs (Plate LVIII, 10). On the ventral surface the gonopods lie on segment 8 . They present a striking contrast to those of the pediculi infesting man, in that they are quite flat and lie widely apart. They are flat processes, narrowing posteriorly, and their median free border is somewhat strongly chitinized and set with a row of stout hairs. Anteriorly they are joined by a fold of the integument which projects caudad in two blunt points (Plate LVIII, 11). They have arisen, apparently, as an infolding of the integument of the segment, and may be considered homologous with the gonopods of the Trichodectidae as described by Morse (1903:609).

\section{THE INTEGUMENT AND BODY WALL}

The integument is tough rather than hard, and chitin is well developed only in certain clearly defined regions. Sculpturing of the cuticula, described by Mjöberg (1910:185) as typical of most Siphunculata (Anoplura), is absent from this species. In the head the cuticula is strongest along the sides, where the muscles controlling the backward movements of the pharynx are inserted, and in two transverse bars - one in the region of the clypeus, where the muscles of the pumping pharynx are inserted, and a second in the frons, where the muscles of the true pharynx are inserted

Where the head passes into the thorax a ring of chitin forms the neck, and from its median dorsal surface two chitinous processes extend into 
the thorax. These were described in this and other Siphunculata (Anoplura) by Enderlein (1904:126), who named them " Hinterhauptvorsatz" and thought that morphologically they probably originated as tendons of the retractor muscles of the head. Mjöberg (1910:202-203) named them the "occipital apodeme." Gross dissection reveals the continuation of these processes as muscle bands having their origin on the apodeme of the metathorax, while muscles controlling the lateral movements of the head are inserted on their posterior lateral borders.

The dorsal surface of the thorax is strongly chitinized and the segments are completely fused with one another. In mature lice the sternal plate is present on the ventral surface. On the prothorax, and also on the anterior angles of the sternal plate, is a pair of very small openings approximately 0.03 millimeter in diameter, which are present at all stages of development (Plate LVIII, 6, 8, and 10) and have been passed over or variously described up to the present time. Stevenson (1905:15), in his description of the thorax, says: "On the ventral surface between the appendages is a chitinous shield. In each anterior lateral angle of this shield or plate is an opening calied the osteole, leading from a canal that extends cephalad." Mjöberg does not mention either of the pairs of openings, and Neumann (1911:407) describes "a pair of very small thoracic stigmata" 5 and "a small stigma in each anterior angle" 5 of the sternal plate. Patton and Cragg (1913:548) describe both pairs of openings as stigmata. On the sternal plates of seventeen species of Siphunculata (Anoplura) figured by Kellogg and Ferris (1915: Pl. IV), no such openings are present.

Gross dissection has shown that these openings are quite different from the stigmata of the tracheae, are without a closing device, and communicate with a canal which has no connection with the respiratory system. The dorsal openings on the prothorax are comnected with those on the sternal plate by a rigid, uniformly chitinous canal passing directly dorsoventral laterad of the thoracic tracheal trunk. One short branch is given off almost at right angles to the main stem and at about one-third of the total length of the latter from its dorsal surface, and passes caudad terminating in the transverse band of muscle which lies between the second pair of legs (Plate LVIII, 12). Series of cross sections made through the

6 Translated froz the original French. 
thorax at various angles after impregnation of the tissue with silver chromate proved conclusively that the structure has no connection with the tracheae and that the canals are unmodified ingrowths of the body wall. They are composed of chitinous cuticula covered with a layer of small hypodermal cells, and form a rigid internal frame, analogous to the skeleton of higher animals, for the partial support of the muscles of the first and second pairs of legs and a transverse muscle of the thorax. No communication between these and a canal extending cephalad, as described by Stevenson, has been found. They are to be regarded as a paired apodeme of the prothorax and the prosternum.

In the region of the metathorax on the median line there is a marked ingrowth of the cuticula, which forms the center of a ridge-like thickening on the inner surface of the segment. This ridge serves for the insertion of the muscles of the neck, the legs, and the dorsal abdominal plate, and may be named the metathoracic apodeme. In the abdomen the segmentation is clearer on the dorsal than on the ventral surface. Segments 1 and 2 are small and have the appearance of belonging to the thorax. As already said, these tergites are clearly defined in both sexes. Segments 3 to 8 have strongly chitinized plates on the pleurites and moderate chitinization of the tergites, while the sternites are almost colorless. The primary cuticula is very thin and can be dissected off with ease from the secondary cuticula, which is of a leathery consistency and in sections has a striated appearance as if deposited in layers. When stained with hematoxylin and eosin the secondary cuticula stains pink except in the strongly chitinized regions, where the primary and secondary cuticulae both retain their yellow color.

The hypodermis underlying the cuticula is made up of uniform cells which become longer and more slender on either side of the trichogen cells. The latter are considerably larger than the hypodermal cells and their basal part is subcircular, and in some cases multinuclear sensory cells lie alongside them sending a prolongation into the hair.

\section{THE RESPIRATORY SYSTEM}

Hooke (1665) saw numerous tracheae intimately connected with the fat cells of the louse, but did not recognize their true function. Swammerdam (1682, English trans., 1758:32) saw seven pairs of stigmata with their tracheae. He described their structure and their numerous branches 
passing among the viscera, pointing out the resemblance between them and the windpipe of man. Landois (1864:12, $1865 \mathrm{a}: 45,1865 \mathrm{~b}: 499)$ gave the first complete descriptions of the general respiratory system, describing in detail and figuring the closing apparatus of the tracheae of Phthirius. Then followed Ströbelt's (1882:106) description of Linognathus vituli (Haematopinus tenuirostris). Both writers agreed in the general arrangement of the tracheae and the number of stigmata, but considered those of the abdomen as being situated on segments 2 to 7 , an opinion held earlier by Denny (1842:34) and later by Stevenson (1905:15) and by Neumann (1911:407). Mjöberg (1910:218) deseribed the general system for Siphunculata (Anoplura) and compared it with that of Mallophaga. Harrison (1916a:101) worked on the respiratory system of the Mallophaga, and used Siphunculata (Anoplura) for comparative purposes. His results confirmed the earlicr work of Mjöberg, who had pointed out the marked resemblance between the Siphunculata (Anoplura) and the less specialized forms of the Mallophaga. In the same year Müller (1915:29-32) described and figured the respiratory system in the clothes louse.

In the hog louse there are fourteen stigmata, the typical number for Siphunculata (Anoplura) - one pair on the thorax in line with the second pair of legs, and six pairs on segments 3 to 8 of the abdomen. The abdominal stigmata on segments 3 to 6 lie on the dorsal transverse median line, while those on segments 7 and 8 are more posterior and lateral in position and can be seen from both dorsal and ventral aspects. The stigmata are slightly raised above the integument and are surrounded by a stout chitinous band, the peritreme. The thoracic stigmata are oblong-ovate, measuring from 0.06 to 0.07 millimeter at the widest part, and the abdominal stigmata are circular, with a diameter of about 0.05 millimeter.

The respiratory system (Plate LIX, 1) consists of two lateral tracheal trunks extending the whole length of the insect, a posterior abdominal commissure, and four more slender commissures in connection with the main ganglia. In the abdomen the main tracheae lie near the dorsal surface on either side of the alimentary tract, and are united posteriorly in segment 8 by a commissure of diameter equal to their own, from which numerous fine branches pass to the fat eells of segment 9 . In segments 8 to 3 a branch is given off from each main trunk to the stigmata of the segment, and they in turn each send off two slenderer branches which, 
breaking up into innumerable tracheoles, pass through the lateral muscles and support the digestive and reproductive organs from their ventral aspect. Between segments 7 and 3 , eight branches are given off centrad from the lateral trunks. These pass to the dorsal muscle plate, the heart, the dorsal fat cells, and the surface of the alimentary tract.

In some species, roots of branches extending laterad from the main trunks, between the branches to the stigmata of scgment 3 and the thorax, have been described by investigators who have regarded them as vestiges of branches to the lost stigmata of segments 1 and 2. Such roots have not been found in this case. In the region of the sccond segment two slender branches are given off, one laterad and the other centrad. The former soon bends downward and breaks into numerous tracheoles on the surface of the salivary glands, while the latter ramifies among the fat cells on the dorsal anterior region of the stomach. Under the sternite of the first segment a slender branch comes off from each main trunk and passes to the dorsal surface of the stomach, and a second fine branch arises where the main trachcae bend somewhat ventrad as they pass into the thorax. This branch breaks up in the thoracic muscle of the third pair of legs.

In the thorax the main tracheae bend underneath the muscles coming from the legs to the metathoracic apodeme. In line with the third pair of legs a very short branch is given off laterad, from the posterior side of which arise two branches, une passing directly into the leg, and the other centrad for a short distance, when it divides into three parts. The first part of this branch is the commissure of the metathoracic ganglion, the second ramifies on the ventral wall of the stomach, and the third bends laterad passing into the leg. Opposite the second pair of legs is a tracheal plexus, from which spread six large branches as well as many small branches supplying the surrounding muscles and fat cells. A stout dorsal branch connects the plexus with each thoracic stigma. The first branch going cephalad divides, one part passing laterad to the first pair of legs, the other passing centrad as the commissure of the prothoracic ganglion, first giving off a branch which turns backward and also enters the first pair of legs. The second branch going cephalad is a continuation of the lateral tracheal trunk and passes to the head. A branch passes directly centrad as the commissure of the mesothoracic ganglion, and from it a branch arises at the lateral border of the ganglion and bends 
around, passing into the second pair of legs. The fifth branch leaves the plexus almost at the same point as the preceding, turns back, and enters the main trunk centrad of the point of issue of the tracheae of the third pair of legs, thus forming a loop, which may correspond to the thoracic tracheal triangle described by Harrison (1916 a:105) in some Mallophaga. There, however, the thoracic stigma forms the apex of the triangle, while this loop lies behind the stigma. Harrison suggests that the inner side of the triangle may be the only survival of wing tracheae. The sixth branch comes from the branch to the thoracic spiracle just dorsad of its entrance into the main trunk, and passes into the second pair of legs. As has been shown, two tracheae pass into each leg; one of which lies ventral and the other dorsal. In the coxae, branches are given off which break up into many fine tracheoles; in the femur a large branch is given off from each trachea, and one of these branches passes along with the main branches into the tibia, where the latter subdivide many times, passing into the spur, the pad, the tarsus, and the claw.

The main trunks, on leaving the tracheal plexus, bend centrad and dorsad, passing into the head on either side of the esophagus and the aorta directly under the occipital apodeme. Just behind the sub-esophageal ganglion they diverge, and shortly give off a lateral branch to the neighboring muscles. Behind the brain a branch is given off centrad, and from its root the commissure of the sub-esophageal ganglion issues, while it passes forward close to the lateral borders of the brain. The main trunks continue forward alongside the antennal nerves, give off a branch to each antenna, and break up into numerous branches among the glands, the fat cells, and the sensory cells of the anterior region of the head.

The external surface of the stigma rescmbles a cart wheel with an open hollow axis, and sections show the vestibule between the stigma and its trachea to be filled with hair-like, chitinous structures radiating from its inner surface to a thin wall surrounding a slender central canal (Plate LIX, 3). These spoke-like projections doubtless prevent the entrance of foreign particles along with the air. A similar structure has been described by Müller (1915:30) in the clothes louse. Between the vestibule and the trachea is inscrted the closing apparatus, concerning the mechanism of which there is still some uncertainty. Krancher $(1881: 522-533)$ briefly described the structure in Haematopinus suis. His figure shows the nature of the vestibule, the closing lever, and one intrinsic muscle between 
the free end of the lever and the wall of the trachea opposite the attachment. No further description appeared until that of Mjöberg (1910:221), who figures a single muscle attached to the free end of the lever, and describes its insertion in the body wall near the stigma. At the close of a detailed study of the stigmata of Heteroptera and Homoptera, Mammen (1912:172) divides insect stigmata into four groups, according as they have one extrinsic muscle, one intrinsic muscle, two muscles, or three muscles, connected with the closing apparatus. Harrison (1916a:116) gives a brief résume of the literature on the subject. He finds in Siphunculata (Anoplura) and in Mallophaga two muscles, which may be homologous with the "Musculus constrictor" and the "Musculus tendinosus" deseribed by Solowiow (1909:707) in the caterpillar of Cossus cossus L. Müller (1915:30) refers to Landois' work on Phthirius, and says that he himself could get no clear picture of the structure in Pediculus vestimenti from the study of sections.

Study of the hog louse has revealed a closing apparatus resembling that of Heterodoxus longitarsus as figured by Harrison (1916a:116), who describes it as an intermediate type and gives no account of the musculature. The thoracic and abdominal stigmata are essentially the same in structure and in mechanism, but the vestibule of the thoracic stigmata is somewhat shorter, measuring approximately 0.08 millimeter from the surface of the stigma to the closing lever, while that of the abdominal stigmata (Plate LIX, 3) measures 0.11 millimeter. The approximate diameter of the vestibule of tine abdominal stigmata is 0.03 millimeter, and at its inner end it narrows and both walls become strongly chitinized. A chitinous lever about 0.03 millimeter long is attached to the ventral wall, and the dorsal wall projects into the lumen as a sharp point. Beyond the lever the wall continues strongly chitinized and somewhat convex for a distance of about 0.016 millimeter, when it passes into the trachea proper. This region corresponds to the bulla of Harrison. In gross dissections no muscles have been found (Plate LIX, 2), but from the study of sections cut at various angles there appear to be two nuscles arising from the free end of the lever. One of these is inserted in the convex wall of the bulla, and the other in the body wall just clorsad of the stigma. This agrees with the finclings of Harrison in other siphunculata (Anoplura) and in the Mallophaga. He offers two interpretations of the structure: (1) both the extrinsic and the intrinsic muscle function in closing the 
stigma, or (2) closing is effected by the intrinsic muscle and reopening by the extrinsic muscle. With Harrison, we consider the former the more reasonable explanation, in which case it is assumed that the trachea opens through its own elasticity on the relaxing of the closing muscles.

\section{THE MUSCULAR SYSTEM}

With the exception of Osborn's (1904) note on the musculature of the protrusible disks and the claw, nothing has been published concerning the muscular system of the hog louse, and the only work on an allied species is that of Ströbelt (1882, English trans. 1883:100) on Linognathus vituli (Haematopinus tenuirostris). Landois (1864:22, $1865 \mathrm{a}: 33,39$, and $1865 \mathrm{~b}: 495$ ) described and figured a part of the musculature of the species affecting man, and was the first to observe the arrangement of the muscles in the female. Recently Müller (1915:10) has confirmed the work of Landois and has described in addition the arrangement of the muscles in the male. Nuttall (1917 a:295) has briefly mentioned and summarized the different arrangement of the abdominal muscle plates in the two sexes as described by Landois and Müller. The musculature of the hog louse presents some striking contrasts to that of the pediculi infesting man.

The head contains many muscles, of which the majority control the pharynx and the mouth parts and are described later in connection with those parts. The muscles controlling the antennae are confined to the head and the first segment of the antennae, those in the head all originating in the dorsal wall and none of them in the ventral as in the pediculi infesting man. There are six muscles, which originate in close succession on either side of the dorsal median line above the frontal ganglion and immediately posterior to the elevator muscles of the pumping pharynx. The two anterior muscles pass obliquely backward and downward, and are inserted in the ventral articulation of the antennae with the head; the two median muscles pass almost directly ventrad and are inserted in the dorsal articulation of the antennae with the head; and the two posterior muscles pass obliquely anterior and downward and are inserted immediately postcrior to the median muscles. In the antennae the muscles are confincd to the first segment, and consist of four bundles originating at the articulation of the antennae with the head and inserted two in the anterior and two in the posterior articulation of segments 1 and 2 . 
The muscles controlling the movements of the head lie in the anterior part of the thorax and have their origin in the metathoracic apodeme and in the strongly chitinized tergite of the prothorax. The elevator and retractor muscles are six in number and originate in the metathoracic apodeme, three on either side of the median line; the two median muscles are inserted in the distal ends of the occipital apodeme, and the two lateral muscles on either side pass cephalad and are inserted in the neck. The two depressor muscles are made up each of three strands, and originate in the dorsal wall of the prothorax on either side of the elevator muscles on the transverse median line of the first pair of legs. They pass obliquely ventrad and cephalad, and are inserted as two short, stout tendons in the chitinous ring of the neck on either side of the ventral median line. The lateral movements are controlled by muscles made up each of four strands. They originate in the dorsal wall of the prothorax laterad of the depressor muscles, and pass obliquely centrad, where they are inserted in the lateral borders of the prongs of the occipital apodeme at its distal end.

The muscles controlling the legs originate in the metathoracic apodeme, and if the dorsal surface of the thorax be carefully removed or if horizontal sections be made through this region, the muscles are seen to have a stellate arrangement with the apodeme as the center point of the star. A similar condition exists in the pediculi infesting man, and has been figured by Müller (1915). There are in all eighteen groups of muscle strands originating in the apodeme, and three of these groups are inserted as stout tendons - two in the dorsal articulation of the coxa with the thorax, and one a short distance within the ventral wall of the coxa, in each leg. Each group is composed of some five to seven strands, which vary in length according to their point of origin in the apodeme. The muscles passing to the first pair of legs are also supported by the apodeme, which passes from the prothorax to the prosternum, and if this be dissected out it is seen to pass through some of the individual strands of the bundles.

On the ventral surface of the thorax there is no muscle plate resembling that of the pediculi infesting man, but two transverse muscle bundles, passing, respectively, between the ventral bordcrs of the coxae of the second and third pairs of legs, are present and correspond to the intercoxal muscles described by Müller. The anterior band consists of four strands, and in these are inserted the posterior arms of the apodeme of the prothorax 
and prosternum. It lies just anterior to the stomach, below the esophagus, and is covered ventrally by the thoracic ganglia and many fat cells. The posterior band consists of two strands and passes across the ventral surface of the stomach. From each of the points of its insertion in the coxae of the third pair of legs, a muscle passes somewhat obliquely cephalad, and these muscles are inserted in the posterior arms of the apodeme where they enter the anterior transverse muscle band. In sections made through lice having the stomach filled with blood, the transverse muscle bands appear to be imbedded in the stomach, owing to its walls having become distended on either side of them.

The work of Landois and of Müller has made known the great difference in the longitudinal abdominal musculature of the two sexes of the maninfesting louse, and Nuttall (1917 a:296) has summarized this difference as follows:

Dorsal abdominal Ventral abdominal muscles are present muscles are present under segments under segments

In the male $\ldots \ldots \ldots \ldots \ldots \ldots \ldots \ldots \ldots \ldots \ldots \ldots \ldots \ldots \ldots \ldots \ldots \ldots \ldots \ldots, 3,4,5,6,7,8 \quad 2+3,4,5,6$

In the female....................... $6,7,8 \quad 2,3,5,6$

In the hog louse no such difference is found. In both sexes a dorsal muscle extending the whole length of the abdomen is present. It consists of some eight muscle strands on either side of the median line. In segment 1 these strands converge to the point of their attachment to the posterior surface of the metathoracic apodeme, and posteriorly, in segments 8 and 9 , the two halves of the plate diverge and the heart lies between them. The contraction of the muscle plate raises the posterior end of the abdomen. In both sexes the ventral muscle plate (Plate LIX,4) begins in the anterior border of segment 2 and extends caudad to the posterior border of segment 6. The number of strands in each segment is apparently not arbitrary, and the following have been found most frequently:

Number of strands in male

Segment 2, 12 central and 4 lateral Segment 3, 14

Segment 4, 14

Segment 5, 14

Segment 6, 14
Number of strands in female

10 central and 4 lateral 18

16

16

16 
In segment 2 the four lateral strands frequently appear as three, because the two outermost fuse almost immediately after leaving their attachment between segments 2 and 3. At their proximal end these lateral strands are attached to the lateral body wall a short distance cephalad of the anterior border of the pleurite of segment 3 , and at their distal end, when looked at from their ventral aspect, the innermost strand and a part of the next innermost are seen to underlie the three outermost of the central strands. The dorsal and ventral muscle plates are composed of segmental muscles in which the attachment between those of the successive segments has become stronger than their attachment to the intersegmental folds of the body wall, so that the dorsal and ventral muscles can be dissected off as entire muscle plates.

While the two sexes bear a close resemblance in the longitudinal musculature of the abdomen, they show a marked contrast in the dorso-ventral musculature. In the male the digestive and reproductive organs occupy only the center of the abdomen, but in the female the ovaries occupy most of the lateral regions as well. In the male there is a powerful dorsoventral musculature, which not only assists in respiration but plays an important part in the act of copulation. That part of each of segments 2 to 8 between the alimentary canal and the lateral body wall is filled with stout blocks of muscle, definite in number and arrangement for each segment (Plate LIX, 5). In segment 2 there are two blocks of muscle, in segments 3 and 4 eight blocks, in segments 5,6 , and 7 . nine blocks, and in segment 8 eight blocks. The tracheae from the stigmata to the lateral trunk pass between these blocks of muscle, and between the muscle and the lateral body wall lie numerous fat cells. In segment 9, where the muscles controlling a part of the copulatory apparatus originate, there are no dorso-ventral blocks of muscle.

In the female there is a deep lateral indentation between the successive segments from 3 to 8 , that between segments 6 and 7 being somewhat deeper than the others. Internally these indentations have the appearance of pillars or sections of the cuticula which divide the lateral parts of the successive segments into a series of small chambers. At the end of each cuticular pillar two bands of muscle are attached to the dorsal and ventral walls of the abdnmen, and these curve close to the centrad wall of the pillar. In segments $4,5,6,7$, and 8 , in the anterior half of the segment 
there is a moderately stout band of muscle which is attached to the dorsal and ventral cuticula between and in line with the bases of the pillars. Within the lateral chamber of each of segments 3 to 8 there is a group of five slender muscle strands, and in segment 9 there are six larger strands. On the ventral surface these delicate strands are attached to the body wall just below the strongly chitinized pleurite, and from there they pass somewhat obliquely centrad and dorsad to the cuticula just within the central border of the chamber.

The leg muscles are similar in both sexes and show no unusual modifications except in those controlling the claw. Landois (1855 a:33 and $1865 \mathrm{~b}: 495)$ studied in part the leg muscles of the man-infesting pediculi, and Müller (1915:14) has figured the muscles of the leg of a female clothes louse. As already said, Osborn (1904) described the musculature controlling the tarsus and claw of the hog louse. There are four muscles in each coxa, which originate in its articulation with the thorax and are inserted in its articulation with the trochanter. Within the latter are the flexor and extensor muscles of the femur, with their origin and insertion in its proximal and its distal articulation, respectively. The flexor muscle of the tibia is made up of a number of fibers which originate at intervals along the dorsal wall of the femur and come together in one tendon for their insertion in the ventral line of the articulation of the femur with the tibia. The extensor muscle is made up of two bundles of fibers originating in the articulation of the trochanter with the femur and in the proximal dorsal wall of the femur; it ends in two tendons which are inserted in the articulation of the femur with the tibia on the dorsal side of the leg. In the tibia there is one large muscle, made up of a number of closely set fibers which originate in the proximal posterior and ventral walls of the tibia. The muscle passes along the whole length of the segment, midway giving off a branch which is inserted in the base of the protractile disk. On entering the tarsus the muscle becomes a tendon which ends in a strongly chitinized process of a diameter somewhat greater than that of the tendon itself. It is inserted in the ventrai wall of the tarsus under the base of the blunt process situated there, so that its anterior end lies just within the border of the claw and is attached to its ventral curve. The position and attachment of this muscle has been determined from the study of mounts of gross specimens and from numerous dissections of legs. It must be regarded as the extensor muscle of the claw, and the 
branch going to the disk must be the retractor muscle of the disk. Osborn figured this large muscle lying in the tibia as inserted in the dorsal wall of the tarsus, and a continuation passing from there to the dorsal curve of the claw. He also figured a flexor muscle of the tarsus. Neither of these two conditions has been found in the present investigation, and the absence of flexor muscles of the tarsus and the claw may be explained on the following grounds: the tarsus becomes defined as a segment distinct from the tibia only after the final molt, and is then practically immovable, while the claw in its normal resting position is bent over with its tip touching the ventral anterior extension of the tibia, so that only an extensor muscle is necessary for its function. No mechanism for ejecting the protractile disk has been found, and, as Osborn suggested, this ejection may be accomplished by means of an elastic framework.

The foregoing account deals only with what may be called the skeletal muscles of the louse. The muscles controlling the various systems of the body are described later in their respective connections.

The histological structure of the muscle is best seen in the material fixed in Bouin's solution and stained with Mallory's anilin-blue connectivetissue stain, when all the cross-striations stand out with great clearness. All the muscles have a well-developed sarcolemma and are richly supplied with peripheral nuclei.

\section{THE VASCULAR SYSTEM}

In the writings of the early investigators of the Pediculidae, no real description of the dorsal vessel is to be found. Landois (1864:11), after many attempts, distinguished in freshly molted insects a slender tube originating in the region of the transverse tracheal band. He traced it cephalad to the middle of the abdomen, but could follow it no farther. Its pulsations were more rapid than those of the stomach. Mjöberg $(1910: 223)$ pointed out the similarity of the heart in the two groups which he studied, and drew attention to the lack of any thorough work in the Siphunculata (Anoplura). According to Schröder (1912-13:390), Provazek in 1905 described and figured the heart of Hacmatopinus spinulosus Burm., and this appears to be the first anatomical description of the heart of a siphunculatan. Müller (1915:27) has figured the heart of the clothes louse in gross and in sections, and has described in detail its anatomy and its pulsations in living specimens. Harrison (1916 b:220) 
again called attention to the similarity of the heart in Mallophaga and Siphunculata (Anoplura), and referred to Fulmek's (1905) work on Mallophaga, in which there is a short résumé of the literature of the heart, beginning with the work of Wedl (1855), who first distinguished in the dorsal vessel a posterior, specially contractile part - the true heart and an anterior, more vessel-like part - the aorta.

In the hog louse the heart lies in the two posterior abdominal segments, between the halves of the dorsal muscle plate, and is attached to the dorsal wall on either side of the median line by two delicate septa. It is oblong-ovate, measuring approximately 0.38 millimeter in length and 0.075 millimeter in breadth, and has two lateral indentations on either side which give it a three-chambered appearance (Plate LIX, 6). Attached to the lateral and ventral surfaces are three pairs of wing muscles which pass directly laterad under the two halves of the dorsal muscle plate and are inserted in the lateral body wall toward the ventral surface. To the central wing muscles on either side is attached a group of six pericardial cells similar to those described by Fulmek (1905:620) in Nirmus sp. In gross dissections the ostia cannot be clearly seen, but sections show three pairs, lateral in position. Anteriorly the heart leads into the aorta, which lies free throughout most of its length in the body cavity and passes cephalad entering the head alongside the esophagus. Its width varies from 0.03 millimeter at the posterior end to 0.02 millimeter at the anterior end. In some few cases it seemed swollen to a bulb in the region of segments 6 and 5 , but we did not find this to be a constant character.

The wall of the heart is very thin, and in section it is seen to be of uneven thickness (Plate LIX, 7). Its histological elements appear to be mostly muscular, and, while nuclei are visible, they resemble those of the sarcolemma rather than those of a true epithelium. Where the wall is slightly contracted, it has a false appearance of being toothed. Where the heart passes into the aorta there is a succession of six pairs of valvelike structures extending from opposite walls of the aorta into its lumen and almost meeting on the median line. Sections showed no definite structure that would reveal the true histological nature of these.

The blood is a colorless fluid and its cells can be seen singly and in groups scattered throughout the heart and the aorta. They are definite round cells with a well-defined central nucleus, and do not appear to be 
numerous. Owing to the thickness of the cuticula it is impossible to watch the pulsations of the heart in living specimens, as was done by Landois (1864:11) and by Müller (1915:29) in the clothes louse.

The most successful preparations of the dorsal vessel have been obtained by first removing the dorsal cuticula of the whole abdomen and then the dorsal muscle plate. If the posterior attachment of the muscles of segment 9 be carefully loosened, the heart and its wing muscles will generally be found intact on the ventral surface of the muscle plate.

\section{THE NERVOUS SYSTEM}

Since the time of Swammerdam (1682, English trans. 1758:36), it has been known that lice possess three large thoracic ganglia and no abdominal ganglia, and that nerves pass backward from the metathoracic ganglion over the ventral stomach wall. It was not, however, until almost two hundred years later that a more detailed description of the central nervous system appeared, when Landois (1864:24) published his description of Phthirius inguinalis. He referred to Swammerdam as correctly describing three thoracic ganglia, and to Burmeister (1847) as incorrectly describing two in the Pediculidae. He figured the brain, the connectives, and the thoracic ganglia, but showed neither a sub-esophageal ganglion nor a sympathetic system. In his study of Pediculus vestimenti, püblished a year later (Landois, 1865 a:54), he found no noteworthy difference between the species. Brüh $(1871: 477)$ devoted his attention chiefly to the study of the peripheral ganglia, which he deseribed as "Haar-Gehirne" and of which he counted approximately one hundred and fifty on each louse. Graber (1872:165) reviewed the work of Landois, and described the connectives between the brain and the thoracic ganglia as being at least four times the length given by Landois. On one oecasion he found and figured a pear-shaped ganglion with two nerves pasing backward from it. He thought it was the hitherto undescribed sub-coplageal ganglion, but, since it lay on the dorsal surface of the csophagus, he concluded that it must be a part of the visceral nervous system. Mjohrerg (1910:222) did no work on the nervous system, but in a short note he mentioned the concentration of the ganglia in the thoracic region and the lack of any detailed work in both siphunculita (Anoplura) and Mallophaga. A considerable advance has been male by Nüller (1915:32-37) in his 
description of the nervous system of the clothes louse, and he has called attention to the fact that, although in the mature louse the ganglia are concentrated in the thorax, in the embryo figured by Cholodkovsky (1903: 124) they extend some distance into the abdomen.

The central nervous system of the hog louse consists of five ganglia, their connectives, and commissures, and its approximate length from the anterior border of the brain to the posterior border of the metathoracic ganglion is 0.93 millineter (Plate LIX, 8). The supra-esophageal ganglion lies in the posterior half of the head behind the level of the insertion of the antennae. It is a large, compact ganglion, deeply grooved anteriorly and surrounding the dorsal and lateral surfaces of the esophagus like a collar; its position is somewhat oblique, and the three segments of which it is composed are very closely fused. Its anterior lobes are joined on the ventral surface by the esophageal commissures, which can be easily seen in sections but are invariably broken in the process of gross dissection. These commissures were seen also by Müller (1915:34) in the clothes louse, and he suggested that they be named the "Commissura cerebri subpharyngealis." From the tritocerebron a pair of nerves pass out anteriorly and soon divide, one branch of each going to the frontal ganglion and the other to the labrum, where each subdivides into at least four branches terminating in large multinuclear sensory cells from which slender processes pass to the anterior wall of the head on either side of the haustellum. The ventral anterior part of the cleutocerebron forms the olfactory lobes. In gross dissection these could not be distinguished, but they were found in series of longitudinal sections through the head, and from each a large nerve passes to the antennae: These nerves lie dorsad and somewhat laterad of the nerves from the tritocerebron. The optic lobes, also indistinguishable from the mass of the brain, send nerves out to the eyes, which are situated on prominences behind the antennae, are poorly developed, and are without pigment. The sub-esophageal ganglion is concealed anteriorly by the protocerebral lobes of the brain, and the esophageal connectives are so short as to be invisible unless the brain be raised. It is a heart-shaped ganglion, broadest anteriorly, and having a small indentation in which the esophagus rests. In sections, three pairs of nerves can be seen passing from it to the mouth parts.

From the apex of the sub-esophageal ganglion two closely apposed connectives pass backward along the median line to the prothoracic 
ganglia. They measure approximately 0.22 millimeter in length. The thoracic ganglia are large and broad. Their approximate length is 0.38 millimeter and width 0.28 millimeter. They are closely fused, showing neither connectives nor commissures, but both in gross specimens and in sections it is evident that each ganglion has arisen through lateral fusion of two ganglia. They lie in the most anterior part of the thorax, and when the stomach is distended their position is oblique dorso-ventral rather than ventral. All three send out lateral nerves to the legs and the thorax, and the metathoracic ganglion sends in addition eight nerves to the abdomen, of which the two nearest the median line are the largest. These nerves pass backward to the ninth abdominal segment and give off in their course many slender branches to the visceral and reproductive organs.

The sympathetic system is well developed. The frontal ganglion is somewhat pear-shaped and lies some 0.03 millimeter in front of the brain, on the median line above the junction of the pumping pharynx with the true pharynx. Slightly laterad on either side of the ganglion a small nerve is given off anteriorly from the branches connecting the ganglion with the brain. The course of these nerves has not been seen, but they may connect the frontal ganglion with two smaller ganglia which are united to each other and lie on the median line above the anterior part of the buccal plate of Harrison (Plate LX, 1). Similar ganglia have been seen by Sikora (1916:28) in the clothes louse, and she has suggested that they are homologues of the prefrontal nerve plexus described in other insects. From the anterior end of the frontal ganglion a nerve passes forward on the median line, and from it numerous lateral branches are given off. From the posterior end of the frontal ganglion the recurrent nerve runs back, passing under the brain close to the dorsal surface of the esophagus and finally terminating in the thorax in a small ganglion situated above the entrance of the esophagus into the stomach. From this ganglion at least two slender nerves pass backward over the dorsal stomach wall.

Both in gross dissections and in the study of serial sections, two subcircular structures, of a diameter approximating 0.03 nillimeter, have been found under the protocerebral lobes of the brain. They are made up entirely of ganglion cells, show no central substance, and stain more dceply than the surrounding tissues. In no case has any connection 
been traced between them and the brain, but they are in close association with the tracheoles of the commissure passing under its posterior part. While a study of the texts of Berlese (1909:588) and Schröder (1912-13: 86) suggests that these bodies may be homologues of the "corpora allata" described by Carrière and Bürger in 1897, Heymons in 1899, Janet in 1899, and others, a knowledge of their development is essential for their correct interpretation. A short distance behind the brain and approximately above the esophageal ganglion, there has been seen in longitudinal sections of the head a ganglion in the course of the recurrent nerve, but no branches have been found issuing from it. This may be the hypocephalic or hypo-cerebral ganglion figured by Berlese (1909:596).

No attempt has been made to interpret a peripheral nervous system such as was described by Brühl (1871:477) in the pediculi infesting man, but if the nerve to the antennae be followed, it is seen to give off branches to the second and third segments which end directly under the cuticula in large multinuclear sensory cells similar to those at the termination of the labral nerves. In the terminal segment the nerve breaks up into branches corresponding in number to the blunt spinelike processes on the terminal sensory plate. Each branch terminates under its process as an oblong-ovate multinuclear sensory cell (Plate LIX,9), but the actual connections between the cells and the processes have not been seen. Similar sensory cells have been seen in a few sections underlying the hairs of the abdomen.

THE STOMODAEUM, MOUTH PARTS, AND SALIVARY GLANDS

Writing of the clothes louse, Sikora (1916:22) says: "Es gibt kaum ein anderes Insekt, über dessen Anatomie so lange gestritten wurde, und über das so viele voneinander gänzlich abweichende Meinungen geäussert worden wären, wie die Laus." Most of the literature is the outcome of investigations of the man-infesting pediculi, but in some instances more or less detailed comparative studies have been made on the hog louse. With a few exceptions workers have confined themselves to the study of the mouth parts and their homologies, and this for two reasons: first, because in the middle of the last century a controversy was carried on as to whether lice possessed biting or sucking mouth parts, and secondly, because the systematic position of the group, long a matter of uncertainty, was thought to be dependent on the morphological 
interpretation of the mouth parts. Owing to the specialized nature of the mouth parts and the lack of any ontogenetic proof of their homologies, various interpretations have been offered by investigators according to their views of the affinities of the group.

The early naturalists of the latter half of the seventeenth century attributed sucking mouth parts to lice, and based their opinions on the experimental feeding of captive lice on themselves. Nitzsch (1818:304) confirmed the observations of Swammerdam as to the presence of a bristle sheath (not the true sheath, but the proboscis), and put forward the hypothesis that the inner tube of suction consisted of several setae. His drawings of the structure were published, not with the text, but posthumously by Burmeister (1838). A year later Erichson (1839:377) stated that previous workers had erred in their descriptions, and that the louse possessed no hooks on the haustellum but did have a pair of strong, four-jointed palpi and very distinct mandibles. This statement led to Burmeister's (1847) paper upholding and confirming the opinions of Nitzsch, in which he gave an account of the structures in the hog louse. His work, though in the light of more recent investigations incomplete and in parts inaccurate, was a distinct addition to the knowledge of the subject. It was followed the next year by a contribution from Simon (1818:274), who, in his treatise on skin diseases, described his joint work with Erichson and corroborated Erichson's statements as to the presence of true palpi and mandibles and the absence of a sucking apparatus.

The controversy was finally settled in 1864, when Schjödte (1864, English trans. 1866:213) published the results of his investigations and his interpretations of the artifacts which had misled the supporters of the bitingmouth-parts theory. In the same year Landois (1864:3) described the mouth parts of Phthirius as corresponding very closely with Erichson's and Simon's descriptions of those of Pediculus capitis and P. vestimenti, but when he published the results of his investigation of the clothes louse (Landois, $1865 \mathrm{a}: 34$ ) he stated that his first interpretation was wrong and that the mouth parts were of the sucking type. Brüh (1871) described the mouth parts of the three species affecting man, and along with Schjödte considered the picreing mouth parts as having arisen through a modification of the mandibles and the maxillive, a view which, according to Enderlein (1905:631), originated in 1853 with Gerstfeldt, who regarded the mandibles as a tube made up of two halves and the 
maxillae as the bristles lying within it. Graber (1872:138) distinguished in the mouth parts of Phthirius an upper lip, an under lip (proboscis), and a sucking tube formed possibly by the fusion of the mandibles and the maxillae and capable of protrusion from the proboscis, but he did not realize the true nature of the piercers and their sheath. He saw these structures extending far back in the ventral region of the head, and interpreted them as the retractor muscle of the proboscis.

The next two in the long succession of publications appeared at intervals of ten years, and both dealt, one entirely and the other in part, with species affecting domestic animals. Ströbelt (1882, English trans. 1883:86) described very incompletely some of the structures surrounding the mouth openings of Linognathus vituli (Haematopinus tenuirostris) without seeing the real mouth parts, while Meinert (1891-92:58) used Haematopinus suis to illustrate his study of the mouth parts of Pediculus humanus and figured the different parts of the apparatus. Meinert called the whole structure the pharynx, distinguishing the anterior part of the stomodaeum proper as the epipharynx and the ventral sheath and piercers as the hypopharynx.

A third decade passed before another contribution appeared, and then Cholodkovsky (1903:120) attacked the subject from a different aspect. Realizing the uncertainty pervading all the earlier litcrature-most of which had appeared before the application of section-cutting to investigation methods - as well as the urgent need of embryological studies to supplement the early work of Melnikow (1869:153), Cholodkovsky not only studied mature species of Pediculus and Haematopinus, but also many mounts and serial sections of different stages of embryos of two of the species infesting man. The result led him to believe that mandibles and maxillae are present in the early stages of the development of the germ band but disappear entirely before the escape of the young insect from the egg, and that the piercer sheath and its apparatus are formed from the labium alone. Melnikow (1869:153) had emphasized the relationship between the Mallophaga and the Pediculidae, and considered both as a family of the Rhynchota. Cholodkovsky agreed with the first part of this statement, but thought the two groups should rather be classed with the Orthoptera (particularly with Pseudoneuroptera), or, preferably, should be placed in a separate order by themselves, for which he suggested the name Pseudorhynchota. 
This suggestion was criticized by Enderlein (1904:121 and 1905:626), who. helieved that these insects were hemipterous in their affinities, and consequently homologized the piercing apparatus with the maxillae, hypopharynx, and labium of the Rhynchota. His method of investigation was by gross dissection and by the study of cleared and mounted specimens. He used a number of related forms but gave the most detailed work to the interpretation of the hog louse. He compared the "mandibles" of the latter with those of the Corixidae, a proceeding which led to a discussion of the question by Handlirsch (1905:668), who emphasized the much clearer resemblance existing between the mandibles of the Siphunculata (Anoplura) and of different species of Mallophaga as figured by Snodgrass (1899). One outcome of the controversy between Cholodkovsky and Enderlein was the publication by Pawlowsky (1906:156) - a pupil of Cholodkovsky - of a résumé of the literature up to his time on the mouth parts of lice, and a description of the anatomy of the piercing and sucking apparatus of the Pediculidae.

Mjoberg (1910:203) made no study of the mouth parts but confined himself to a brief summary of the work of others, dealing at greatest length with Enderlein's work on the hog louse and his interpretation of the mandibles. Patton and Cragg (1913:531) gave an account of the mouth parts of Pediculus vestimenti "prepared, with the assistance of the above papers [of Enderlein and Pawlowsky], from sections and dissections." This account included also a description of the first part of the alimentary canal. The fact that the man-infesting pediculi are an etiological factor in the transmission of certain diseases has led to the publication within the last few years of three detailed papers on the anatomical structure of the anterior part of the alimentary canal and of the mouth parts proper. Those of Harrison (1916 b) and Sikora (1916) appeared almost simultaneously, and that of Peacock (1918) some two years later. Owing to war conditions the work of Sikora was not available to the other two investigators, nor their work to her. Harrison and Peacock confined their investigations to the species affecting man, while Sikora introduced several species, among them the hog louse, for purposes of comparative study.

The head of the hog louse is most strongly chitinized on the lateral regions, and the chitinization extends a little way beyond the borders of both dorsal and ventral surfaces. The remainder of the ventral surface is only weakly chitinized, and at the anterior end the integument is 
capable of considerable wrinkling; while the dorsal surface is strengthened by three rigid transverse areas, one in the region of the clypeus, a second between the bases of the antennae, and a third above the anterior part of the brain. At rest the mouth opening is a longitudinal slit and is not visible from the dorsal surface. At the anterior border of the head on either side of the mouth opening are two strongly chitinized areas, which extend a little way onto the dorsal surface of the head but considerably farther onto the ventral surface, and on each of which are situated two pairs of bristles (Plate LX, 2-4). Sikora (1916:13) found in the six species of lice she studied-Pediculus vestimenti, Haematopinus suis and H. eurysternus, Polyplax spinulosus (End.), Haemodipsus ventricosus (End.), and Trichaulis vituli (End.) - a paired chitinous structure having the form and size of mandibles, situated between the upper and lower lips and apparently adapted for biting or rasping. In sections made through the anterior head region (Plate LX, 1), structures corresponding in part to this description have been found, but they are apparently only very weakly chitinized and are not covered by an underlip. Their inner border is slightly serrated and they appear to be attached by slender muscles to the process on the inner lateral wall of the head with which the basal part of the "Inandibles" of Enderlein are continuous. Whether these structures could play any part in feeding is uncertain.

\section{The haustellum}

Projecting in front of the anterior border of the head on the median line is a small tubelike structure, the haustellum. It is convex on the dorsal surface and has an open longitudinal slit, the buceal slit, on the ventral surface (Plate LX, 2 and 3 ). Its approximate length is 0.05 millimeter and width 0.03 millimeter, and its chitin is continuous externally with that of the head and internally with that lining the food canal. In the interior of the haustellum are four pairs of double teeth arranged in two longitudinal parallel rows. They are present in both young and mature lice and are known as the buccal teeth. At the inner end the haustellum is connected by a fold of soft cuticula with the buccal plate.

The buccal plate

The buccal plate (Plate LX, 2 and 3) is a strongly chitinized structure identical in width at its anterior end with the haustellum and at its 
posterior widest part measuring 0.08 millimeter across. It has the shape of a capital A in which the crossbar is a slight, curve, convex toward the apex of the letter, and on the dorsal surfure the space between this curve and the apex of the letter is solict. Its total length from the anterior edge to the posterior end of the arms is approximately 0.22 millimeter. Laterally it curves downward and centrad, but the opposite sides do not meet, so that on the ventral surface there is an open slit continuous with the buccal slit. The posterior arms of the buccal plate are fused with the lateral wall of the pumping pharynx.

\section{The pumping pharynx}

The pumping pharynx (Plate LX, 2 and 3 ) is strongly chitinized on the ventral and lateral surfaces and is capable of considerable dilatation on the dorsal surface. Its width at rest is 0.06 milimeter and the combined length of the buccal plate and the pumping pharynx is 0.5 millimeter. Its ventral surface extends forward to the posterior end of the ventral slit of the tubelike part of the buccal plate, and its dorsal surface is continuous with that of the buceal plate. Toward the posterior end there is a somewhat knoblike projection of the lateral walls, followed by a rather short backward prolongation of the more strongly chitinized part at the junction of the pumping pharynx with the true pharynx.

\section{The pumping pharyngeal tube}

From the anterior end of the pumping pharynx, two half tubes (Plate LX, 1 and 2) pass into the groove of the buccal plate but do not extend quite to its anterior end. Their ventral edges overlie each other; their dorsal ends lie apart, but so close under the buceal plate that a tube is formed through which blood is drawn during feeding. This tube has been called by Harrison (1916 b:209) the "buccal tul)e," by Sikora (1916: 26) the "Haustellumhalbröhre," and by Peacock (1918:101) the "pumping-pharyngeal tube." The true nature of the connection between this tube and the pumping pharynx can be followed only in sections, and is discussed later.

\section{The pharynx}

The pharynx (Plate LX, 1 and 2) was called by Enderlein (1904:127) the "Iarynx," and he deseribed it as a chitinous band bent around on itself over the esophagus and never fused with the pharynx (pumping pharynx). 
In cleared specimens he evidently saw only the anterior, strongly chitinized band of the pharynx. It is a somewhat cone-shaped structure having its widest diameter, which is approximately 0.15 millimeter, a little posterior to its transverse median line. In sections its ventral aspect is seen to lie almost level along the median longitudinal line of the head, and its dorsal surface passes obliquely toward the top of the head. Between its transverse median line and its part of greatest diameter is a more strongly chitinized region crossing the dorsal surface as a band and passing obliquely and posteriorly down the sides to the ventral surface, where the two bands run backward for a short distance, each lying somewhat laterad of the median line (Plate LX,3). Behind the muscle insertions is a second region of strong chitinization, followed by a sphincter muscle, behind which the diameter lessens until it passes as the slender esophagus under the brain.

\section{The esophagus}

The esophagus (Plate LX, 2 and 3) passes directly backward between the tritocerebral lobes of the brain, over the sub-esophageal ganglion, and into the thorax between the two main tracheal trunks. At the posterior end of the heid the esophagus, the dorsal vessel, the tracheae, and the connectives between the sub-esophageal and thoracic ganglia, are inclosed by a wall of thin cuticula, which is continuous with and shows the same staining reactions as the cuticula separating the posterior end of the piercer sheath from the thorax. It is a structureless membrane (Plate LX, 5). At its posterior end the esophagus passes over the anterior part of the stomach lying in the thorax, and enters its dorsal surface under the tergite of the sccond abdominal segment. Its length from the posterior end of the truc pharynx to its passage into the stomach is approximately 1.03 millimeters and its diameter 0.03 millimeter. In sections its wall is seen to consist of flattened epithelial cells lined by a thin chitinous intima, but no basement membrane can be distinguished. The usual muscle layers are present, but are so fine as to be distinguished only with considerable difficulty. At rest and empty, as it is seen in sections, the wall shows a number of small convolutions.

\section{The "mandibles" of Enderlein}

On either side of the pumping pharynx, where the posterior arms of the buccal plate fuse with its lateral walls, lie two triangular chitinous 
structures (Plate LX, 2 and 3) which Enderlein (1904:127) interpreted as "mandibles" and Sikora (1916:16) as "dreieckige Skelettstücke." Just anterior to the posterior dorsal margin of each is a groove, and at its lateral end articulates a rodlike structure which, according to Enderlein (1904:128), is the basal part of the mandibles and articulates anteriorly with the lateral wall of the head. Serial sections of the head show this basal part passing directly into the chitin of the wall, but show no articulation of the parts, a condition which has been described also by Sikora (1916:13-14). At their central angle these structures are attached to the sides of the pharynx by a structureless tissue, but it has not been found possible to determine the exact nature of the connection.

\section{Musculatire of the stomodaeum}

During the act of feeding, the stomodaeum is moved forward by protractor muscles, and by the forward movement of the buccal plate the haustellum is protruded and the buccal teeth are everted (Plate LX, 4). There are two pairs of protractor muscles, a dorsal pair originating in the anterior wall of the head and having their insertion in the posterior arms of the buccal plate, and a ventral pair originating in the posterior lateral angles of the "mandibles" of Enderlein and having their insertion in the ventral surface of the knoblike processes at the posterior end of the pumping pharynx (Plate LX, 2). By the contraction of these two pairs of muscles the whole pharynx is moved forward.

There are three pairs of retractor muscles, two dorsal and one ventral. The former originate side by side on the dorsal wall of the head, laterad of the pharynx and just posterior to the muscles passing from the median line of the dorsum to the antennae. Both pairs of dorsal retractor muscles are of approximately the same dimension, and pass forward to end, the outer pair as long, slender tendons inserted in the lateral walls of the pumping pharynx in the margin of its fusion with the posterior arms of the buccal plate, and the inner pair, which lie close to the lateral wall of the pharynx, as much shorter tendons inserted in the dorsal surfaces of the posterior knoblike projections on the lateral walls of the pumping pharynx. The tendons of these muscles were recognized as such by Meinert (1891-92:Pl. I, fig. 3), and represent the "fulturae" of Enderlein (1904:127). The ventral retractors originate in the lateroventral wall of the head in the region of the anterior level of the brain. 
They are somewhat smaller than the dorsal retractors, and are inserted as slender tendons in the ventral surface of the posterior knoblike projections of the lateral wall of the pumping pharynx.

In addition to protractor and retractor muscles, the pumping pharynx has six pairs of elevator muscles which originate in the dorsal wall of the head and are inserted in the flexible dorsal wall of the pumping pharynx. Four pairs of these muscles are slender. These originate somewhat laterad of the dorsal median line of the head, and pass rather obliquely centrad to their insertion in the median line of the pumping pharynx. The two remaining pairs of muscles, which are the second and fourth pairs in the succession from the anterior end, are much stouter. They originate in the dorso-lateral wall of the head and pass obliquely centrad to their insertion in the lateral edges of the two small chitinous plates imbedded in the roof of the pumping pharynx. Both their origin and insertion are distinctly laterad of those of the slender muscles. The frontal ganglion lies imbedded among these elevator muscles, and is protected laterally by the sixth pair, which, after their origin, pass rather obliquely backward for a short distance, until they meet the flexor muscles of the antennae, when they bend directly ventrad to their insertion in the posterior end of the pumping pharynx.

In the man-infesting louse, Harrison (1916b:213) describes two sphincter muscles, an anterior and a posterior, surrounding the pharynx; Sikora (1916:31) says there are many constrictors present; and Peacock (1918:105) describes an anterior, a medial, and a posterior sphincter. In this respect, as well as in the number and arrangement of the dilators, the pharynx of the hog louse is markedly different from that of the man-infesting louse. The whole structure is apparently covered with a layer of circular muscle, which varies considerably in thickness. Anteriorly, where the cuticula is only weakly chitinized, the muscle is well developed and surrounds the whole structure as a sphincter. Posteriorly, in the region of the first chitinized plate, the muscle is very thin except on the ventral surface, while in the region of the second chitinized plate it is thicker and on the median line sends off a number of strands which pass directly upward between the dilator muscles to the dorsal wall of the head. Before the pharynx passes into the esophagus the muscle layer assumes a moderate thickness throughout, and this part may be called the posterior sphincter. Only in its posterior 
half is the wall of the pharynx capable of any dilatation, and there are inserted four muscles of which the two median are the largest. They originate in the dorsal wall of the head above the anterior lobes of the brain, and pass obliquely forward and downward to their point of insertion. Their contraction, while it may dilate the pharynx, would seem rather to draw it back to its resting position.

Between the eye prominences and the neck three bands of muscle originate in the lateral wall of the head. The median band extends farthest back and the ventral the next farthest, while the dorsal is the shortest. Just behind the antennae these bands unite in a common tendon which is inserted in the anterior lateral angles of the "mandibles" of Enderlein. In his first description of the mandibles (1904:128-129) Enderlein did not see these tendons, but in his second paper (1905: 629-630) he describes and figures them as the tendons of the mandibular flexors. He also figures tendons passing forward from the posterior lateral angle of the mandibles to the anterior wall of the head, and calls them the tendons of the mandibular extensor. Sikora (1916:16), however, describes these last as a uniformly thin strand passing from the ventra] border of the triangular skeletal piece to the side of the underlip. In gross dissections the "mandibles " remain attached to the anterior wall of the head by this strand, but its true bistological nature has not been determined, since it has not been identified in any of the series of sections made through the head. Enderlein found the "mandibles" well developed only in the hog louse, but considered that the finding of the muscle tendons removed every doubt as to their morphological interpretation. Sikora $(1916: 13,17)$, on the other hand, rescrves the term "mandible" for the already-mentioned structure lying between the upper and lower lips and adapted for biting or rasping. She calls the " mandibles " of Enderlein "gewölbten Chitinplatten" or "dreieckige Skelettstücke," and denies the possibility of their being mandibles on the ground of their position back in the head and their separation by the pharynx. She suggests two functions for them, namely, to draw the pharynx forward and to transmit to the true mandibles the motor impulse of the muscles. Since the "mandibles " are attached to the lateral wall of the pumping pharynx and the buceal plate, the contraction of the tendon muscles would excrt a backward pull on their anterior angle, and they, working as al lever, would serve to push forward the buccal plate and the pharynx, a function performed 
by the two pairs of protractor muscles. Sikora's second suggestion is based on the fact that she $(1916: 18)$ regards the basal part of the "mandibles" of Enderlein as the posterior articular processes of the true mandibles, which Enderlein (1905:637) in turn has interpreted as the ventral prolongations of the lateral sclerite. According to Enderlein these are pushed far under the scalelike labium and are covered by it ventrally. Sikora attributes the double function of opening the mandibles and moving forward the pharynx to the ventral protractor muscles, and their closing to the contraction of the tendon muscle. No constructive criticism of this interpretation is offered for the present, because it is believed that the final morphology of the parts can be determined only by embryological investigation.

\section{The mouth parts}

From the ventral surface of the stomodaeum at the junction of the buccal plate and pumping pharynx a diverticulum is given off. It passes backward under the alimentary canal to the extreme posterior end of the head, which is separated from the thorax by a thin, structureless, cuticular membrane, staining pink in hematoxylin and cosin preparations. Within this diverticulum lic the piercers and the salivary duct. The piercers (Plate LX, 7 and 8) consist of dorsal and ventral elements, and their total length is approximately 1.2 millimeters. The ventral element is made up of two parts, a dorsal and a ventral, which are very closely apposed to each other throughout the greater part of their length.

\section{The sheath}

The wall of the sheath is continuous with that of the stomodaeum and consists of somewhat flattened epithelial cells lined by a fine chitinous intima (Plate LXI, 7). On its inner surface next the coelom the sheath is also covered by a fine chitinous cuticula, the origin of which is discussed later. Its dorsal and lateral walls are of uniform thickness and appearance, while on the ventral wall there is imbedded a chitinous plate. This plate occupies approximately the posterior two-thirds of the floor of the sheath and is separated from the anterior third by a transverse suture. A similar condition has been described by Harrison (1916b:209) in the body louse. In this region of the plate there is a central groove in the 
floor of the sheath. Posteriorly the diameter of the sheath decreases, until in the region of the rami of the piercers it surrounds them closely.

\section{The piercers and the salivary duct}

The piercers resemble long-handled two-pronged forks, having the prongs, which are 0.23 millimeter in length, situated posteriorly. They are long and slender, and lie free in the anterior part of the sheath, while their posterior forks are imbedded in tissue, completely filling the lumen so that sheath and piercers form a compact mass. This tissue extends forward among the piercers in two slender, pointed prolongations. A similar arrangement of tissue has been described by Sikora (1916:38) in the clothes louse. The dorsal element consists of two half tubes which in sections appcar like two brackets having their contiguous edges fused (Plate LXI, 2). Posteriorly these become flattened, and after forking attain a width of 0.25 millimeter at their widest part, whence they narrow again and finally end in two ligament-like bands which come together at the point of their insertion in the posterior wall of the sheath. Anteriorly the two halves do not lie side by side, but are curved upward and toward each other so as to form a tube. The ventral aspect is made up of two parts, a dorsal and a ventral, which are closely apposed to each other but can be pulled apart without injury to either after being dissected out from the surrounding tissue. The posterior rami of the dorsal part are wider than those of the dorsal element of the piercers, and are somewhat different in shape (Plate LX, 6). They do not become flattened, and in sections appear subcircular. A small lateral process is given off from each shortly before they unite to form the piercer, which is a moderatcly heavily chitinized groove with more delicate edges spreading out flangelike over the edges of the ventral part of the piercer (Plate LXI, 1). The latter is also a canal-like structure (Plate LXI, 2), and its posterior rami are imbedded in the floor of the sac. Both parts of the ventral element of the piercers are bilobed at their proximal end. The lobes of the ventral half are somewhat wider apart than those of the dorsal, and both are finely serrated.

The salivary duct lies between the dorsal and ventral elements of the picrcers, and at its posterior end is dilated in the form of a slender bulb which can be seen lying between the rami of the dorsal element, to the ventral surface of which the duct is attached through part of its length 
by a strand of tissue. Anteriorly it appears to lie free between the elements, while just behind the haustellum it lies within the canal of the dorsal part of the ventral element. This duct was seen and figured by Stevenson (1905:13), but its function was not recognized until Harrison (1916 b:209) carried out his investigation of the mouth parts.

When the piercers leave the sheath at the junction of the buccal plate with the pumping pharynx, they bend at an obtuse angle and pass forward in the groove of the buccal plate beneath the pumping pharyngeal tube to the mouth opening (Plate LXI, 1-4).

\section{Musculature of the mouth parts}

In the region of the rami the sheath is no longer a structure distinct from its contents, and both sheath and contents are controlled by one set of protractor muscles (Plate LX, 6). These originate as slender strands in the posterior end of the sheath, where the free ends of the rami are imbedded in its wall. They pass forward along the ventro-lateral borders of the sheath and are inserted in the lateral borders of the ventral plate (Plate LX, 6). The individual strands vary in length, so that, if they be detached from their origin and pulled away from the sheath, they resemble the extended dorsal fin of a fish. The longest strands extend to the anterior border of the plate. The contraction of these muscles bends back the ventral plate and telescopes the hinder part of the sheath into the front part, so that the piercers are pushed out of the head.

The retraction of the piercers and the sheath to their resting position is brought about by two sets of retractor muscles, a lateral and a posterior. The lateral retractors consist of two muscles originating in the wall of the head and inserted in the lateral wall of the sheath in the region of the anterior border of the ventral plate. The dorsal lateral retractor originates in the dorso-lateral posterior angle of the head and passes obliquely downward and forward between the bands of the tendon muscle and the brain to its insertion in the sheath. The ventral lateral retractor is considerably shorter than the dorsal, and originates in the lateroventral wall of the head alongside of the ventral retractor of the pharynx, whence it passes forward to its insertion in the sheath (Plate LX, 6). The posterior retractors are two large muscles lying on either side of the end of the sheath almost in the neck, two muscles lying under its ventral surface, and two lying on its dorsal surface. Each of the first has a 
double origin, one branch originating in the dorsal wall of the head and the other in the chitinous cuticula between the head and the thorax. After the fusion of the two branches each muscle passes ventrad and slightly forward to the level of the floor of the sheath, where they bend at a rather sharp angle and pass a little way backward to their insertion in the floor of the sheath under the anterior ends of the rami (Plate LX, 6). The ventral muscles are two stout strands originating in the ventral wall of the neck and passing forward under the sheath almost to the angle of its posterior retractors, when they bend sharply back on themselves. Each muscle almost immediately divides into two slender strands, which are inserted in the posterior ends of the rami of the elements of the ventral piercer. They are the retractors of the ventral element of the piercers. The dorsal muscles lie on the dorso-lateral wall of the sheath and are the retractors of the dorsal element of the piercers. They originate in the posterior chitinous cuticula between the head and the thorax, and lie doubled on themselves just as do the retractors of the ventral element of the piercers. They are inserted in the posterior ends of the rami of the dorsal element of the piercers. The lateral posterior retractors control the sheath and the piercers, while the dorsal and ventral posterior retractors control the movements of the separate elements of the piercers. The contraction of the lateral retractors of the sheath brings its anterior part to a resting position, and the simultaneous contraction of the posterior retractors begins the withdrawal of the mouth parts from the wound. They come to their final resting position through the relaxation of the protractor muscles and the consequent straightening, through its own elasticity, of the plate imbedded in the floor of the sheath.

The true relationship between the pharynx and the sheath and mouth parts can be fully understood only if the study of serial sections supplement that of gross dissections and mounts in toto. In a section through the head at the anterior level of the attachment of the basal part of the "mandibles" of Enderlein to the lateral wall of the head, the two halves of the dorsal piercer are seen lying tubelike close under the dorsal wall of the buccal plate and are here more strongly chitinized than elsewhere. Beneath it lies the ventral element of the piercers, with the salivary duct in its canal (Plate LXI, 1). The pumping pharyngeal tube does not reach this far forward when in its resting position. From the ventral wall of the buccal plate two outgrowths are continued ventrad as a chitinous 
cuticula on either side of the mouth parts, below which they pass closer to each other for a short distance before turning at right angles and passing to the lateral walls of the head. At the anterior level of the "mandibles" (Plate LXI, 2) the buccal plate is somewhat more tubelike, but it still continues ventrad as a delicate cuticula alongside the mouth parts. This prolongation appears now to be a continuation of the dorsal and ventral surfaces of the plate, while in succeeding sections it comes to be a continuation of the dorsal ends of the pumping pharyngeal tube, the anterior ends of which are now seen lying between the buccal plate and the dorsal element of the piercers. In this anterior region a band of tissue crosses the head transversely above the stomodaeum and appears to be attached at either side to the lateral wall of the head just dorsad of the basal part of the "mandibles" of Enderlein. It is very similar to epithelial tissue, and each cell has a definite nucleus lying near its base. The cells attain a considerable length, particularly on either side of the stomodaeum, and their dorsal surface is attached to a well-defined basement membrane. In sections stained with iron hematoxylin they closely resemble secreting cells. At the level of the articulation of the basal part of the "mandibles" of Enderlein with the triangular part, this band of tissue rests on the top of the buccal plate, and at its most posterior part it appears to form an attachment between the buccal plate and the lateral wall of the head. The buccal plate gradually becomes flat and there is a marked increase in the thickness and rigidity of the dorsal wall of the head. Also the shape of the buccal cavity changes, marking the beginning of the ventral wall of the diverticulum, but the mouth parts are still lying under the pumping pharyngeal tube. As the chitinous intima of the buccal cavity passes dorsad, it curves around into the lateral edges of the dorsal element of the piercers, and at this point shows stronger chitinization, afterward continuing as a fine cuticula to the ventral ends of the halves of the pumping pharyngeal tube. The dorsal ends of these half tubes are also continued as a fine cuticula, which passes downward to surround the ventral part of the buccal cavity. Between these two chitinous layers is a layer of epithelial tissue which broadens considerably on either side of the mouth parts and there appears to contain some muscular elements (Plate XLI, 3). Inmediately behind the section shown in Plate XLI, 3, the buccal plate divides into two arms united by a thin cuticula which forms the roof of the pumping pharynx and which, as it passes backward, 
is raised in a ridge along the dorsal median line (Plate LXI, 4). The cuticular strands coming from the now more widely separated dorsal ends of the halves of the pumping pharyngeal tube are at first strongly chitinized and pass laterad to the edges of the arms of the buccal plate, where they turn ventrad and surround the sheath as a basement membrane to its epithelium. The inner cuticula of the sheath is continued upward to the ventral ends of the pumping pharyngeal tube as shown in Plate LXI, 3, but the strong chitinization in the region of the dorsal piercers extends farther dorsad, and the points passing around their lateral edges are less curved downward. The gradual movement centrad and ultimate fusion of these points cuts off the piercers from the pumping pharyngeal tube. At the same time the strong chitinization continues dorsad until it fuses with the ventral ends of the pumping pharyngeal tube, which gradually move apart. In this way the pumping pharynx is formed, which, at its anterior end, has the ventral surface much narrower than the dorsal (Plate LXI, 5). The cuticula coming from the dorsal ends of the pumping pharyngeal tube is thick and strong, and fuses with the lateral edges of the arms of the buccal plate, which are here elevated knoblike and form a firm base for the insertion of the dorsal protractor muscles (Plate LXI, 4). From their lateral edges the thin cuticular layer still extends downward to surround the epithelium of the sheath. The floor of the pumping pharynx gradually broadens and assumes a rounded shape (Plate LXI, 6). In only two areas - those of the insertion of the two large pairs of dilator muscles - is there any strong chitinization of the dorsal wall of the pumping pharynx. Just behind the anterior area and after the floor has become rounded, the pumping pharynx and the diverticulum become entirely separated from each other, and a short distance behind this separation the chitinization of the ventral wall becomes stronger and that of the lateral walls less strong (Plate LXI, 7). The dorsal wall only is capable of dilation, and in the figures is seen in a resting condition. At the level of the antennae the ventral surface narrows somewhat and a stronger chitinization is evident throughout the structure as it passes into the pharynx. Also at the level of the antennae there appears the anterior part of the plate imbedded in the floor of the sheath, which becomes chitinized and bent to form a central furrow. The circular muscle of the pharynx is well developed and surrounds the anterior part as a sphincter (Plate LXI, 8), but in no case has a transverse section of the pharynx 
appeared like a cross as it is figured in the man-infesting louse by the different investigators. The tissue of the pharynx wall is in parts very much developed, but its precise histological nature has not been determined. Neither in appearance nor in staining reaction does it correspond to a simple epithelium. Where the wall of the pharynx is strongly chitinized, both the muscle and the epithelium are thin (Plate LXI, 9), but in the region between the second area of chitinization and the transition to the slender esophagus the wall is so thick that the lumen is reduced at rest almost to a slender transverse slit (Plate LXI, 1).

\section{The salivary glands}

Since the time of Landois (1864:9) it has been known that lice possess two pairs of salivary glands situated in the thorax. It was Pawlowsky (1906:199-200), however, who first described the glands opening into the piercer sheath, and his name has been given to these glands by subsequent workers. Still more recently a fourth gland, situated between the rami of the piercers, has been described.

Pawlowsky's glands are simple tubular glands lying on either side of the piercer sheath, into which they open through wide conduits at the level of the eyes (Plate LXII, 1). They have at this point a depth of 0.1 millimeter and a width of 0.05 millimeter, while their length is approximately 0.33 millimeter. They rest on the tendon of the dorsal lateral retractor muscle of the piercer sheath, and this causes an oblique indentation in their posterior ventral surface. They have a lining of epithelial cells which are not clearly defined from one another and which show the usual reactions to stains. Pawlowsky (1906:200) suggests thet their secretion may serve to irritate the wound or to lubricate the piercing organs, but Harrison (1916b:217) has seen no sign of glandular activity and suggests that they are functionless. No secretion has been found in the lumina of the glands in any of the sections studied, but in a rather oblique longitudinal section there is some appearance of activity of the cells. This, however, may be due to the fact that the section is rather close to the lateral wall of the gland (Plate LXII, 2).

Between the rami of the piercers lies an unpared gland (Plate LX, 5 and 6), which was first seen by Sikora (1916:54) in Pediculus vestimenti and was called by her the "Stacheldrüse." It is somewhat wedgeshaped, being broadest at the anterior end, is clothed with cylindrical 
epithelium, and appears to be continuous with the posterior end of the chitinous bulb which marks the termination of the salivary duct.

The two pairs of thoracic salivary glands lie closely apposed to either side of the anterior end of the stomach, and the long, horseshoe-shaped gland is folded around the oblong-ovate gland in a characteristic manner (Plate LXII, 3). In the man-infesting pediculi the glands are described as "kidney-shaped" and "horseshoe-shaped," and their position in the thorax has been variously figured by a number of authors but the smaller one has never been shown surrounded by the larger. Ströbelt (1882, English trans. 1883:89) described the glands of Linognathus vituli (Haematopinus tenuirostris) as "elongated" and "globular," and thought that the efferent duct of the former was situated at one end of the gland and that the horseshoe appearance was due entirely to the position of the gland at rest. The length of the horseshoe-shaped gland (Plate LXII, 4) is approximately 0.66 millimeter and the width of the arms 0.33 millimeter. The length of the oblong-ovate gland (Plate IXII, 5) is 0.12 millimeter and its width 0.05 millimeter. The large cells of the epithelial lining shine through the outer membrane of the gland, and at the exit of the duct the transition from these to the small cells lining the duct can be seen even in gross specimens (Plate LXII, 6). In sections the epithelial cells are seen to be considerably larger than those of Pawlowsky's glands, and the nucleus, with its dark-staining nucleolus, lies rather toward the base of the cell. There is a distinct though small lumen within each gland. The efferent ducts of the two glands pass cephalad without uniting. In gross dissection they have been followed as far as their entrance to the head, but their union with the salivary duct lying between the dorsal and ventral elements of the piercers has not been seen. In his description of dissections prepared by Mr. Bacot, Entomologist to the Lister Institute, and the late Major Sidney Rowland, of the Royal Army Medical Corps, Martin (1913:85) says the four salivary ducts open into the base of the piercer sheath; while Harrison (1916b:209) has not succeeded in tracing definite connections between the salivary duct of the mouth parts and the ducts of the glands. Sikora (1916:56) describes the ducts as passing into the head alongside the esophagus as far as the posterior end of the sub-esophageal ganglion, where they turn back, and through a ventro-caudal bend reach the end of the piercer sheath. In Pediculus vestimenti she figures the two ducts of each side as uniting 
in a common duct for a short distance before entering the middle of the dorsal surface of the piercer sheath by a common opening, while in Haematopinus eurysternus she describes them as running separately to the opening into the salivary duct of the mouth parts. Peacock (1918: 115) refers briefly to Martin, and to a dissection made by Mr. Lloyd, Chief Entomologist to N. Rhodesia, as demonstrating that the four salivary ducts open into the bulbous structure at the posterior end of the chitinous salivary tube.

Of these interpretations that of Sikora is probably the most accurate, because it alone describes an arrangement of the ducts which allows of their being drawn forward by the mouth parts during feeding without danger of their rupture.

Patton and Cragg (1913:559) describe a small collection of round cells surrounding the esophagus and constant in position, which differ from the cells of the fat body in their more glistening appearance. They distinguished no duct with certainty, though in some dissections a fine filament, which may have been a duct, was seen passing upward with the salivary duct. Müller (1915) discusses these cells in connection with the fat body, but remarks that up to that time no fat has been demonstrated in them. Harrison (1916 b:220) says that in the Siphunculata (Anoplura), groups of specialized binucleate cells, richly tracheated, lie about the ducts of the salivary glands, at the base of the esophagus. Sikora (1916: 57-58) gives a detailed account of the structure and appearance of these cclls, which she calls "grosszellige Drüsen," in Pediculus vestimenti, and mentions their presence in the other species investigated. She considers them as quite distinct from the fat cells and suggests that they withdraw some constituent from the body fluid and store it or act on it in some way before returning it to the body fluid.

In the hog louse there is a cluster of small, subcircular cells, arranged like a pair of wings, lying above the base of the esophagus. Between these cells and the esophagus pass cephalad the dorsal vessel and the ducts of the salivary glands. On dissection each half of the cluster is found to consist, on the average, of forty small cells united by a network of very fine tracheoles. The two median posterior cells, which are somewhat larger than the others and pear-shaped, lie side by side on the end of the esophagus with their pointed ends caudad, and from each of them a slender tracheole passes to the surrounding network of the fat cells 
scattered on the dorsal anterior region of the stomach wall. We have found only two nuclei in any one of these cells, while four or five may be present in each fat cell. Recently Nuttall and Keilin (1921:184) have published the results of their investigation of these cells. By the intracoelomic injection of ammonia-carmine, they have demonstrated that the cells in question have, in Pediculus, an excretory-accumulatory function, and so they have named them peri-esophageal nephrocytes.

\section{THE ALIMENTARY CANAL AND ITS APPENDAGES}

The stomach of the hog louse (Plate LXII, 7) is a simple tubular structure measuring approximately 1.98 millimeters in length. It consists of a wider anterior part 1.38 millimeters long with a diameter of 0.62 millimeter, and a more slender posterior part 0.6 millimeter long with a diameter of 0.2 millimeter, and extends from the region of the mesothorax to that of the sixth and seventh abdominal segments, where it bends cephalad on itself for a short distance, receiving the malpighian tubes and passing into the intestine when it again turns caudad.

The stomach of the adult hog louse differs from that of the man-infesting pediculi in two respects: its anterior end is not divided into two blind pockets, and it does not possess a "Magenscheibe." Ströbelt (1882, English trans. 1883:90) found no "Magenscheibe" in Linognathus vituli (Haematopinus tenuirostris), while Sikora (1916:62) found one in Polyplax (Haematopinus) spinulosus End. but not in Haemodipsus (Haematopinus) ventricosus End. Sikora describes as present in young specimens of Haematopinus suis a refractive whitish body on the dorsal surface of the abdomen, which in sections shows a structure similar to that of the "Magenscheibe" of man-infesting lice. In the present investigation no such structure has been seen, but the majority of the specimens sectioned have been mature lice, and the structure, as Sikora's work suggests, may be present only in the immature stages.

That part of the digestive tract lying in the thorax anterior to the entrance of the esophagus differs markedly in its structure from the true digestive mesenteron. That it is to be considered as a terminal enlargement of the esophagus, comparable to the crop of certain insects, is suggested by a number of facts. In gross specimens the musculature of the wall does not resemble that of the true mesenteron, because the circular fibers still lie outermost. At its distal end, just behind the entrance 
of the esophagus the circular muscles become emphasized as a narrow band and the longitudinal fibers pass out from under them, forming, on the surface of the true stomach, with the underlying circular muscles an open-meshed network. A study of sections has revealed no trace of an esophageal valve, either where the slender esophagus passes into the enlarged part or where the abrupt transition to a digestive epithelium takes place, and the structure of the wall is identical in both slender and enlarged parts. A similar abrupt transition from the esophagus to the mid-intestine without the intervention of a valve or a sphincter has been described in the bedbug, by Cragg (1915:709). It consists of a delicate museular coat and a layer of much-flattened epithelial cells lined by a fine chitinous intima. In the region of the above-mentioned circular muscle band there is an abrupt transition to the digestive part of the stomach, which is lined with a layer of secretory epithelial cells. In lice dissected some hours after feeding, the thoracic enlargement is frequently found empty; while in the anterior part of the true mesenteron there is a considerable volume of blood, and if a smear be made from the contents of such a stomach a large number of intact corpuscles are found. Also, where digestion is taking place the active epithelial cells shine through the stomach wall as light spots among the blood, a condition never seen in the wall of the anterior dilatation.

At the junction of the stomach and the intestine, four malpighian tubes are given off. They measure approximately 6.3 millimeters in length and 0.25 millimeter in diameter, and are about two and a quarter times as long as the combined length of the stomach and intestine. They first pass backward along the sides of the intestine, and then forward to the anterior end of the abdomen, where they turn again caudad terminating finally in the region of the last two abdominal segments. In structure they show no unusual features, and in no sections have secondary invaginations of their lumina been seen, such as are figured by sikora (1916:67, Pl. III, figs. 14, 15) in Pediculus vestimenti.

Posterior to the malpighian tubes lies the small intestine. It has an approximate length of 0.43 millimeter and diameter of 0.2 millimeter. When empty its epithelium, which is much more slender than that of the mesenteron and is covered with a delicate intima, lies in six longitudinal folds. Three muscle layers are present, but are not readily distinguished 
since the longitudinal fibers are gathered in six strands. There is no valve between the stomach and the small intestine.

Between the small and large intestines is a region, measuring 0.25 millimeter in diameter, which is characterized by the presence of six whitish, oblong-ovate plates imbedded in its wall (Plate LXII, 7). These plates, which in sections (Plate LXII, 8) are seen to extend a considerable distance into the lumen of the intestine, are surrounded by a large number of tracheae. They have no definite cell structure, their content is granular with nuclei scattered throughout, and in some sections irregular clefts are present which are evidently not due to mechanical rupture and may be definite lumina. No ducts opening into the intestine have been seen. With hematoxylin and eosin the groundwork stains an uneven pink, and with iron hematoxylin a light grayish brown. Whether these plates are modified glands is uncertain. Their inner surface is lined with a well-defined intima, and at either end a definite epithelium is represented by a few cells in the clefts between the plates, but in the middle of the region (Plate LXII, 8) no such cells are to be found. The inner layer of circular muscle is present, and the longitudinal muscle consists of six bands each made up of six or seven fibers lying in the indentations between the plates, but no outer circular layer has been seen. Sikora (1916:67-68) calls these plates the "Enddarmdrüse," and objects to the use of the name "rectal glands" on the ground that in the louse these plates have no connection with the rectum. Her figures of their structure in Pediculus vestimenti represent them as much more glandlike than they appear to be in Haematopinus suis. Toward the posterior end the cuticula increases considerably in thickness and the plates are succeeded by a well-defined epithelium. The longitudinal muscle fibers are lost sight of among the large circular fibers surrounding the rectum (Plate XLII, 9). This is a short, straight tube leading direct to the anal opening and measuring only 0.18 millimeter in length and 0.08 millimeter in diameter. Its wall lies in six folds, and it is lined by a thick cuticula which is not very strongly chitinized and stains a clear blue with Mallory's connective-tissue stain after fixation in picro-aceto-formol.

\section{FEEDING AND DIGESTION}

In experimental feeding, when a louse is placed on the arm it crawls around and appears to test the surface with the antennae and the sensitive 
areas in front of the head. When the spot for feeding has been selected, the contraction of the dorsal and ventral protractor muscles, assisted perhaps by the contraction of the tendon muscles in the side of the head, moves forward the buccal plate and the pharynx, bringing the former with the inclosed pumping pharyngeal tube in contact with the skin. At the same time the haustellum is automatically pushed out, so everting the buccal teeth, which anchor the head to the skin of the host; and the sheath and piercers must also be carried forward, since the cuticula of the sheath is continuous with that of the buccal cavity. Immediately following the contraction of the protractors of the pharynx, the protractors of the sheath and the piercers contract and telescope the hinder part of the sheath into the front part, carrying with it the piercers and the salivary duct, which are inserted into the skin of the host. Salivary secretion passes into the wound, and probably contains an anti-coagulin similar to that demonstrated by Nuttall (1917c: 74) in the saliva of the man-infesting louse. The closing of the anterior sphincter of the pharynx causes a negative pressure in the pumping pharynx, the dorsal surface of which is meantime raised by the contraction of the dilator muscles, and the blood flows through the canal of the dorsal piercers to the pumping pharyngeal tube and so to the pumping pharynx. When the latter is filled with blood, the simultaneous relaxing of the interior sphincter of the pharynx and of the dilator muscles of the pumping pharynx drives the blood into the pharynx, whence it passes to the esophagus on the relaxation of the posterior sphincter. From the esophagus the blood is carried by peristalsis to the rest of the alimentary tract. The process can best be seen in newly molted specimens, and is so rapid that the muscles either act simultaneously or in very rapid succession. At the close of feeding, the whole structure is brought to its resting position by the contraction of the retractor muscles and the relaxing of the protractors, while the elasticity of the plate imbedded in the floor of its posterior region gives the final impetus to the piercers and the sheath.

The wall of the mid-intestine consists of the usual four layers, a delicate epithelium resting on a basement membrane and surrounded by inner circular and outer longitudinal muscles which are arranged in a very loose network comparable to that described by Cragg (1915:712) in the bedbug. The epithelium of the stomach is similar throughout, no definite areas being adapted respectively for secretion and absorption, 
and in accordance with the mode of life of the insect it appears to be always in a state of activity. In the study of the epithelium many series of sections of the alimentary canal have been made, at intervals of from half an hour and one hour after the time of feeding up to twelve hours, by which time the stomach in captive specimens appeared to be empty of blood. Sections have also been made of lice starved to the point of death.

The epithelial cells vary in outline according to their state of activity. In the resting stage (Plate LXIII, 1) they are flattened and extend farthest into the lumen in the region of their nuclei. During absorption the individual cells expand until they appear cuboidal, and during secretion the free ends of the cells, where the ball of secretion accumulates, become subcircular. These secreting cells show great variation in the degree to which they extend into the lumen. They may remain attached to the basement membrane by a broad base, or they may be greatly attenuated and apparently attached to the membrane by a very narrow base, and in sections blood is seen extending between the individual cells (Plate LXIII, 1). In no case has a definite cell wall been found between any two cells, and the whole appearance suggests a syncytium; but further proof would be necessary before the acceptance of this view. Each cell has a large oval nucleus with a subcentral nucleolus surrounded by irregularly scattered chromatin granules. There is considerable variation in the position of the nucleus in the cell, and this, in addition to the irregularity of the cells, gives the effect of a several-layered epithelium (Plate XLIII, 1 and 2). In most cases the nucleus is seen lying in the cytoplasm immediately behind or to one side of the secretion products, and on their excretion remains intact, but in a few cases the nucleus has been seen to be carried along with the secretion (Plate LXIII, 2). In the latter case the death of the cell must follow, and the question of its replacement arises. In many insects a regular destruction of the epithelium takes place and new cells are formed from regenerative centers, or nidi; but no such structures are present in the hog louse, nor has Sikora (1916:65) found them in Pediculus vestimenti. Nuclear division has not been seen taking place in the epithelium, but just within the basement membrane at the base of and between some of the epithelial cells lie single, very small nuclei, each hardly more than a nucleolus, definitely surrounded by a small amount of protoplasm; and these may be the source of the new epithelial cells. A similar condition was described by Van Gehuchten 
(1890:246) in the larva of Ptychoptera contaminata. The epithelial cells are bounded on their free edges by a border, which appears in most cases to be definitely striated.

Taken from its host and confined without food, the hog louse is a shortlived insect, and starved specimens invariably died in from twenty-eight to thirty hours after their last feeding. In lice killed, respectively, seventeen and twenty-four hours after feeding, and sectioned, the stomach was found empty of food, its walls contracted, and the majority of the cells swollen with secretion while in some cases the border of the cell was ruptured and the ball of secretion had escaped into the lumen. This would suggest that hunger stimulates the activity of the secreting cells, and also the liberation of their products into the lumen.

From a louse fed two hours previously, the stomach was dissected out in physiological salt solution and a part of the wall teased. Microscopic examination revealed the presence within the cells of two types of granules, of which the more numerous were fine, irregular-elongated, and dark, and the less numerous were coarse, round, and refractive. A 2-per-cent solution of osmic acid was then introduced under the cover glass, and the coarse granules turned black, showing them to be either lipoid or proteid, while the fine ones probably represented secreting granules. A series of twelve lice were killed with chloroform at intervals of one hour and the stomachs immediately dissected out in a mixture of equal parts of 2-percent osmic acid and salt solution and fixed in Flemming's weak solution for twenty-four hours. After sectioning, some were mounted unstained and others were stained with safranin. Absorption evidently began almost immediately, for at the end of one hour a few deep black granules were found just beneath the border of the cells of the anterior region of the stomach. As the series was ascended, the black granules increased greatly in number and in size. The largest lay just under the border of the cell, and their size was in inverse ratio to the degree of penetration within the cell. In the first six of the series a definite increasing absorption could be traced in the bulk of the cells lining the wide section of the stomach, and this absorption was going on even in cells forming secretion. In the latter the black gramules lay in a circle outsicle the zone of secretion, and were never seen to come in contrat with it even in the few cases in which the border had given way and the secretion was in process of heing excreted. In the louse killed at seven hour's, absorption was proceeding, 
not in the anterior, but toward the posterior, half of the stomach, in the region of the bend cephalad; and in the last numbers of the series it was found throughout the whole slender part of the stomach.

In the cells containing the greatest number of granules, some were seen resting on the basement membrane and a few appeared to be lying among the muscle fibers outside the membrane, but sufficient evidence to prove that they had passed through the membrane unchanged is wanting. Whatever may have been the fate of these granules, they disappeared from the cells, leaving in their places numerous vacuoles among which the first traces of secretion were seen. The secretion accumulated in the form of a compact mass, resembling a ball of thread, whose surface layer takes a deep stain while the axis remains almost clear. This ball pressed against the free ental border of the cell, pushing it into the lumen and finally rupturing it.

The above experiments show that absorption and secretion are carried on by the same cells. In every section some cells, evidently in a resting stage, are seen, but it is not clear whether the cells pass through this stage after each secretion or at longer intervals. The formation of the secretion appears to begin at the close of absorption, and, as the study of the starved lice suggested, its excretion is stimulated by hunger, so that it is already present in the stomach when the blood is ingested. No attempt has been made to investigate the exact nature of the granules or the changes they may undergo, as this would necessitate a long series of experiments with various reagents, such as were carried out first by Fischer (1899) and later by Murlin (1902).

If lice be fed as in the previous experiment, and blood smears be made from the stomach contents at intervals of one hour and stained with Wright's stain, the gradual action of the epithelial secretion on the blood can be followed. Within one hour after feeding, the red cells become vacuolated and fat globules appear, but the leucocytes and the platelets are evidently not affected. The changes in the red cells continue until only an amorphous mass remains, which, in sections stained with hematoxylin and eosin, can be recognized as a mass of brownish granules. No blood platelets have been seen in any but one-hour smears. At two hours the nuclei of the leucocytes are intact but their cytoplasm has been attacked; there is a gradual change in its staining reaction, and after three hours it takes the basic stain, appears light blue, and can be distinguished 
from the background only with considerable difficulty. At six hours the nuclei of the leucocytes show the first signs of disintegration, while at eight hours the whole has an amorphous appearance and the hemoglobin is disappearing.

In accordance with their parasitic habit, hog lice probably draw blood from their host at frequent intervals and in small quantities; so that in any one specimen taken at random and fixed and sectioned, all stages of digestive activity will probably be found in the length of the midintestine. Those fed to repletion in captivity showed absorption taking place, as it were, in a gradual succession throughout the canal; and even in these cases, not only have one or more cells in a state of active secretion been found scattered among the absorbing cells, but absorption and secretion have been seen taking place at one time in the same cell.

\section{THE FAT BODY}

In both larva and adult the hog louse is richly supplied with fat cells arranged in a more or less definite plan. In the head they lie along the lateral regions among the muscles and are most numerous toward the ventral surface. There are also two small clusters dorsad of the sub-esophageal ganglion just behind the brain. On the dorsal surface of the thorax a cluster of fat cells lies above the occipital apodeme, while on the ventral surface, between the ganglia and the hypodermis, lie four compact, grapelike clusters which extend laterad to the coxae. In the abdomen, with the exception of three clusters on the dorsal surface in the region of segments 5 and 6 , the fat cells are not arranged in compact groups but are more widely spread in dorsal and ventral peripheral layers. They are more numerous among the lateral abdominal muscles than among the viscera, particularly in the female. In the male these lateral cells are crowded between the blocks of muscle and the body wall in the neighborhood of the spiracles.

In gross dissection the fat cells can be removed in clusters held together by a rich network of tracheae. They are large, subcircular cells whose wall is a transparent membrane through which the granular content is clearly seen. In sections (Plate LXII, 10) the cells are seen to contain a variable number of nuclei, each with an oblong-ovate nucleolus surrounded by a clear zone in which are scattered chromatin granules of varying 
sizes, the largest being peripheral in position. Both in cells stained with hematoxylin and eosin and in those stained with iron hematoxylin, the groundwork appears to be alveolar with many dark-staining granules adhering to the walls of the alveoli. When they are stained with iron hematoxylin and the differentiation with the iron-alum solution is not carried far, it is impossible to distinguish the fat from the other granules; but if the destaining is carried further than is customary, the fat retains its black color, while the other granules become a grayish brown.

In living specimens the distribution of the fat body is clearly seen shining through the integument, and in mature specimens there may be seen in the abdomen many green cells scattered among the white fat cells. In his description of the fat body of Phthirius, Landois (1864:11) mentioned emerald green cells which stood out with greatest clearness in the lateral region of the abdomen of adult males, but he did not refer to such cells in his later work on the two species of Pediculus. Graber (1872:152) also described, in Phthirius, cells with a greenish, transparent, viscous content and usually with two distinct nuclei. In Linognathus vituli (Haematopinus tenuirostris) Ströbelt (1882, English trans. 1883:90) found that "a fine and delicate membrane envelops the yellowish green, finely granular contents, which readily allow two nuclei to be recognized," while in the abdomen he saw small, globular cells with darker-colored contents. Nuttall (1918:378) has also mentioned these green cells as appearing in Phthirius when the insect attains sexual maturity. He criticizes the statement of Oppenheim (1901) that the pigment is formed by a ferment in the salivary glands and is deposited in the insect's fatbody, and states that the significance of the pigment is yet to be determined. In sections through mature lice these ceils are found lying among the fat cells in the lateral regions of the abdomen. They are much smaller than the fat cells, and have, as a rule, only one nucleus with a well-defined nuclcolus, although two nuclei have sometimes been seen. Their cytoplasm is filled with granules which stain a neutral tint as compared with the positive tint taken by the granules in the fat cells. The structure and position of these green cells suggest their interpretation as nenocytes, or further investigation may prove them to be disseminated nephrocytes such as Nuttall and Keilin (1921:184) have just described in Pediculus. 
THE REPRODUCTIVE ORGANS

Male

Mjöberg (1910:226-229) was the first to give an account of the male reproductive organs of Haematopinus suis Leach. He interpreted the male copulatory apparatus and introduced the following nomenclature for the different parts: (1) the basal plate, lying within the body, articulating distally with more or less free structures, the ejaculatory duct always passing dorsal to it; (2) the parameres (a term used first by Verhoeff in relation to Coleoptera, and quoted by Mjöberg), strongly chitinized parts articulating on the distal part of the basal plate; (3) the preputial sac, surrounding the penis and the distal part of the ejaculatory duct and appearing to be attached to the distal part of the basal plate between it and the parameres. Mjöberg suggested that the sac, like the penis, may have originated from an invagination of the ninth and tenth intersternital cuticula. He mentioned the mesodermal organs very briefly, giving most of his description to the ectodermal parts, which he figured with the penis both at rest and ejected.

With the exception of Ströbelt, the earlier workers dealt exclusively with the lice infesting man. Swammerdam did not describe the male reproductive organs; the forty specimens he studied were females. Leeuwenhoek (1695:387, and 1697:187 [English trans. 1807:163]) first discovered the male, but regarded the penis as a sting. Gaulke (1863) thought the penis was an ovipositor for inserting the eggs under the skin. Landois (1864:17-21 and 1865a:52-54) described and figured the male reproductive organs of Phthirius inguinalis and Pediculus vestimenti. Graber (1872:158-159) referred to the work of Landois, and dealt briefly with the structure of the seminal vesicles and the copulatory apparatus, suggesting that the latter was a much more complicated organ than Landois had thought. Ströbelt (1882, English trans. 1883:99) described the male generative organs of Linognathus vituli (Haematopinus tenuirostris) very briefly and incompletely.

More recent work on the genitalia of the lice affecting man has been done by Pawlowsky (1908), Patton and Cragg (1913), Müller (1915), and Nuttall (1917 a). The work of the last-named is the most complete account yet published of the copulatory apparatus of the Pediculidae. It does not include the internal reproductive organs. According to 
Nuttall (page 304 of reference cited), "the essential parts of the apparatus are: (1) the basal plate, (2) the dilator (parameres), (3) the vesica penis [preputial sac], including its rib or strut, statumen penis, embedded in its wall, (4) the penis, and (5) the ductus ejaculatorius." In the preceding year Cummings (1916:257) had given the following explanation of the terminology used in describing the male copulatory apparatus of Siphunculata (Anoplura) and Mallophaga:

In almost all Anoplura and Mallophaga, it is easy to recognise at once the basal plate and the parameres. The basal plate - probably double in origin as two longitudinal apodemes - is a chitinous lamina usually, if not always, longer than broad, to the posterior lateral angles of which are articulated the two chitinous appendages known as parameres. Between the parameres is the mesosome, the parts of which are not so readily made out unless a specimen be carefully dissected. Fundamentally, the mesosome is a sac - the enlarged and extrusible end continuous with the ductus ejaculatorius. This sac - called by Mjöberg: "the preputial sac" - presents two regions of chitinisation - a distal and a proximal. At the distal end is the rod of the penis or virga, with frequently a splint on each side called the telomere, and one below - the hypomere. ${ }^{*}$ At the proximal end are the endomeres, usually strongly chitinised bands or rods, one on each side, supporting the membrane of the sac, of which they are only Iocal thickenings. The whole of the genitalia exhibit enormous variety in form, and the mesosomatic parts in particular are occasionally so much modified that it becomes difficult to recognise their conformation to the general plan just sketched out above. For example, in many Philopterids, such as Docophorus, no sacular portion of the apparatus is recognisable, and the distal chitinisations lie well back within the proximal, the whole forming a solid and compact mesosome. The above terms are, therefore, adopted solely for convenience of description.

* For these terms, first applied to specialised Philopterid forms, see Waterston, Annals of the S. African Museum, vol. $\mathrm{x}$, pt. 9,1914, p. 279 .

In the hog louse the mesodermal reproductive organs of the male (Plate LXIV, 1) consist of two pairs of testes, slender vasa deferentia, seminal vesicles, and a long ejaculatory duct, and the ectodermal organs (Plate LXIV, 1 and 2) of a penis, a vesica penis, a basal plate, and parameres.

The testes are oblong-ovate with somewhat bluntly rounded ends, and the individuals of each pair touch at one end, where each opens into its vas deferens, which almost immediately unite to form a single canal. The testes lie on the dorsal wall of the mid-intestine between the metathorax and the posterior border of the fifth abdominal segment. Their free ends point respectively cephalad and caudad, and the left pair frequently lie a little anterior of the right. The vasa deferentia are long, very slender tubes lying coiled upon themselves and then passing backward to the region of the eighth abdominal segment, where they pass into the seminal vesicles just below the rectum. The latter are closely apposed to the wall of the mid-intestine and pass directly cephalad to 
the anterior border of the fourth segment, where they turn ventrad and slightly caudad, appearing as a blunt angle on the ventral wall; again passing laterad and caudad, they turn cephalad at the posterior border of the seventh abdominal segment and cross the ventral wall parallel to the posterior arm of the above-mentioned angle, turning caudad about the anterior border of the third segment. In the region of the fourth segment they unite to form the single ejaculatory duct, which crosses the mid-intestine parallel to the last loop of the vesicles and is easily recognized by its marked musculature. Near the anterior end of the basal plate the duct loses its thick muscular wall and becomes a thinwalled muscular tube which is twice folded upon itself and then passes along the median line dorsad of the basal plate through the wall of the vesica penis into the chitinous penis.

A study of the copulatory apparatus of Haematopinus reveals a general resemblance to that of Pediculus and a much more detailed resemblance to that of the more closely related Linognathus limnotragi Cummings. The basal plate (Plate LVIII, 9, and Plate LXIV, 1, 2, and 3) lies within the ventral body wall and is much longer than broad, extending cephalad to the anterior border of the sixth abdominal segment. Its proximal end is rounded; it appears to consist of two halves joined along a median suture, which indicates its probable double origin, according to Cummings, as two long apodemes. Its anterior edge is weakly chitinized. Then follows a region of strong chitinization for muscle attachment, where there are two small apodemes along the median line, one dorsal and one ventral. The median chitinization soon disappears, but the lateral continues as stout borders ending in knoblike enlargements with which the parameres articulate. In cross section the plate is seen to consist of two lamellae, a dorsal and a ventral, and anteriorly these are fused along their lateral borders. In the region just anterior to the articulation of the parameres the lamellae become slightly broader and the two surfaces separate from one another. The inner, or dorsal, lamella grows up and closely surrounds the dorsal wall of the vesica penis, and on its lateral regions the parameres develop as chitinous thickenings. The outer, or ventral, lamella grows up surrounding the whole copulatory apparatus, and at its dorsal lateral borders forms deep fold on each side for muscle insertion (Plate LXIV, 1 and 5). Such an outgrowth of the basal plate was not seen by Mjöberg, 
a:d according to Nuttall is not present in Pediculus. Cummings ( 1210 : 260) has described a somewhat similar condition in Linognathus limnotragi Cummings in which the parameres

are of a remarkable type. Proximally they are broad blade-like pieces which meet each other (but do not fuse) beneath the mesosome in a fairly long median groove, then dorsally wrap themselves around the mesosome lying between them, forming a kind of sheath, from the end of which the penis projects, and, like the somewhat narrower distal ends of the parameres, curls up dorsalwards.

The parameres are two strongly chitinized regions on the lateral walls of the dorsal lamella of the basal plate, and articulate anteriorly with its lateral processes in the region of the seventh abdominal segment (Plate LXIV, $1,2,3$, and 5). They are boat-shaped structures, with the keel external and lateral, and can be seen through both dorsal and ventral aspects. Distally they almost meet on the median line and proximally they divorge. The distal points appear to be less strongly chitinized than the remainder of the structure. In feeding experiments males approaching females were frequently seen to protrude and withdraw the parameres.

The vesica penis (preputial sac of Mjöberg, mesosome of Cummings), when lying within the body, rests within the upper lamella of the basal plate, its walls are thrown into folds (Plate LXIV, 1 and 3), and its anterior part is invaginated within the more posterior part. When ejected (Plate LXIV, 3 and 4) it passes backward and slightly downward for about half its length, when it bends slightly upward again. It is from one-half to three-fourths of a millimeter long and at its widest posterior part is approximately half as wide as its length. At its distal end on either side, directly on the median lateral line, are two small lobes covered with teeth, as is the whole sac with the exception of an area on the ventral surface near the proximal end. The thin, smooth wall of the sac surrounds the penis like a sheath for one-half of its length from the point of branching to the tip. It points directly dorsad. At its distal end the sac appears to be continuous with the basal plate. Above the copulatory apparatus and between it and the anal opening is the pregenital fold. No postgenital fold is present, unless the dorsal and ventral lamellae of the basal plate be considered as forming such.

The penis is a strongly chitinized tube made up of two half-tubes closely apposed to each other (Plate LXIV, 1 and 4). It lies within the vesica penis, its posterior pointed end turned toward the canal between the parameres, and its anterior part, into which the ejaculatory duct passes, in 
line with their basal articulations. Here the chitinous structure is no longer a canal, but two divergent arms which may correspond to the statumen penis of Nuttall.

When killing lice with chloroform it was noticed that the males frequently ejected the copulatory apparatus in part or completely, and this characteristic has been utilized in the study of the musculature and movements of the apparatus. The protractor muscles of the basal plate have their origin in the ventral wall of the ninth abdominal segment where it turns dorsad, and their insertion in the anterior ventral surface of the basal plate. They form a thin plate of muscle fibers lying parallel to one another and identical in outline with the plate. When they contract, the basal plate is drawn caudad until the proximal edge lies just anterior to the boundary between segments 6 and 7 , and the parameres are protruded from the sexual orifice for from one-third to one-half their length. Their dorsal aspect shows no collar-like membrane forming a sheath for the transit of the vesica penis as figured by Nuttall in Pediculus. Its place is taken by the already described upgrowth of the basal plate. They point dorsad and slightly cephalad, so that their ventral aspect is now caudad $($ Plate LXIV, 4). They are controlled by muscles which lie at rest alongside them and which, by their contraction along with or immediately following that of the muscles of the basal plate, hold them rigid during copulation. There are ten muscle strands on either side, of which the five posterior lie in a regular succession and the five anterior in a close group. They originate in the ventral body wall in the region of segments 6,7 , and 8 . The posterior strands are inserted in the deep lateral fold of the upgrown ventral lamella of the basal plate (Plate LXIV, 5), and the anterior strands are inserted as a stout tendon in the anterior dorsal border of this upgrowth. Mjöberg (1910:189) has explained the purpose of the genital plate, at any rate in some cases, as the basis of attachment of these muscles, and his figure of Haematopinus bufali de Geer shows them inserted in the border of the genital plate. Cross sections through this region in the hog louse show these muscles originating laterad of the genital plate. The dorso-ventral lateral muscles of the abdomen next contract and drive the coelomic fluid caudad and into the vesica penis, which is thereby everted carrying the cjaculatory duct and the penis along with it. The thick muscular part of the duct has been drawn caudad until its posterior end lins at the level of the articulation of the 
basal plate and parameres, and the slender part has passed along the center of the vesica, where it is surrounded by a sheath composed of slender muscle fibers. This sheath originates as two lateral bundles on the proximal border of the basal plate and is inserted as fine strands on the wall of the vesica at its junction with the penis.

At the close of copulation the protractor muscles and the body muscles relax, and the coelomic fluid passes back into the body. The vesica penis is drawn to its resting position by the contraction of the muscle sheath of the slender part of the ejaculatory duct, as well as by the contraction of many fine muscle fibers which are inserted on the surface of its anterior half and have their origin in the dorsal anterior border of the basal plate. When at rest these muscle fibers form a thick layer on the anterior region of the basal plate and a thin layer between the vesica penis and the basal plate. Some muscle fibers originate in the ventral body wall between segments 6 and 7 and are inserted in the anterior border of the basal plate, and these by their contraction bring the framework of the apparatus to its resting position.

The histological structure of the mesodermal organs shows some interesting features. The testes are surrounded by a three-layered wall - an inner slender epithelium, a very fine basement membrane, and a peritoneal wall in which there is no pigment. Fat bodies are closely apposed to the dorsal surface of the testes, and among them, as also in the peritoneal wall, tracheoles are very numerous. The contents of the testes consist of cells and developed spermatozoa, which for the most part lie in clusters of from six to twelve individuals. This is similar to the finding of Landois (1865 a:53) in Pediculus, and is common in insects. Each spermatozoon has a rod-shaped nucleus in the head, which takes the hematoxylin stain so intensely as to appear black. Anterior to the nucleus can be distinguished a small area of cytoplasm staining a bright pink with eosin just as the tail stains. No middle piece can be distinguished. These clusters of spermatozoa are in that half of each testis which lies next to the vas deferens, and appear to rest in a matrix of nutritive cells with very palestaining nuclei. The remainder of each testis is filled with cells typical of the different zones of development. At the base there is a very small cluster of spermatogonia, followed by sperinatocytes of both orders in process of division and reduction, and then a small section of spermatids. 
The remaining mesodermal structures are slender tubes varying in diameter. Seen in cross section (Plate LXIII, 3) the inner layer of their wall is composed of epithelial cells resting on an exceedingly fine basement mombrane. Outside this is a thin, structureless layer, the true nature of which has not been determined. The anterior half of the ejaculatory duct is surrounded by a strong wall of circular muscle fibers, among which are also, toward the posterior end, strands arising at right angles to the duct wall and passing to the outer edge of the circular fibers. Nuttall (1917 a:307) attributes this strong development of muscle to the force necessary to drive the spermatic fluid down the long, slender part of the duct.

The epithelial cells lining the vasa deferentia are small and somewhat flattened, and have a straight surface in the lumen. The anterior sections of the seminal vesicles act as a reservoir for the developed spermatozoa, and there, as in the sections of the vasa deferentia, they can be seen. The epithelium of the region is regular and columnar, and the nuclei, which are circular and have a well-defined nucleolus, lie near the base of the cells, of which the cytoplasm contains many dark-staining granules. Lower in the tubes the cells lose their clearly defined inner borders and appear finely granular, while a secretion which stains a deep pink with eosin surrounds the spermatozoa. This secretion soon takes a definite form and is oval in outline, and, in appearance, not unlike a cross section of an orange or the illustration of the "Magenscheibe" given by Landois (1865a:Pl. IV, fig. 8), and it contains minute vacuoles (Plate LXIV, 6). These suggest spermatophores, but in section no spermatozoa could be seen within them. Still farther along in the vesicles the inner borders of the cells project into the lumina as blunt, thumblike processes, which are slightly pink in sections stained with hematoxylin and eosin, while the remainder of the cell is dark blue. No cell walls are seen and the cells are evidently in active secretion. The clearly defined "spermatophores" now become markedly vacuolated and gradually lose all semblance of a definite form. Probably this secretion acts as a solvent. In the anterior part of the muscular section of the ejaculatory duct the cells are small, but in the posterior part the epithelium is much thickened and has it markedly glandular appearance. From many of the cells of the vesicles and the ejaculatory duct, slender processes project into the canals and even directly into the central mass of secretion, while in some parts of 
the duct they interlace, giving the appearance of a network near the epithelium. The slender part of the ejaculatory duct has a small, roundcelled epithelium, but in one quarter of the wall it is thickened and projects into the lumen as a more or less blunt cone, which, in the passing of the duct to the penis, forms its dorsal wall.

In gross dissection of the parts no accessory glands have been found. Patton and Cragg (1913:559) describe and figure small glands in Pediculus vestimenti at the junction of the vasa deferentia with the seminal vesicles, but such are not present in Haematopinus. Nuttall (1917 a:308) mentions the accessory glands of Pediculus as lying on the muscle of the dorsal surface of the basal plate and undergoing passive movement along with the ejaculatory duct and the penis at the extrusion of the copulatory apparatus, but no such glands have been found in Haematopinus. It may be that the place of accessory glands has been taken by the enlarged glandular epithelium of the different parts of the ejaculatory duct.

\section{Female}

From the work of Landois (1864:14 and 1865 a:48) it has long been known that the Pediculidae possess polytrophic egg tubes. Graber (1872:159) differed from Landois in his conception of the egg tubes, and described them as telotrophic like those of the Hemiptera but gave no figures, and subsequent work has shown him to be wrong. Ströbelt (1882, English trans. 1883:94) made the earliest reference to the ovaries of Haematopinus suis, and he described them as bilocular. His findings in regard to the structure of the tubes and the development of the eggs confirmed the work of Landois. The classic work on the ovaries of Siphunculata (Anoplura) and Mallophaga is that of Gross (1906:347) in which he showed the close resemblance between the two groups. He studied four species, of which Haematopinus suis was one, and described in detail the gross anatomy and histological structure of the ovaries and the development of the egg. Mjöberg (1910:253) cited the work of Cross but did not himself mention the female reproductive organs of the hog louse. The female reproductive organs of the Pediculidae affecting man have been described by Pawlowsky (1908), who illustrated his work with transverse and longitudinal sections (PI. II and III, figs. 4-12, of reference cited) but included no drawing of the gross anatomy; by Patton and Cragg (1913:560), who figured and briefly described the 
organ; by Müller (1915), who alse showert a number of figures; and by Peacock (1916). Nuttall (1917 a:312) deseribed the copulatory apparatus.

The essential reproductive organs of the female are the paired ovaries and their oviducts, with the colleterial glands. The remaining parts are the uterus and the vagina (Plate LXV, 1). In the hog louse neither spermatheca nor bursa copulatrix is present.

The ovaries are clustered, consisting of five egg tubes on each side, and this number seems to be constant in the Siphunculata according to the different workers in the group, but the number of egg chambers in each tube differs in the various species. Each egg tube consists of a terminal filament, a terminal chamber or germarium, and as a rule two egg chambers or vitellaria although three are sometimes seen. The fine terminal filaments of each ovary of a pair unite, and pass as a single filament above the mid-intestine into the fat cells and their tracheoles. Graber (1872:159) alone, among the earlier workers, thought that three terminal filaments, or vessels as they were then called, passed from each egg tube; but, as Gross (1906:350) suggests, he probably confused tracheae with terminal threads. The ovaries lie in the abdominal cavity on each side of the mid-intestine, and in the region of the sixth abdominal segment they fuse to form a short common oviduct on either side. They pass into the uterus at the anterior border of the seventh segment after receiving the colleterial glands, which are large, trilobed glands with convoluted edges. Their anterior lobes, pointing cephalad, lie along each side of the mid-intestine under the lateral borders of the ventral abdominal muscle plate, and extend to midway between the posterior and anterior borders of segment 4; the posterior lobes are shorter, and, pointing caudad, extend just within the anterior border of the eighth segment; the lateral lobes surround the oviducts and the mid-intestine near the anterior border of segment 7 .

The uterus is surrounded by a stout muscular wall which, as Landois (1865 a:51) first pointed out, is made up of circular as well as longitudinal fibers. After receiving the oviducts it passes caudad through segment 7 into segment 8, then bends back along itself just into segment 7 , where it again turns caudad describing a semicircle, so that the point of its passage into the short, thin-walled vagina lies on its own spiral. The meaning of its length and musculature is revealed in examining specimens having a mature egg in the uterus. It is then a long, straight, and wicle tube, 
whose anterior border lies approximately on the anterior border of the fourth segment.

The structure of the female copulatory apparatus is much simpler than that of the male. It is situated in the last three segments of the body, and the external indications of sex are the shape of the abdomen, two triangular chitinous plates on the dorsal surface of segment 9 (which ends in two pointed lobes), and the gonopods on the ventral surface of segment 8. The gonopods (Plate LVIII, 11) are flat processes, triangular in shape. Their median free border is somewhat strongly chitinized and is set with a row of stout hairs. Anteriorly they are joined by a fold of the integument which projects caudad in two blunt points. As has already been said, they appear to have arisen as an infolding of the integument of the segment. The sexual orifice is on segment 8 under the anterior border of the gonopods. It leads directly into the vagina, a thin-walled chitinous sac lying close to the ventral body wall and at its anterior end passing into the uterus ventrad of its semicircular coil. In Pediculus the walls of the vagina are covered with minute, outwardpointing teeth. In Haematopinus no teeth could be seen on the vaginal wall in gross preparations treated with potash and mounted in balsam.

A plate of closely set muscle fibers originates in the anterior border of segment 7 immediately posterior to the ventral abdominal muscle plate, and is inserted in the anterior border of the gonopods. The contraction of these muscles raises the gonopods and brings the sexual orifice and the vagina into position for copulation. Muscle fibers originating in the lateral wall of the vagina and in that of the uterus near its passage into the vagina, are inserted in the sternite of segment 9 , and by their contraction draw the vagina and the uterus to their resting position.

The histological structure of the ovarian tubes at different stages of development has been thoroughly studied and described by Gross (1906: 352-364), and a brief résumé of his work is here inserted. There is no peritoneal wall surrounding the egg tubes, and the tunica propria (basement membrane) is unusually well developed. In the terminal threads of adult females the content consists of a homogeneous granular protoplasm which Gross regards as degenerated remains of the cells to be found in younger stages. Landois (1864:16) had seen these cells also in the terminal chamber of Phthirius, and he considered them as specific yolkforming elements and hence the terminal chamber of the one-egg tube 
ws a true yolk chamber. This chamber remains small, there is no boundary between it and the terminal thread, and its epithelium is composed of small nuclei between which cell boundaries are seldom seen. In young individuals the chamber contains only a few cells besides the epithelial nuclei (Plate LXVI, 4), while in older animals the cells are quite degenerated and are broken up intoscattered fragments until finally only epithelial nuclei remain and these have migrated into the interior of the chamber (Plate LXVI, 7). In every case Gross found a zone of transversely arranged epithelial cells behind the terminal chamber. Such a zone is characteristic of telotrophic egg tubes and has not been found in any other group having polytrophic egg tubes. In Haematopinus it is very short and in some cases is represented only by a row of much degenerated epithelial nuclei, distributed in the longitudinal direction of the egg tube. In the egg chamber (Plate LXVI, 9) there is a definite number and arrangement of nutritive cells. There are five of these, and the odd one lies in the apex, with the others in two successive rows immediately behind. The nuclei of all are irregular in outline. Such an arrangement was seen by Landois (1865a:48) in Pediculus. The two hindmost nutritive cells push into the plasma of the egg, and there is seen a layer of dark-stained, ball-like, little nuclei which are the nutritive substance introduced from the cell to the egg for the formation of the yolk. In the older individuals the follicle epithelium is clearly seen to be of two kinds. That surrounding the nutritive cells is thin and flat, having few nuclei and no distinct cell walls; while that surrounding the egg chamber is made up of deep cylindrical cells closely apposed on one another and containing cylindrical nuclei with an elongated nucleolus. The mitosis seen in the epithelium of younger stages has now given place to amitosis, and finally each cell contains two nuclei which lie behind each other in the longitudinal axis of the cell (Plate LXVI, 10). Gross has never seen cell division following the amitotic division of the nuclei, and in the light of more recent researches this nuclear division is to be regarded rather as a redistribution of nuclear material than as a true amitosis. Behind the egg cell the follicle cells are hemmed in by a collection of dark nuclei similar to those behind the nutritive cells, and cell boundaries are wanting at this point; both these facts support the view that in Haematopinus, as in so many other cases, the follicle epithelium cooperates in the formation of the yolk. The 
successive egg chambers are connected by short stalks of cpithclial cells, apparently a continuation of the follicular epithelium.

The egg tubes of each side pass into a short oviduct which receives the wide conduit of the colleterial gland before passing into the uterus. The wall of the oviduct is made up of a thin muscular layer, a fine basement membrane, and small epithelial cells with an inner delicate chitinous lining; that of the colleterial gland consists of a peritoneal membrane, a thin basement membrane, and large columnar epithelial cells with large nuclei (Plate LXV, 2). These large epithelial cells secrete the cement which glues the eggs to the bristles, and in sections stained with hematoxylin and eosin the secretion is seen as a pink, homogeneous, more or less vacuolated mass, while with iron hematoxylin it appears dark brown or black. The uterus receives the oviducts laterally and somewhat posterior to its apex. In this region the muscular coat is only moderately developed, the epithelium and its basement membrane are clearly seen, and the chitinous lining is smooth (Plate LXV, 3). Posterior to the point of entrance of the oviducts the wall is thrown into deep folds and the muscular outer coat is very highly developed. The epithelial cells are small and no distinct cell boundaries are seen. The chitinous lining is thrown into innumerable sharp convolutions resembling moderately long, sharp teeth (Plate LXV,4), which, posteriorly in the region of the coil, appear as blunt, rather flattened teeth (Plate LXV, 5 and 6). From sections made through a uterus containing an egg, it appears that these teethlike projections retain their form when the uterus is fully expanded.

The earliest description of the egg of the hog louse is that of Leuckart (1855:140-141). He recognized the presence of a third chorionic layer, but without sections it was impossible to get a true conception of the structure. He figured a piece of the shell, showing it to be provided with innumerable canals running perpendicular to the surface of the chorion. Ströbelt (1882, English trans. 1883:96-97) described briefly the egg of Linognathus vituli (Haematopinus tenuirostris), citing Leuckart and Landois. The most complete and accurate description is that of Gross (1906:364-377), who found, in the eggs of Siphunculata (Anoplura) and Mallophaga, structures so similar as to indicate close relationship between the two groups. Mjöberg (1910:257-262) refers to the work of Gross and describes briefly the eggs of several additional species of Siphunculata (Anoplura) and Mallophaga. 
The follicle epithelium of the egg chamber secretes first the vitelline membrane, which in this case is also the cell membrane of the egg, and then the chorion. According to Gross, of whose work the following is a résume, the formation of the chorion begins at the posterior end and a thin endochorion and a thicker exochorion are formed. The former appears striated in section and may be porous. The follicle cells are somewhat convex on their inner surface and an imprint of this is left on the exochorion. Up to this time their nuclei have been lying toward their inner surface, and the formation of the epichorion (exochorion oi Leuckart) begins as a constriction between the nuclei, and in the indentations so formed appear small, rather regularly rhomboid, chitinous structures. (The egg shell is not formed of true chitin, since it is soluble in potassium hydroxide.) By further constriction of the epithelial cells between the nuclei a system of hollow cavities in communication surrounds the egg, and these become almost filled by a deposition of chitin forming a distinct chitinous lamella (Plate LXVI, 21 and 22). Up to this point a nucleus has rested on each side of the constriction, but row the one between the epiand exochorions passes through the canal leaving only a tip of protoplasm (Plate LXVI, 23 and 24). The epichorion now moves closer to the eggshell proper, and the pores assumie the appearance of rather long canals (Plate LXVI, 25, a); so that looked at from the surface (Plate LXVI, 26), the epichorion appears pierced by numerous canals perpendicular to its surface (Leuckart, 1855:140; stomata of Stevenson, 1905:16). Between these pores is a network of three-sided cavities. During this development the staining properties of the epithelium have undergone a change; the protoplasm takes a deep stain, while the nucleoplasm has become transparent and the nucleolus no longer shows great affinity for stain.

On the operculum there is no epichorion formed and the exochorion is much thickened (Plate LXVI, 25, b). 'The chitin formation extends down the sides of the epithelial cells, but it is an outgrowth from the exochorion and not a separate formation. There are polygonal areas on the lid surrounded by a network whose ridges are much deeper than those on the egg, but, as there is no epichorion here, the two parts do not differ in level.

The epithelial cells now rapidly degenerate, and characteristic, very darkly stained structures, like broken circles, are seen in their protoplasm. On the operculum these are attached to the ridges and extend lengthwise 
so that a fork is formed, between the prongs of which are transverse ridges (Plate LXVI, 28). These structures have no very regular character, and Gross could not determine whether they originated as separate rings or as lamellae. In the vicinity of the furrow between the egg and the operculum the appearance is distinctly modified (Plate LXVI, 27, b). Here the branches of the network are themselves forked and their prongs are extended as longitudinal rings; also, the transverse rings are more numerous and irregular. Behind the operculum there is still another structure. Over the network of the exochorion, and at first without any connection with it, is formed a characteristic trellis of longitudinal and transverse rings, having as a groundwork a narrow, undulating band whose curved edges lie always on a furrow of the epichorion. The whole is then set through with transverse parallel rings, some of which are found also between the epichorion network. Directly behind the opercular furrow the chorion extends as two specially large projections which bend forward and are forked at their outer ends (Plate XLVI, 27, a). These are two lamellae, which extend around the whole circumference of the egg, overarching the furrow and protecting it. In the fully developed egg (Plate LXVI, 29) the rings are said to be made of chitin and to have become a part of the chorion. The remainder of the epithelium is now an amorphous mass and is the so-called egg-white layer around the egg, of which Gross says (page 370 of reference cited): "Auch dieser Umstand, dass der Follikel schliesslich sich zur Eiweisshülle umbildet, ist, soviel ich weiss, ohne Analogon unter den Insecten." The epichorion is connected with the exochorion anteriorly at the opercular ridge and posteriorly at the egg stigma, a complicated structure whose significance is not clear. A diffusion of air through the pores cannot take place because of the egg white. An interchange of gas cannot take place, although the space between the exochorion and the epichorion contains a quantity of gas; rather is this chamber of gas to be regarded as a warm covering for the egg, or it may serve as a protection against injury from blows to which eggs attached to the hair of animals are exposed.

In the egg of the hog louse the micropyles are not indicated by any special formation. In sections they can be seen as simple canals, narrowing somewhat at their inner ends, in the vicinity of the operculum. Leuckart (1855:141) did not state their number; according to Gross (1906:371) there are at least thirty. 
At the posterior pole of the egg is a very characteristic structure (Plate LXVI, 34), to which Graber (1872:165) gave the name "Eistigma." The earliest description of this structure is that of Leuckart $(1855: 139,141)$, who observed it on the eggs of Pediculus capitis and Haematopinus suis, and it was seen also by Landois (1864:15) on the egg of Phthirius. Gross (1906:372) has given the first detailed description of it and figured its structure. The egg stigma forms a roundish swelling on the chorion and is pierced by numerous thin-walled canals, which narrow toward their inner ends and converge to one side. Gross studied its formation in cletail, and in young stages found the egg follicle closed by a plug extending far into the interior of the yolk, but as growth proceeds the plug becomes leveled. The nuclei are small and the inner ends of the cells are drawn to a point. These inner ends are cut off from the cells in a characteristic manner and the nucleus is drawn to the outer wall, while between them is a zone of protoplasm in which cell boundaries can no longer be recognized. Between the detached inner pieces begins the deposition of chitinous substance, and this appears as fine striae, while at the exterior, where the deposition has become more advanced, the thin, chitinous lamellae have lost their color. Then are formed in the region of the stigma the endochorion and the exochorion. The stigma is now completely developed. The point formed by the pointed ends of the cells still remains attached inside, cell walls can be recognized, and it can be seen that each cell forms a canal.

No satisfactory biological interpretation has been found for the egg stigma, a structure found in no other insect order. Earlier authors advanced three views, none of which has proved satisfactory. Leuckart (1855:139) and Melnikow (1869:154) regarded it as an attachment disk; but if this were its function, why should it be pierced by canals in most cases? Kramer $(1869: 462)$ regarded it as the true micropyle; but in some species, for example Nirmus, the canals do not pass to the inner ends of the cells. Graber (1872:163) interpreted it as a means of aeration for the eggs and so named it; but in most cases it is covered over by secretion. The closing of the pores by secretion would be essential in Pediculus, since, according to Sikora (1915:530) and Nuttall (1917 d:148), the embryo escapes from the egg by pumping air through its alimentary canal in order to increase the pressure in the egg and force open the operculum. 


\section{TECHNIQUE}

In the laboratory the following methods of keeping lice have been tried:

\section{Conditions}

On laboratory table in petri dishes

In incubator in open vials

In incubator in vials having in the bottom a layer of moist cotton batting $\frac{1}{4}-\frac{1}{2}$ inch thick

In a gauze bag worn on the body

In vials plugged with cotton and gauze and carried close to the body day and night

As in last experiment

Temoperature

Opportunities of feeding in 24 hours

4

4

$36^{\circ}-37^{\circ} \mathrm{C}$.

dry heat

$36^{\circ}-37^{\circ} \mathrm{C}$.,

moist heat

$35^{\circ} \mathrm{C} . \pm$
Constant
Length of life

7-10 days

Under 24 hours

3 days
Lice would not feed through gauze

Up to 35 days

$35^{\circ} \mathrm{C} . \pm$ First day, $3 ; 26$ days second to
fifteenth
day, $2 ;$
sixteenth
to twenty-
sixth day, 1

We have found the last method the best for rearing hog lice in captivity. In the glass containers, hog bristles and teased gauze were provided as a foothold.

Chloroform has been found the most satisfactory medium for killing lice both for dissection in toto and for sectioning. For the former purpose, the lice may be preserved indefinitely in 80- to 85-per-cent alcohol, but the following fluid has been found much more satisfactory:

Distilled water . . . . . . . . . . . . . 30 parts

Alcohol, 96-per cent.............. 15 parts

Formaldehyde................ 6 parts

Glacial acetic acid............. 4 parts 
This fluid was first used by Pampel (1914:298) in his work on the female Ichneumonidae, and he found that it kept the tissue soft and elastic for dissecting purposes. After chloroforming, a small slit was cut in the side of the abdomen to allow the preserving fluid to penetrate more rapidly.

Owing to the toughness of the cuticula, dissections could not be made on slides, and so the lice were fixed to the top of a thin layer of paraffin in the bottom of a watch glass and covered with physiological salt solution. Scalpels with curved blades, microscope scissors, and fine needles were used, and all dissections were made under a Zeiss binocular. After some practice the different systems could be removed intact and placed on slides in a drop of salt solution, where the parts could be arranged in the desired way and fixed in position with Bless' fluid according to the method followed by Patton and Cragg (1913:718-720). The material could then be carried through the alcohols and stained in toto. The best result in such staining has been obtained with Grenacher's borax carmine, the stain being allowed to act for from twenty-four to forty-eight hours. In dissecting organs for sectioning, the physiological salt solution was replaced by the medium in which the tissue was fixed.

In the study of the epithelium of the digestive tract, the alimentary tract was dissected out and prepared for imbedding in paraffin. In order to cut more than one stomach at a time, the method learned by Minchin from fellow workers in the Zoological Station at Naples in 1891, and used by Minchin and Thomson (1915:508) for sectioning the stomachs of fleas in their study of the rat trypanosome, was tried. Their method consisted of cutting thin free-hand sections of amyloid liver, arranging three stomachs on it with the anterior borders level, and fixing them in position with a drop of albumen fixative. This block could be oriented easily, but it was found more satisfactory to simply imbed single alimentary tracts.

In sectioning whole lice it was necessary to double-imbed in celloidin and paraffin, and three methods were followed, all of which gave equally good results. The slow method of celloidin imbeddling, loeginning with a thin solution and gradually increasing the thickness until the object was sufficiently permeated with celloidin to be hardened in chloroform and carried on to paraffin in the usual way, was first triecl. Then, in order to shorten the period of infiltration, a modificution of Gilson's rapid method (Lee, 1905:131) was substituted. At the same time the oil- 
mixture method introduced by Apáthy (1912:464, 468; also Kornhauser, 1916) was used, but it gave no better results than Gilson's rapid method and involved many more steps. After double-imbedding it was found possible to make good series of longitudinal and transverse sections of 5 microns, $7 \frac{1}{2}$ microns, and 10 microns, in thickness.

The reagents used for fixing were Zenker's fluid, Bouin's fluid, and Flemming's weak solution. In every case the insect was chloroformed and its legs were cut off close to the thorax before it was placed in the reagent. Both the Zenker-fixed and the Bouin-fixed material were stained with hematoxylin and cosin, hematoxylin and orange $G$, and methylene blue and eosin. In addition the Bouin-fixed material was stained with Mallory's anilin-blue connective-tissue stain, a combination used by Kingery (1916: 292) in studying the intestine of the grasshopper. This stain differentiates the chitinized from the non-chitinized cuticula, the former staining red and the latter a clear blue, and also brings out strikingly the striations of the muscle fibers. The Flemming-fixed material was stained with iron hematoxylin according to the method of Heidenhain, and with safranin, a solution made of equal volumes of a water-soluble and an alcohol-soluble stain being used.

All measurements given in the text were made with an ocular micrometer valued in terms of a stage micrometer used in a Zieiss microscope fitted with an objective A, 15 millimeters; and an ocular No. ¿, and having a tube length of 160 millimeters.

\section{SUMMARY}

At the close of his paper on the mouth parts of the body louse, Harrison (1916 b:218) has pointed out the many resemblances found by himself and other workers between the Siphunculata (Anoplura) and the Mallophaga, particularly those of the suborder Ischnocera. The present study has served to again emphasize the general similarity in structure of the two groups, and has brought to light some structures which have not yet been described in this order.

No mention of the apodemes extending from the dorsal to the ventral surface of the thorax has been found in the literature. While the name suggested for them - the apodemes of the prothorax and the prosternum - is intended to call attention to their position in the anterior part of the thorax, it must not be forgotten that they probably originated as invagi- 
nations respectively of the transverse conjunctivae between the pro- and the mesothorax and between the pro- and the mesosternum.

A second structure hitherto undeseribed in the Siphunculata is found in the head, under the posterior lobes of the brain. The position and structure of this pair of bilaterally symmetrical circular bodies suggests their interpretation as the "corpora allata" of Heymons and other investigators (cited by Berlese, 1909:588, and by Schröder, 1912-13:86).

In the study of the stomodaeum and the mouth parts, the aim has been to present as accurate a picture as possible of their anatomical structure, musculature, and working. Their homology is not touched upon, because in the case of structures so far modified from the generalized type, interpretation should rest upon an investigation begun with the earliest appearance of segmentation in the embryo and continued to maturity. Cholodkovsky (1903:120) alone has touched upon this aspect, in his work on the man-infesting pediculi, whose pharynx and mouth parts are similar in plan to those of the hog louse. In none of the sections of the alimentary canal have protozoan parasites been found, and the physiology of digestion has been touched upon but briefly.

The reproductive systems and the secondary sexual characters resemble those of other members of the order, but in the female no receptaculum entering the uterus has been found. According to Harrison (1916 b:221), " in the Ischnocera, and in all Anoplura save Pediculus, a receptaculum of remarkable structure opens into this uterus by a long narrow duct, the entry of the duct into the receptaculum being marlied by a conspicuous chitinous ring."

The experimental work on the biology of the species has been carried out with much care. In the acceptance of the resulting figures indicating periods in the life history, however, it must be borne in mind that in the natural habitat, with continual opportunity of feeding, these periods may be somewhat shorter.

\section{ACKNOWLEDGMENTS}

Thanks are due to Dr. V. A. Moore, of the New York State Veterinary College at Cornell University, for facilities for keeping a hog for experimental work; to the Department of Entomology of the New York State College of Agriculture at Cornell University, for the payment of the expenses connected with keeping the hog; to the Department of Animal 
Husbandry of the same College for the loan of the hog; to Professor E. S. Savage, of the Department of Animal Husbandry at Cornell University, and to Drs. Carl Ten Broeck and R. B. Little, both of the Department of Animal Pathology at the Rockefeller Institute for Medical Research, for assistance in obtaining lice; to Dr. W. A. Riley, of the University of Minnesota, for a supply of man-infesting lice for comparative purposes; to Dr. S. A. Goldberg, of the New York State Veterinary College, for assistance in taking photographs; and to Professor Ulric Dahlgren, of Princeton University, for access to the library of the Department of Biology at that institution and to the piggeries of the university farms.

The illustrations were drawn by Miss Edlen Edmonson, to whom we are deeply indebted for the great care with which she'has done the work. 


\section{BIBLIOGRAPHY}

Apáthy, STtefan V. Neuere Beiträge zur Schneidetechnik. Ztschr. wiss. Mikros. 29:449-515. 1912.

Bacot, A., AND Linzell, L. The incubation period of the eggs of Haematopinus asini. Parasitology 11:388-392. 1919.

Berlese, A. Gli insetti, 1: Embriologia e morfologia, p. 1-1004. (Reference on p. 588, 596.) 1909.

BRÜHL, J. Zur feineren Anatomie der am Menschen schmarotzenden Läuse. Wiener med. Wchnschr. 21:475 479, 501 505. 1871.

Burmeister, Hermann. Genera insector. icon. illustr., Plate II, figs. 3-6. 1838.

Pediculina. In Handbuch der Entomologie, 21:56-60. 1839.

Ueber die Mundbildung von Pediculus. Linnaea entomologica 2:569-584. 1847 .

Cholodkovsky, N. Zur Morphologie der Pediculiden. Zool. Anz. 27:120-125. 1903.

Zur Kenntnis der Mundwerkzeuge und Systematik der Pediculiden. Zool. Anz. 28:368-370. 1904.

Coburn, F. D. Swine husbandry, p. 1-311. 1888.

Swine in America, p. 1-603. (Reference on p. 497.) 1912.

CRAGG, F. W. The alimentary tract of Cimex. Indian Journ. Med. Res. 2: 706-720. 1915.

Cummings, Bruce. Studies on the Anoplura and Mallophaga. Part I. Zool. Soc. London. Proc. 1916:253-295. 1916.

Dalla Torre, K. W. von. Anoplura. In Genera insectorum, fasc. 81, p. 1-22. 1908.

Denny, Henry. Haematopinus suis. In Monographia Anoplurorum Britanniae, p. 34-36. 1842. 
Enderlein, Gúnther. Über die Morphologie, Klassifikation, und systematische Stellung der Anopluren nebst Bemerkungen zur Systematik der Insektenordnungen. Zool. Anz. 28:121-147. 1904. 1905.

ERICHson, W. Insecten. In Bericht über die Leistungen im Gebiete der Zoologie. Arch. Naturgesch. 52:281-375 [377]. Reference on p. 375 [377]. 1839.

Fischer, Alfred. Fixirung, Färbung, und Bau des Protoplasmas, p. 1-362. 1899.

Fulmek, Leopold. Beiträge zur Kenntnis des Herzens der Mallophagen. Zool. Anz. 29:619-621. 1905.

GaUlKe, - UÜber Läuse und Läusesucht - Phthiriasis - in therapeutischer und medicinalpolizeilicher Beziehung. Vrtljschr. gerichtl. u. öfentl. Med. (Casper's) 23:315 329. 1863.

Gehuchten, A. van. Recherches histologiques sur l'appareil digestif de la larve de la Ptychoptera contaminata. Cellule 6:185-291. 1890.

Gerstfeldt, Georg. Läuse. In Über die Mundteile der saugenden Insekten. Diss,, Dorpat, p. 101-115. 1853.

Giebei, C. G. Pediculina. In Insecta Epizoa. Die auf Säugethieren und Vögeln schmarotzenden Insecten nach Chr. L. Nitzsch's Nachlass, p. 21-47. 1874.

Graber, V. Anatomisch-physiologische Studien über Phthirius inguinalis Leach. Ztschr. wiss. Zool. 22:137-167. 1872.

Gross, J. Untersuchungen über die Ovarien von Mallophagen und Pediculiden. Zool. Jahrb., Anat. u. Ontog. Tiere, 22:347-386. 1906.

Handlirsch, Anton. Phylogenetisches über Insekten. Zool. Anz. 28: 664-670. 1905.

Harrison, Launcelot. The respiratory system of Mallophaga. Parasitology 8:101-127. 1916 a

A preliminary account of the structure of the mouth-parts in the body-louse. Cambridge Philos. Soc. Proc. 18:207-226. 1916 b. 
Hooke, R. Micrographia, or, Some physiological descriptions of minute bodies made by magnifying glasses, p. 1-246. (Reference on p. 211213.) 1665 .

Kellogg, Vernon Lyman, and Ferris, Gordon Floyd. The Anoplura and Mallophaga of North American mammals, p. 1-74. (Reference to Plate IV.) Leland Stanford Junior Univ. Publications. University series. 1915.

Kingery, H. M. Some uses of Mallory's connective tissue stain. Anat. rec. $11: 291-292.1916$.

Kornhauser, S. I. Celloidin paraffin method. Science n. s. 44:57-58. 1916.

Kramer, P. Beiträge zur Anatomie und Physiologie der Gattung Philopterus (Nitzsch). Ztschr. wiss. Zool. 19:452-468. 1869.

Krancher, Oskar. Der Bau der Stigmen bei den Insekten. Ztschr.wiss. Zool. 35 : 505-574. 1881.

Landors, Leonard. Untersuchungen über die auf dem Menschen schmarotzenden Pediculiden. I. Anatomie des Phthirius inguinalis Leach. Ztschr. wiss. Zool. 14:1-26. 1864.

Same. III. Anatomie des Pediculus vestimenti Nitzsch. Ztschr. wiss. Zool. $15: 32-55.1865$ a.

Same. IV. Zur Anatomie des Pediculus capitis. Ztschr. wiss. Zool. 15:494-503. 1865 b.

Leach, William Elford. On the families, stirpes, and genera of the order Anoplura. In The zoological miscellany; being descriptions of new or interesting animals, 3:64-67. 1817.

Lee, Arthur Bolles. The microtomist's vade-mecum, 6th ed., p. 1-538. (Reference on p. 131). 1905.

LemUWenhoek, A van. Arcana naturae detecta ope microscopiorum. Delphis Batavorum. (Reference on p. 386-388.) 1695.

Of the louse. In The select works of Antony van Leeuwenhock, containing his microscopical cliscoveries in many of the works of nature, p. 163-169. (Translated from the Dutch and Latin editions published by the author, by Samuel Hoole. 1807.) 1697. 
Leuckart, Rud. Ueber die Micropyle und den feinern Bau der Schalenhaut bei den Insekteneiern. Arch. Anat., Physiol., u. wiss. Med. 1855: 90-264. 1855.

Linnaeus, Carolus. Pediculus. In Systema naturae 15:2914-2922. 1758.

Mammen, Heine. Über die Morphologie der Heteropteren- und Homopterenstigmen. Zool. Jahrb., Anat. u. Ontog. Tiere, 34:121-178. 1912.

Martin, Charles. Insect porters of bacterial infection. Lancet $1913^{1}$ : 81-89. 1913.

Meinert, Fr. Pediculus humanus L. et Trophi ejus. Lusen og dens Munddele. Ent. Meddel. 3:58-83. 1891-92.

Melnikow, Nicolaus. Beiträge zur Embryonalentwickelung der Insekten. Arch. Naturgesch. 35 :136-189. 1869.

Minchin, E. A., And Thomson, J. D. The rat-trypanosome, Trypanosoma lewisi, in its relation to the rat-flea, Ceratophyllus fasciatus. Quart. journ. micros. sci. 60 n. s.:463-694. 1915.

Mjöberg, Eric. Studien über Mallophagen und Anopluren, p. 1-296. Diss., Lund Univ. 1910.

Moore, William, and Hirschfelder, A. D. An investigation of the louse problem. Univ. Minnesota. Res. pub. 84:8-17. 1919.

Morse, Max. Synopses of North American invertebrates. XIX. The Trichodectidae. Amer. nat. 37:609-624. 1903.

Moufettr, Thomas. The theater of insects: or, Lesser living creatures, as bees, flics, caterpillars, spiders, worms, etc. (English translation, p. $889-1130.1658$.) 1634.

Müller, J. Zur Naturgeschichte der Kleiderlaus. Osterr. Sanitätsw. 27 ${ }^{36-38}$ (Beilage) : 1-63. 1915.

Murlin, John Raymond. Absorption and secretion in the digestive system of the land isopods. Acad. Nat. Sci. Philadelphia. Proc. 54:284-359. 1902. 
Neumann, L. G. Notes sur les Pédiculidés. Arch. par. 13:497-537. 1909.

Notes sur les Pediculidae. II. Arch. par. 14:407-414. 1911.

Nitzsch, Chr. L. Pediculus. In Die Familien und Gattungen der Thierinsekten (insecta epizoica; als Prodromus einer Naturgeschichte derselben. Mag. ent. 3:304-305. 1818.

Nuttall, George H. F. Studies on Pediculus. I. The copulatory apparatus and the process of copulation in Pediculus humanus. Parasitology 9:293-324. 1917 a.

Bibliography of Pediculus and Phthirus including zoological and medical publications dealing with human lice, their anatomy, biology, relation to disease, etc., and prophylactic measures directed against them. Parasitology 10:1-42. $1917 \mathrm{~b}$.

The part played by Pediculus humanus in the causation of disease. Parasitology 10:43-79. $1917 \mathrm{c}$. 1917 d.
The pathological effects of Phthirus pubis. Parasitology 10:
375-382. 1918. 1917 d.
The pathological effects of Phthirus pubis. Parasitology 10:
375-382. 1918. The biology of Pediculus humanus. Parasitology 10:80-185.
1917 d.
The pathological effects of Phthirus pubis. Parasitology 10:
375-382. 1918.

- The systematic position, synonymy, and iconography of Pediculus humanus and Phthirus pubis. Parasitology 11:329-346. 1919.

Nuttall, George H. F., and Keilin, D. On the Nephrocytes of Pediculus humanus. Parasitology 13:184-192. 1921.

Oppenheim, M. Ueber einen von Pediculus pubis gebildeten Farbstoff. Arch. Dermatol. u. Syph. 57:235-244. (Abstracted by author in Verhandl. Gesellsch. deut. Naturf. u. Aerzte 731 [Med. Abt.]:451.) 1901.

Osborn, Herbert. The hog louse. In The Pediculi and Mallophaga affecting man and the lower animals. U. S. Ent. Div. Bul. 7:18-21. 1891. account of the species of importance in North America, with mention of related forms occurring on other animals. U. S. Ent. Div. Bul. 5, n.s.:178-180. 1896. 
Note on morphology of certain clasping organs in the Pediculidae. Ohio nat. 4:107-108. 1904.

Pampel, Wilhelm. Die weiblichen Geschlechtsorgane der Icheumoniden. Ztschr. wiss. Zool. 108:290-357. 1914.

Patton, Walter Scott, and Cragg, Francis William. A textbook of medical entomology, p. 1-768. 1913.

Pawlowsky, E. Uber den Stech- und Saugapparat der Pediculiden. Ztschr. wiss. Insektenbiol. 2:156-162, 198-204. 1906.

[Russian title.] Anatomy of sexual organs of Pediculus capitis and P. vestimenti. Soc. Ent. Rossicae. Horae 38:82-108. 1908.

Peacock, A. D. The louse problem at the western front. Roy. Army Med. Corps. Journ. 27:31-60. 1916.

The structure of the mouthparts and mechanism of feeding in Pediculus humanus. Parasitology 11:98-117. 1918.

Piaget, E. Haematopinus. In Les Pédiculines. Essai monographique, p. $633-656.1880$.

Schjödte, J. C. [Danish title.] Naturhist. Tidsskr., ser. 3:3:48-. (English translation - On Phthiriasis, and on the structure of the mouth in Pediculus. Ann. and mag. nat. hist., ser. 3:17:213-230. 1866.) 1864.

SchröDER, Chr. Handbuch der Entomologie, 1:1-528. 1912-13.

Siкora, H. Beiträge zur Biologie von Pediculus vestimenti. Centbl. Bakt. 1:76:523-537. 1915.

Beiträge zur Anatomie, Physiologie, und Biologie der Kleiderlaus (Pediculus vestimenti, Nitzsch). I. Anatomie des Verdauungstraktes. Arch. Schiffs u. Tropen. Hyg. 20:5-76. 1916.

Simon, - Die Hautkrankheiten durch anatomische Untersuchungen erläutert, p. 1-420. (Reference on p. 274-275.) 1848,

Snodgrass, R. The anatomy of the Mallophaga. California Acad. Sci. Occasional papers 6:145-224. (Reference to Plate X, figs. 8-10, 12.) 1899. 
Solowiow, Paul. Zum Bau des Verschlussapparates der Stigmen bei den Insekten. Zool. Anz. 34:705-711. 1909.

Stevenson, Earle. The hog louse. In The external parasites of hogs, being articles on the hog louse (Haematopimes suis) and mange, or scabies, of hogs. U. S. Anim. Indus. Bur. Bul. 69:9-21. 1905.

Ströbert, Oscar. Anatomie und Physiologie von Haematopinus tenuirostris. Inaug. Diss., Düsseldorf. (English translation, Ann. and mag. nat. hist., ser. 5:11:73-108. 1883.) 1882.

SWAMmERDAM, Johr. The book of nature; or, The history of insects, p. 1-153. (Reference on p. 30-39.) (Translated from the Dutch and Latin original edition by Thomas Floyd. Revised and improved by notes from Reaumur and others, by John Hill. 1758.) 1682.

Watts, H. R. The hog louse. Univ. Tennessee Agr. Exp. Sta. Bul. $1: 201-16.1918$.

Wedr, C. Über das Herz von Menopon pallidum. K. Akad. Wiss. [Vienna], Math.-Naturw. Kl. Sitzber. 17:173-180. 1855.

Widmann, Eugen. Beiträge zur Kenntnis der Biologie der Kleiderlaus und deren Bekämpfung. Ztschr. Hyg. u. Infektionskr. 80:289-298. 1915 a.

Zur Frage der Uebertragung von Bakte
München. med. Wchnschr. 62:1336-1338. 1915 b.

Memoir 41, Lysimeter Experiments - II, the tenth preceding number in this serics of publications, was mailed on November 16,1921 . 


\section{Plate LVIII}

\section{THE HOG LOUSE, HAEMaTOPINUS SUIS LINNE}

1. Claws of adult (a, protrusible pad; b, joint between tibia and tarsus); 2 , eggs attached to hog bristle (a, cap, or operculum; b, vitelline membrane; c, cement); 3 , first instar; 4, second instar; 5 , third instar; 6 , sternal plate; 7 , exuvia attached to bristle; 8 , adult male; 9 , ventral aspect of posterior segments of abdomen of male; 10, adult female; 11, ventral aspect of posterior segments of abdomen of female (a, gonopods); 12, apodeme of prosternum and prothorax attached to sternal plate

$(3,4$, and 5 drawn from exuviae, to same scale as 8 and 10$)$ 

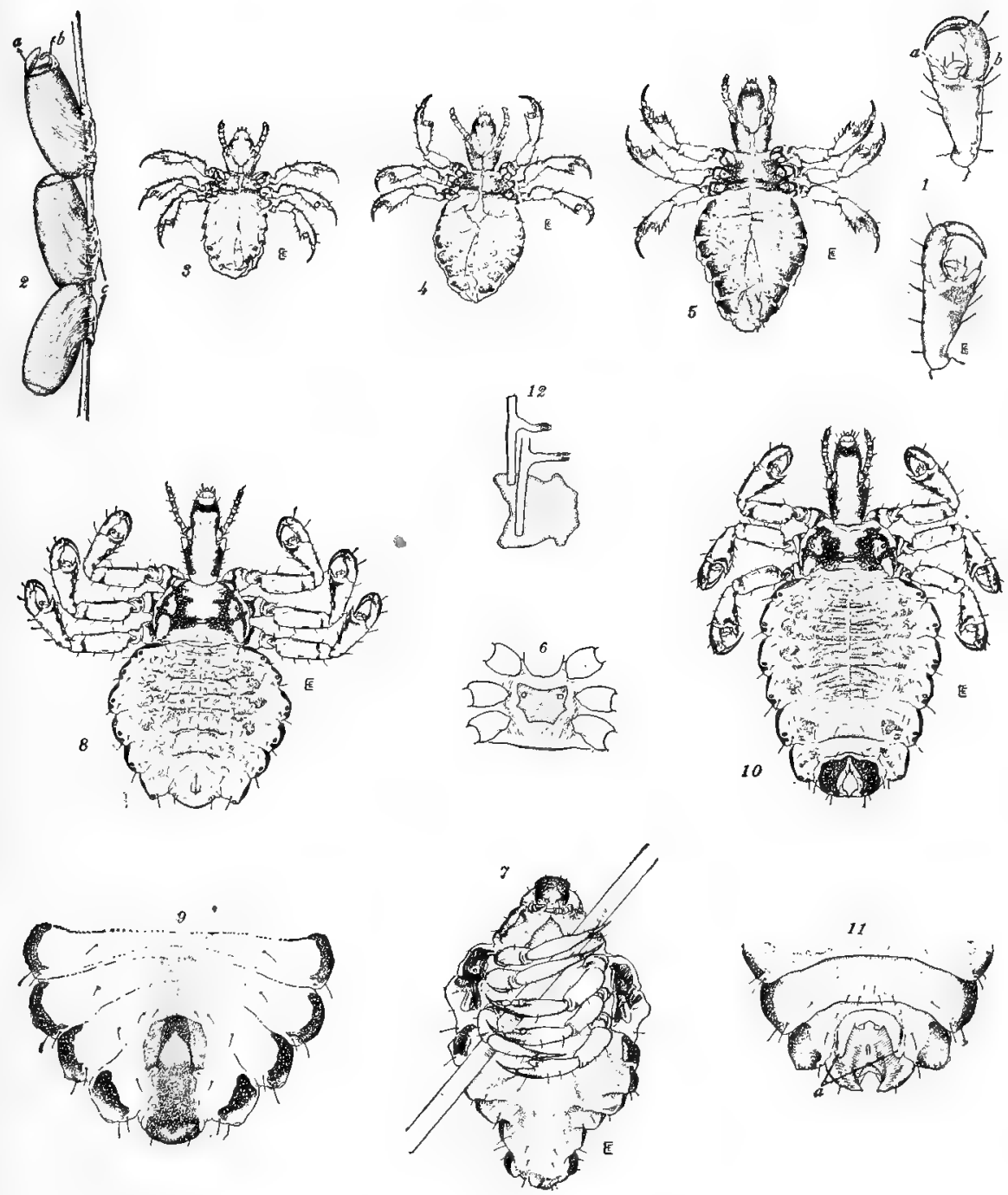


\section{Plate LIX}

\section{THE HOG LOUSE, HAEMATOPINUS SUIS LINNÉ}

1. Diagrammatic representation of primary and secondary tracheae; 2, stigma, vestibule, bulla, and trachea, drawn from cleared specimen; 3 , section through abdominal stigma (a, vestibule; b, lever; c, bulla; d, intrinsic muscle; e, extrinsic muscle); 4 , ventral abdominal muscle plate of female, ventral aspect; 5 , right lateral abdominal muscles of segment 4 of male (drawn from gross dissection); 6 , heart and one-half of length of aorta (a, pericardial cells); 7 , transverse section through heart in region of ostium; 8 , central nervous system and anterior part of sympathetic system ( $a$, frontal ganglion; $b$, recurrent nerve; c, brain; d, subesophageal ganglion; $e$, connertives; $f$, prothoracic ganglion; $g$, mesothoracic ganglion; h, metathoracic ganglion and abdominal ganglion; $\mathrm{i}$, visceral nerves); 9 , sections through tip of antenna showing multinuclear sensory cells (drawn with oil immersion) 

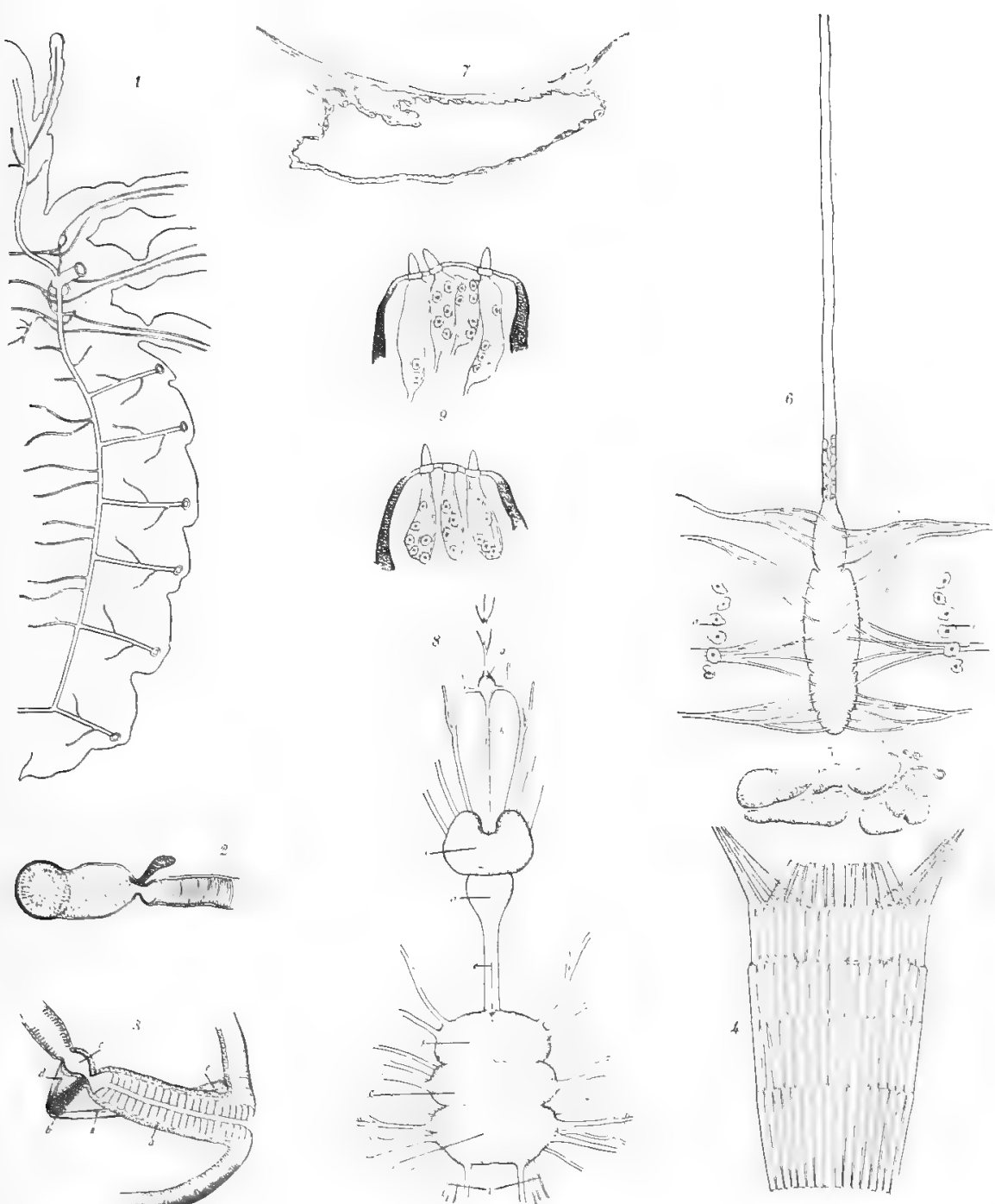


\section{Plate LX}

\section{THE HOG LOUSE, HAEMATOPINUS SUIS LINNE}

1, Transverse section through anterior region of head just posterior to section shown in Plate LXI, 1 ( $a$, buccal plate; $b$, dorsal element of piercers; $e$, anterior ends of pumping pharyngeal tube; 1 , structures corresponding to "mandibles" of Sikora; $\mathrm{mm}$, muscles of these; nn, dorsal protractors of buccal plate; o, prefrontal ganglion); 2, dorsal aspect of anterior part of stomodaeum (a, buccal plate; e, pumping pharyngeal tube; g, pumping pharynx; k, pharynx; nn, dorsal protractor muscles; pp, ventral protractor muscles; qq, anterior dorsal retractor muscles; $r r$, posterior dorsal retractor muscles; ss, dorsal muscles of pharynx; t, esophagus; uu, " mandibles" of Enderlein; vv, Iateral tendon muscles; w, haustellum with buccal teeth; dilator muscles of pumping pharynx not shown); 3 , ventral aspect of anterior part of stomodaeum (xx, ventral retractor muscles; other lettering as in 2); 4, ventral aspect of haustellum protruded and showing buecal teeth; 5 , transverse section through anterior region of thorax, showing posterior ends of rami of piercers with their muscle attachments ( $a$, cuticula enclosing piercers and esophagus; $b$, dorsal element of piercers; d, ventral element of piercers; ee, occipital apodeme; $\mathbf{i}$, aorta; $\mathbf{k}$, recurrent nerve; 11 , tracheae; $m$, connectives; $n n$, posterior arms of apodemes of prothorax and prosternum; 0 , salivary gland between rami of piercers; $t$, esophagus); 6 , mouth parts (b, dorsal element of piercers; $c$, salivary duct; dd, rami of ventral element of piercers; 0 , salivary gland between rami of piercers; $p$, anterior end of chitinous plate imbedded in floor of sheath; ee, protractor muscles of sheath and piercers; ll, ventral lateral retractors of sheath and piercers; $\mathrm{mm}$, dorsal lateral retractors of sheath and piercers; $\mathrm{nn}$, posterior retractors of sheath and piercers; posterior retractors inserted in end of each ramus not shown; sheath torn away leaving only ventral plate and piercers, so that lateral retractor muscles appear in approximate position); 7 , dorsal element of piercers (a, bulb at end of salivary duct; salivary duct underlying piercer shown as a dotted line in proximal part only); 8 , ventral element of piercers ( $p$, chitinous plate imbedded in floor of sheath); 9 , anterior ends of ventral elements of piercers 

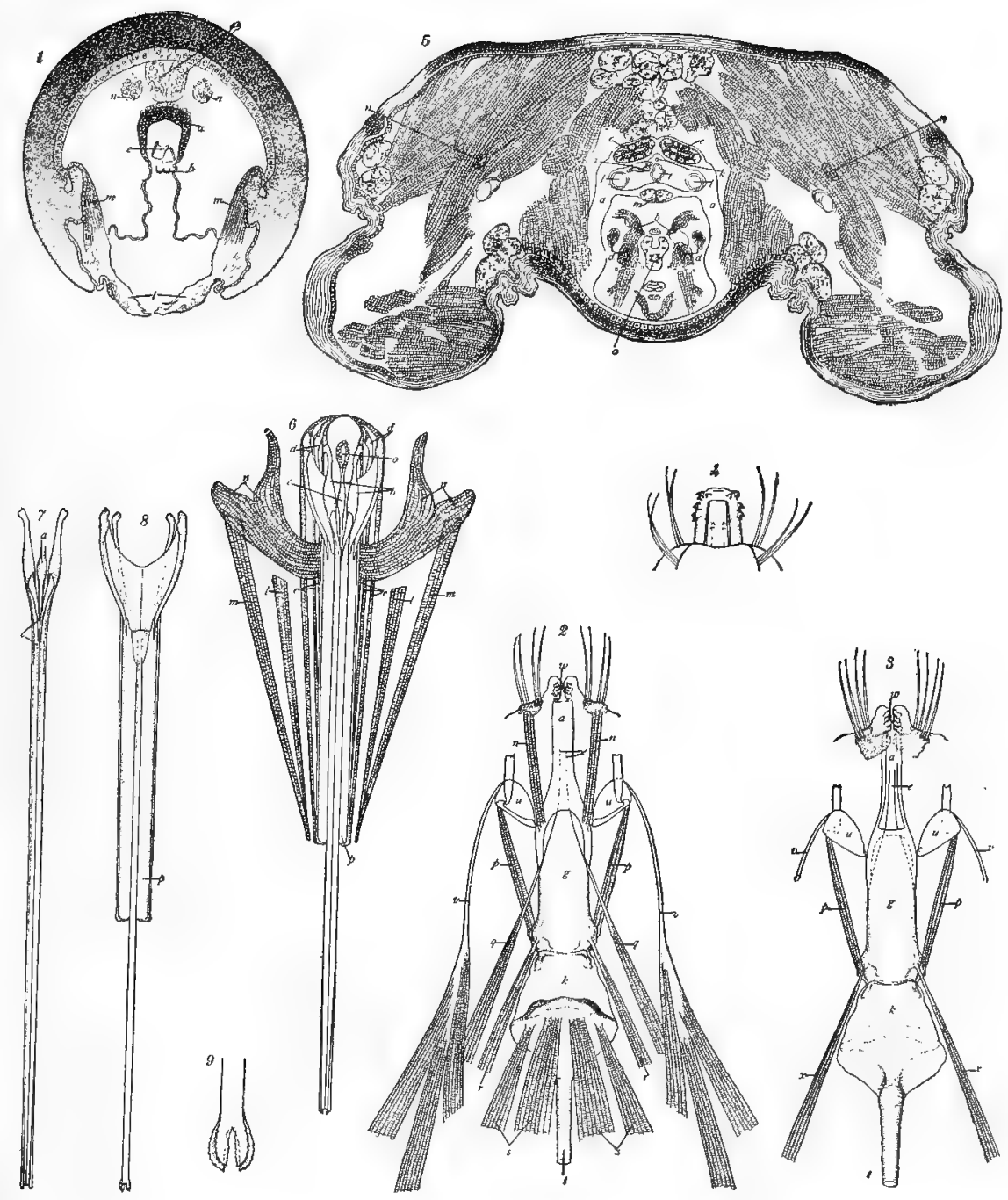


\section{Puate LXI}

\section{THE HOG LOUSE, HAEMATOPINUS SUIS LINNE}

1, Transverse section through stomodaeum at anterior level of attachment of basal part of "mandibles" of Enderlein to lateral wall of head ( $a$, buccal plate; b, dorsal element of piercers; c, salivary duct; $d$, ventral element of piercers); 2, transverse section through stomodaeum at anterior level of " mandibles " (e, pumping pharyngeal tube; other lettering as in 1); 3 , transverse section through stomodaeum at posterior level of "mandibles" (lettering as in 1 and 2); 4, transverse section through stomodaeum in posterior region of buccal plate (aa, posterior arms of buccal plate; f, riclge on dorsum of pumping pharynx; other lettering as in 1 and 2); 5, transverse section through stomodaeum in region of anterior dorsal chitinous plate (g, pumping pharynx; $h$, piercer sheath; other lettering as in 1); 6 , transverse section through stomodaeum immediately behind anterior chitinous plate (ii, tentons of dorsal retractors of buccal plate; other lettering as in 5); 7 , transverse section through stomodaeum just after its separation from piercer sheath (lettering as in 6); 8 , transverse section through anterior region of pharynx ( $\mathrm{k}$, pharynx); 9 , transverse section through posterior region of pharynx behind first dorsal chitinous plate (jj, hollow tendons of central elevator muscles; k, pharynx)

(All drawings on this plate made with oil immersion and drawn to scale) 


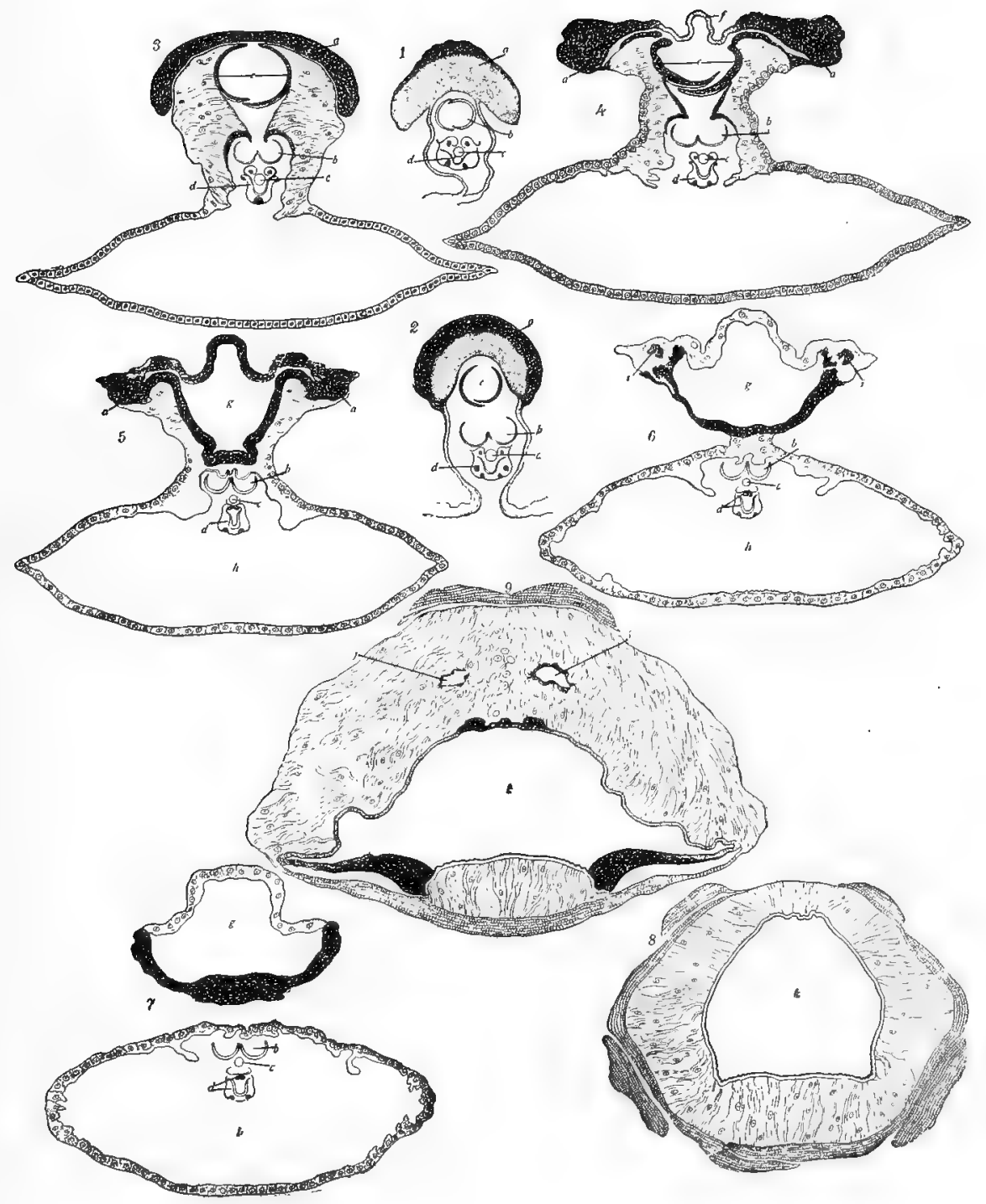




\section{Plate LXII}

\section{THE HOG LOUSE, HAEMATOPINUS SUIS LINNE}

1, Transverse section through head, showing Pawlowsky's glands opening into piercer sheath (a, glands; b, piercer sheath); 2, longitudinal section through Pawlowsky's gland (drawn with oil immersion); 3 , salivary glands in natural position (a, central aspect: $b$, lateral aspect); 4, horseshoe-shaped gland; 5 , oblong-ovate gland; 6, anterior region of horseshoe-shaped gland and duct (drawn from gross specimen with oil immersion); 7 , stomach (a, esophagus; b, mid-intestine; c, small intestine; d, region of plates; e, rectum; $\mathbf{f}$, malpighian tubes); 8 , transverse section through region of plates; 9 , transverse section through rectum; 10, longitudinal section through abdominal segment (a, fat cells; b, oenocytes) 

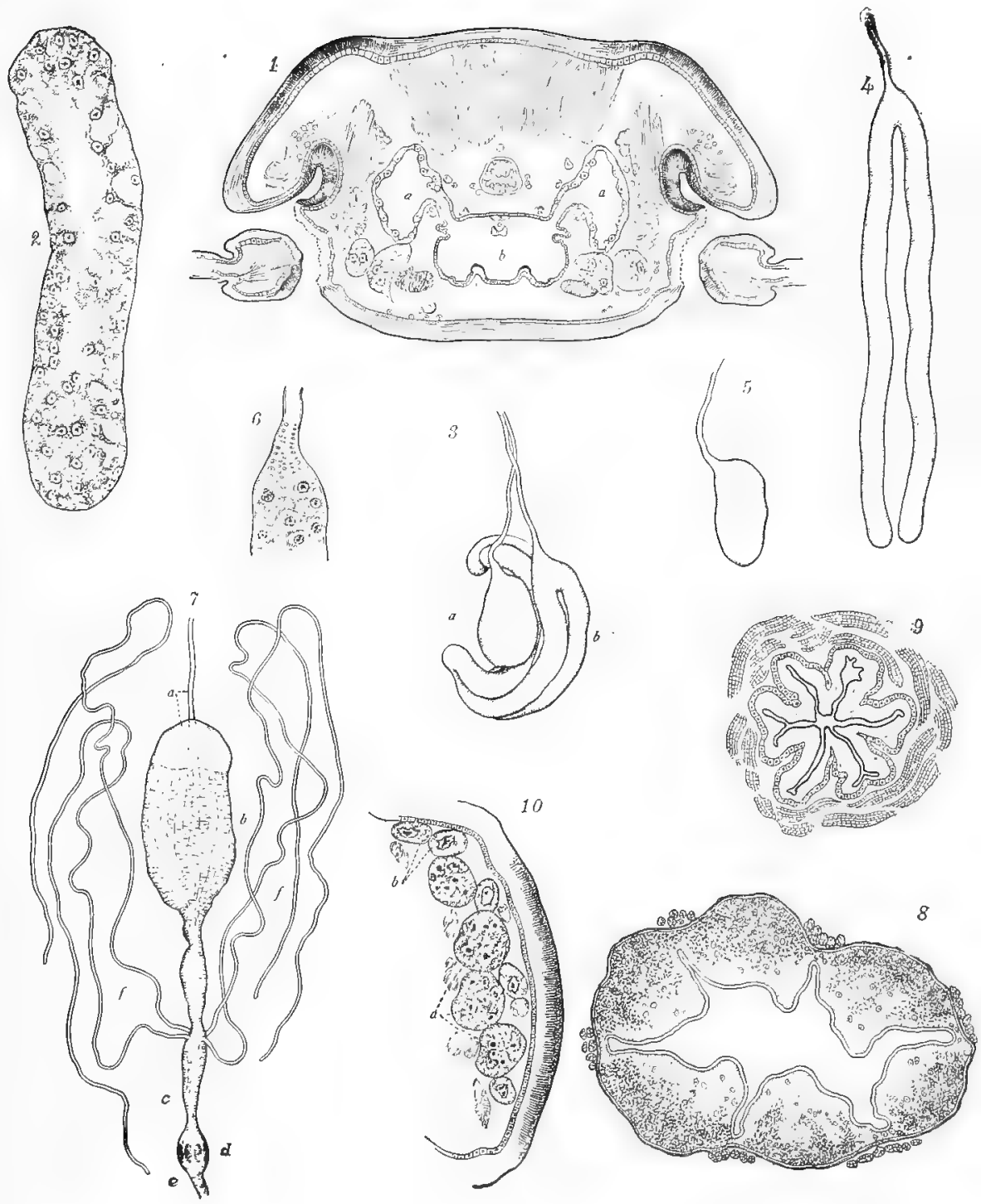


\section{Plate LXIII}

\section{THE HOG LOUSE, HAEMATOPINUS SUIS LINNE}

1. Transverse section through stomach nine hours after feeding, $x$ 1921 (a, region of section enlarged in 2); 2 , region $a$ of $1, \times 600 ; 3$, transverse section through intestine and reproductive organs of male, x 290 (a, intestine; b, seminal vesicles containing spermatophore; $c$, nnuscular part of ejaculatory duct; d, slender part of ejaculatory duct; e, vasa deferens; f, upper region of seminal vesicles which acts as reservoir for spermatozoa; $g$, malpighian tubes; $h$, trachea) 


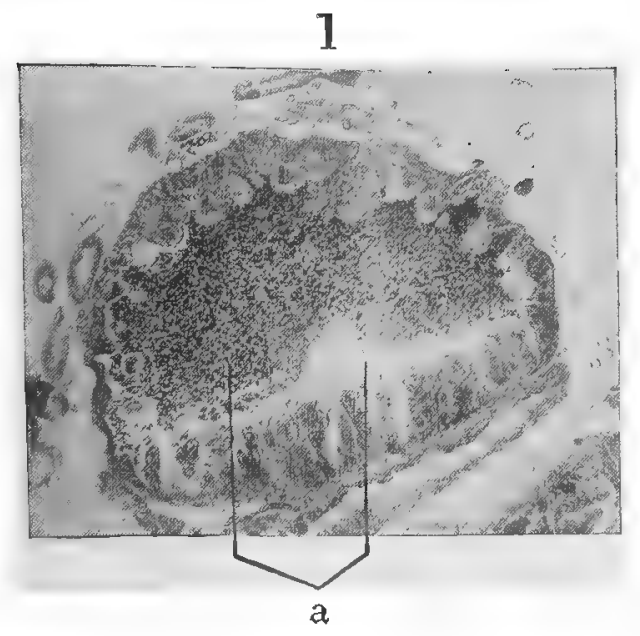

\section{2}
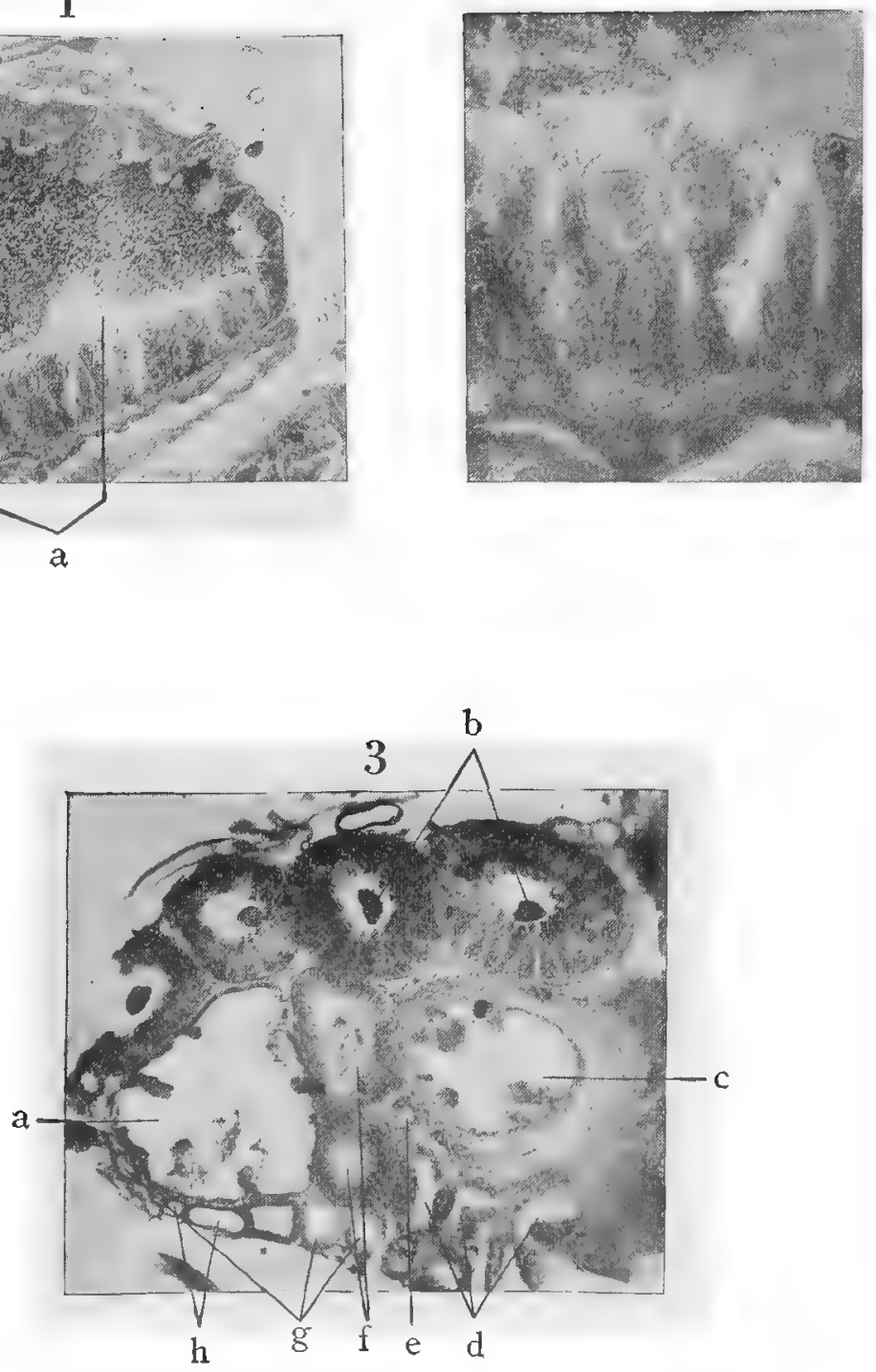


\section{Plate LXIV}

\section{THE HOG LOUSE, HAEMATOPINUS SUIS LINNË}

1, Reproductive organs of male ( $a$, testes; $b$, vasa deferentia; $c$, seminal vesicles; $d$, ejaculatory duct; e, penis; $f$, vesica penis; $g$, basal plate; $h$, parameres); 2 , ectodermal reproductive organs of male in resting position, dorsal aspect (lettering as in 1); 3 , ectodermal reproductive organs of male, vesica extended, ventral aspect (lettering as in 1); 4, posterior region of abdomen with vesica and penis ejected, lateral aspect (B, caudal aspect; I, upgrowth of ventral lamella of basal plate, corresponding to collar described by Nuttall in Pediculus; lettering otherwise as in 1); 5 , transverse section through posterior end of abdomen of male (e, penis; $f$, vesica penis; ga, dorsal lamella of basal plate showing thickening of parameres; $g b$, ventral lamella of basal plate; $i$, muscles of parameres; $j$, retractor muscles of vesica; $k$, protractor muscles of basal plate); 6, transverse section of "spermatophore" (drawn with oil immersion) 


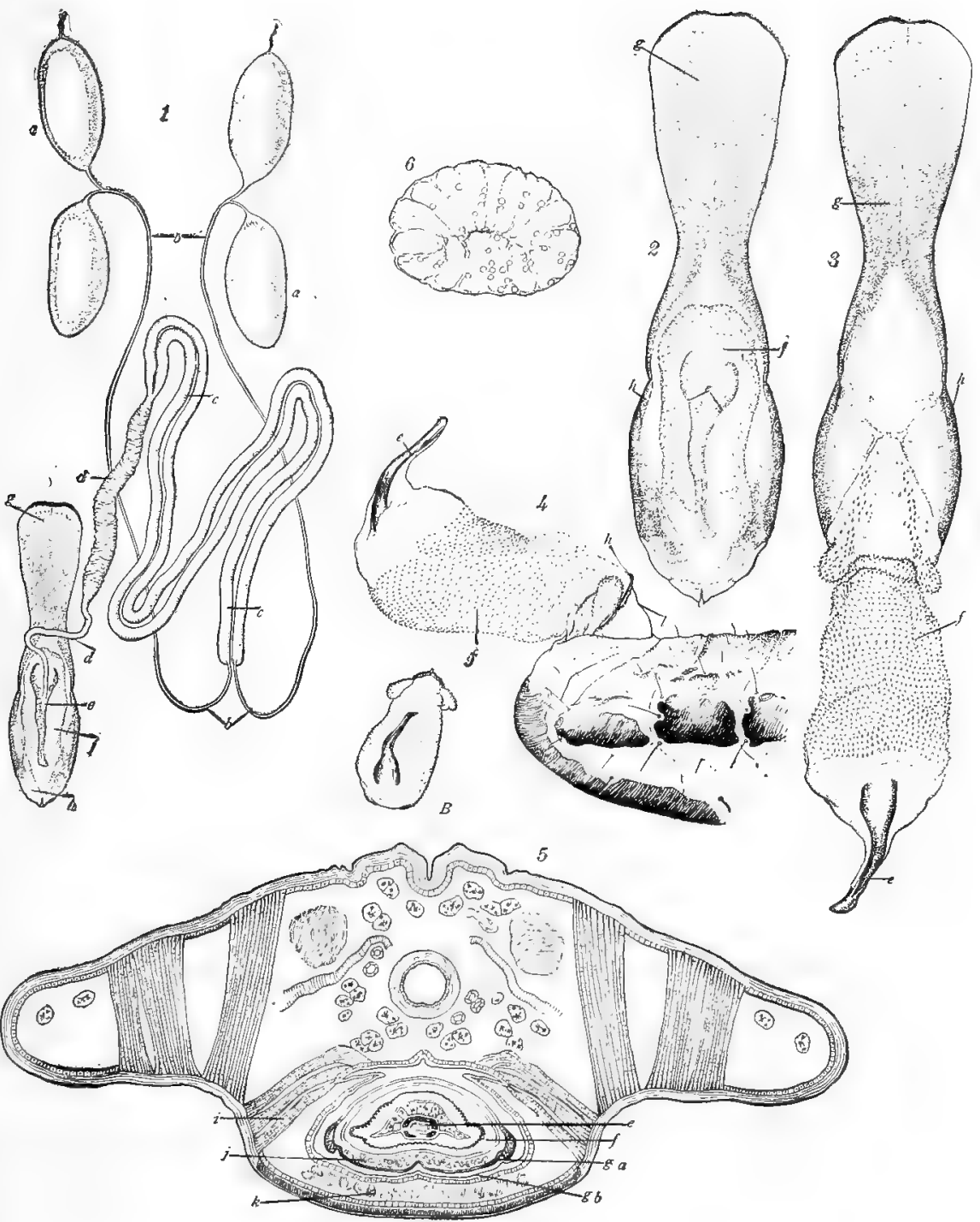




\section{Plate LXV}

\section{THE HOG LOUSE, HAEMATOPINUS SUIS LINNÉ}

1. Reproductive organs of female (a, ovaries; b, oviducts; $c$, colleterial glands; d, uterus); 2 , transverse section of part of wall of colleterial gland (drawn with oil immersion; a, trachea); 3 , transverse section through anterior end of uterus; 4 , transverse section through uterus posterior to the entrance of oviducts (a, secretion from colleterial glands); 5 , transverse section through uterus in region of coil; 6 , teeth of intima in 5 (drawn with oil immersion) 

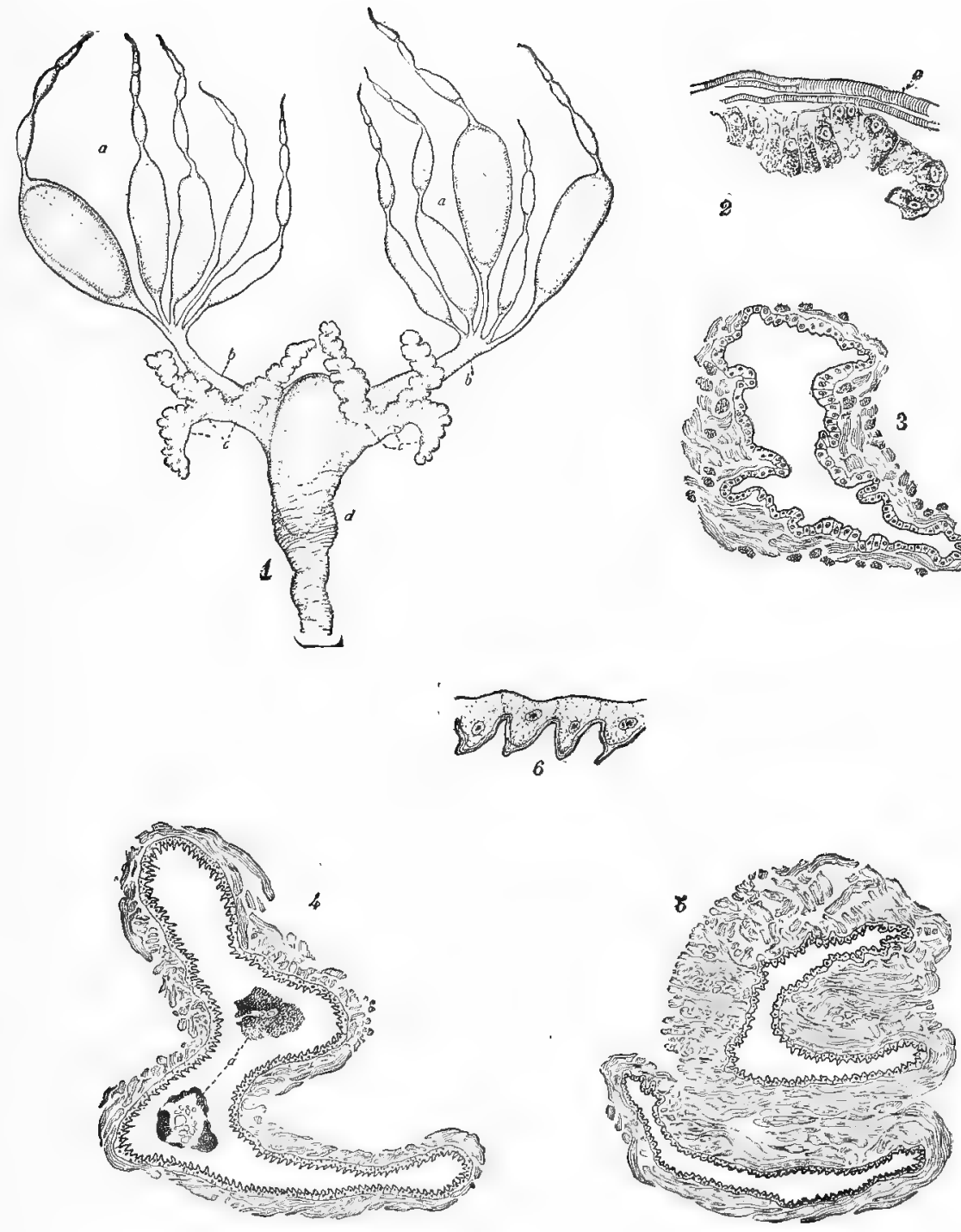


\section{Plate LXVi}

THE HOG LOUSE, HAEMATOPINUS SUIS LINNE

4, Longitudinal section through terminal chamber; 7, longitudinal section through terminal chamber; 9, longitudinal section through egg chamber; 10 , cross section through follicle cells; 21-25, cross sections through follicle cells in different stages in formation of epichorion; 26, surface view of epichorion; 27 and 28 , cross section through follicle cells in different stages in formation of epichorion; 29, section through egg cap; 34, longitudinal section through egg stigma

(Figures on this plate copied from Gross and numbered according to his arrangement) 

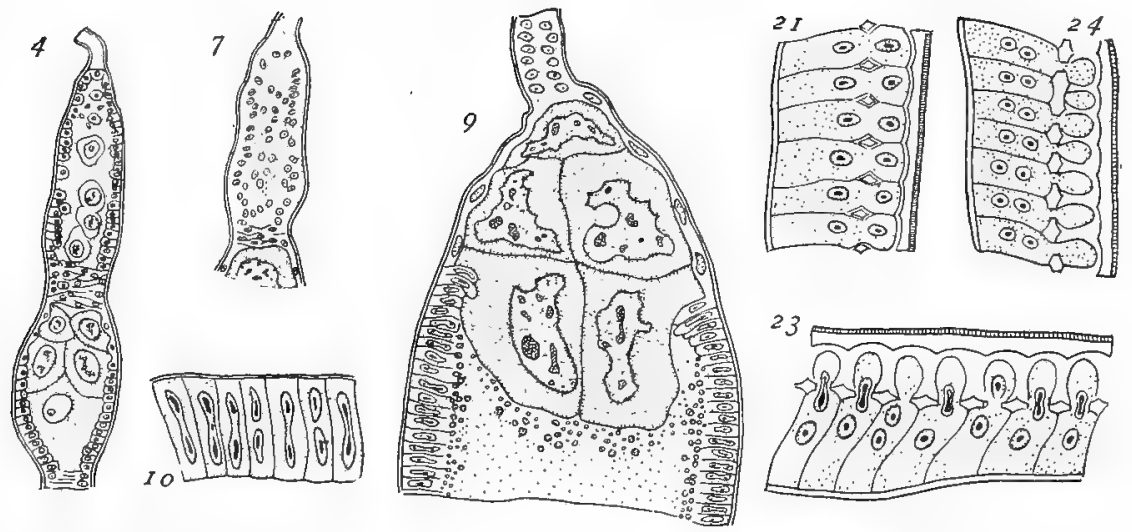

\section{2}

(0) (9)

\section{$25 a$}

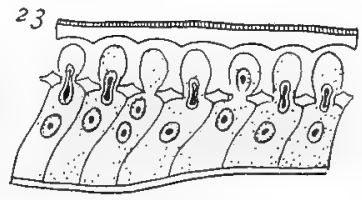

- of of of ofo o o $b$

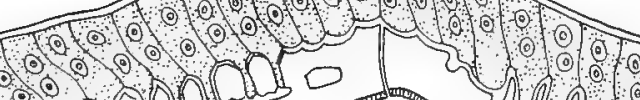
o 0 (c) $0(0)$
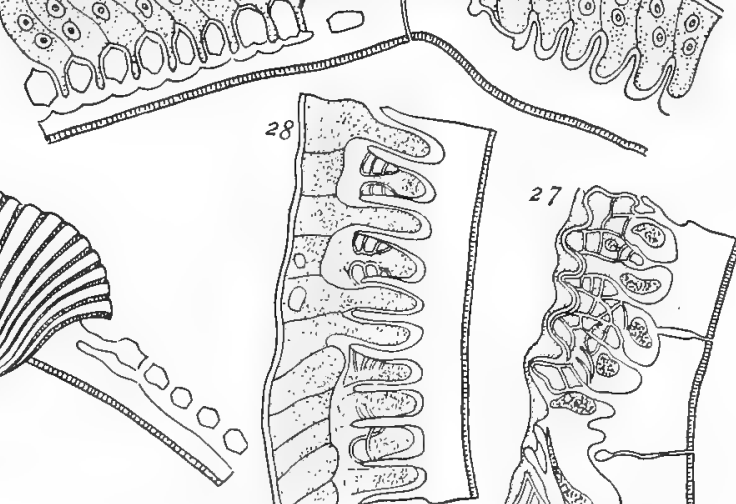

o

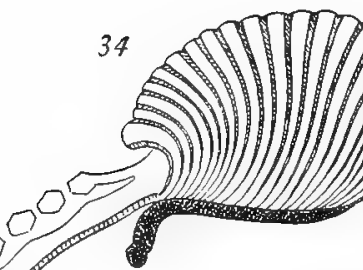

"
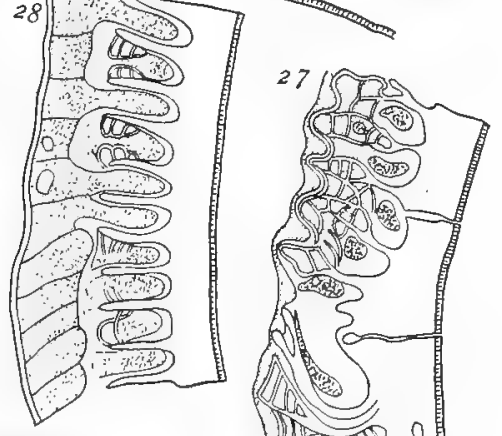

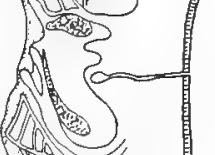
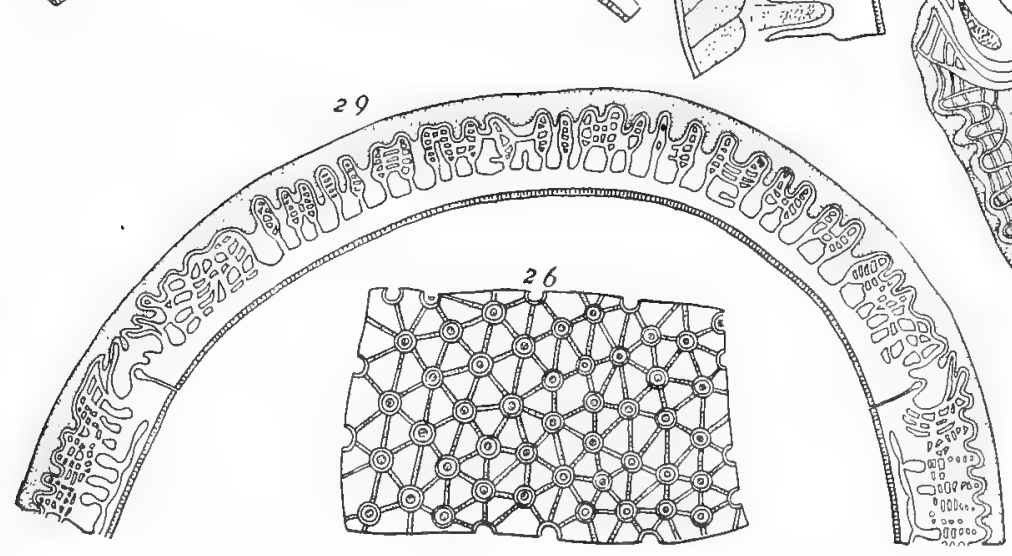



Eampinivi

Binder

Gaylord Bros.Inc

Makers

Syracuse, N. Y. PAT. JAN 21, 1908

DATE DUE

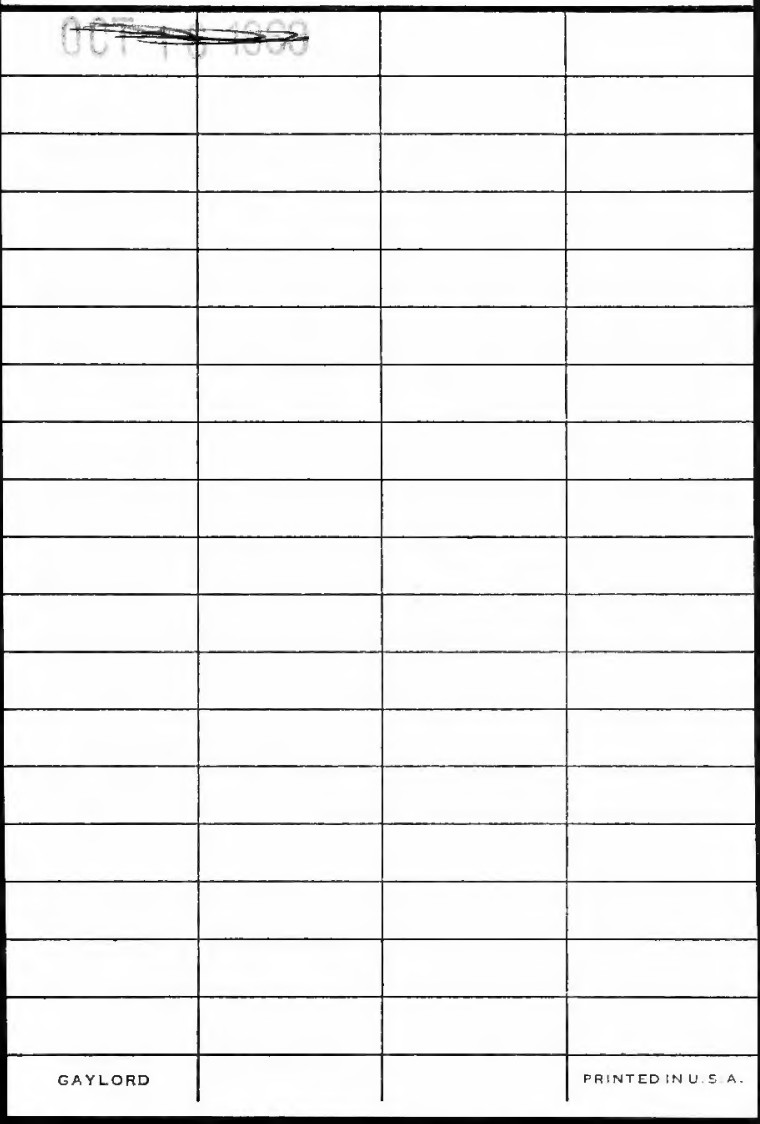


